\title{
Teratomas produced from human pluripotent stem cells xenografted into immunodeficient mice - a histopathology atlas
}

\author{
IVAN DAMJANOV*,1 and PETER W. ANDREWS ${ }^{2}$ \\ ${ }^{1}$ Department of Pathology, The University of Kansas School of \\ Medicine, Kansas City, Kansas, USA and ${ }^{2}$ The Centre for Stem \\ Cell Biology, Department of Biomedical Science, The University of \\ Sheffield, Sheffield, UK.
}

\begin{abstract}
This atlas illustrates the microscopic features of tumors produced from human pluripotent stem cells (hPSCs) xenografted into immunosuppressed mice, according to the generally accepted protocols for performing this teratoma assay of stem cell pluripotency. Microphotographs depict various hematoxylin and eosin (H\&E) stained tissues derived from all three embryonic germ layers (ectoderm, mesoderm and endoderm). The appearance of persistent hPSC in teratomas is also described with special emphasis on the morphogenesis of embryoid bodies and yolk sac components surrounding them. The use of immunohistochemistry for analyzing hPSC-derived teratomas is also illustrated.
\end{abstract}

KEY WORDS: human pluripotent stem cells, ectoderm, mesoderm, endoderm, yolk sac

Human embryonic stem cells derived from pre-implantation embryos are pluripotent cells capable of differentiating into various somatic cells and or tissues (Thomson et al., 1998). Developmentally equivalent cells, termed induced pluripotent stem cells (IPSC), can be produced by reprogramming somatic cells (Takahashi and Yamanaka, 2006; Takahashi et al., 2007; Yu et al., 2007). In this Atlas we refer to these cell types, irrespective of their origin or derivation, as human pluripotent stem cells (hPSC).

From the historical point of view it is worth mentioning that isolation of hPSC was preceded by studies on human embryonal carcinoma cells (ECC) derived from human germ cell tumors (Andrews et al., 1980,1984, Pera et al., 1989). Since the pluripotency of single mouse embryonal carcinoma cell was demonstrated in vivo, by injecting individual cells into adult mice (Kleinsmith and Pierce, 1964), it was assumed the same approach could be used to test the pluripotency of mouse and human embryonic stem cells, human embryonal carcinoma cells, and all other hPSC (Andrews et al., 2005; Solter, 2006; Adewumi et al., 2007). For testing mouse cell pluripotency, syngeneic mice could be used as graft recipients (Solter, 2006). However human ECC or hPSC had to be injected into immunodeficient mice. Histopathologic examination of the resulting tumors was used to determine whether they could differentiate into mature tissues and thus express their complete developmental potential (Andrews et al., 2005). Comparison of hPSC and ECC showed that ECC are the malignant equivalents of hPSC, in a manner that mouse embryonal carcinoma cells are the malignant equivalents of embryonic stem cells (Andrews et al., 2005; Solter 2006). Cells forming teratomas, i.e. xenografts composed

*Address correspondence to: Ivan Damjanov. Department of Pathology, The University of Kansas School of Medicine, 3901 Rainbow Blvd., Kansas City, KS 66160,USA. Fax: 913-588-8780. E-mail: idamjano@kumc.edu; iD http://orcid.org/0000-0002-1394-6052

Submitted: 1 July, 2016. Accepted: 4 August, 2016

(C) 2016 UPV/EHU Press (Bilbao, Spain) and Creative Commons CC-BY. This is an open access article distributed under the terms of the Creative Commons Attribution License (http://creativecommons.org/licenses/), which permits you to Share (copy and redistribute the material in any medium or format) and Adapt (remix, transform, and build upon the material for any purpose, even commercially), providing you give appropriate credit, provide a link to the license, and indicate if changes were made. You may do so in any reasonable manner, but not in any way that suggests the licensor endorses you or your use. Printed in Spain

Int. J. Dev. Biol. 60: 337-419 (2016)

doi: $10.1387 / \mathrm{ijdb} .160274 \mathrm{id}$ 
of derivatives of all three embryonic germ layers (ectoderm, mesoderm and endoderm) were deemed in this teratoma assay to be developmentally pluripotent (Adewumi, et al., 2007; Amps, et al., 2011). Even though there are many tests of pluripotency in vitro, some of which include molecular biology examination of hPSC, the murine xenograft teratoma assay remains a gold standard used to reliably demonstrate pluripotency of these cells grown in vitro (reviewed by Hentze et al.,2009).

The teratoma assay was developed primarily as a test of pluripotency of hPSC. However, as we have pointed out previously (Damjanov and Andrews, 2007), it could also be used as a screening test for detecting malignant transformation of the hESC, as well as for detecting various forms of complex morphogenesis or even organogenesis that would not occur in vitro. To illustrate the full potential of the mouse xenograft teratoma assay and to pinpoint some of its limitations and potential problems, we assembled a panoply of microphotographs prepared from the xenografts produced over the years by the members of the International Stem Cell Initiative (ISCI).

\section{Historical definition of teratoma}

Teratomas are tumors that have intrigued biomedical scientists for many years (Damjanov and Wewer-Albrechtsen, 2013). The actual term teratoma was coined by Rudolf Virchow (1863) from two Greek words: teras meaning monster and onkoma meaning swelling or tumor. Ewing (1911 and 1919) defined teratomas as "complex tumors composed of tissues and organs of one, two or three germinal layers, as monodermal, bidermal or tridermal types". Willis (1951), writing in the first edition of the Armed Forces Institute of Pathology (AFIP) Atlases, deleted from his definition the reference to germ layers and defined teratoma as a "true tumor or neoplasm composed of multiple tissues of kinds foreign to the part in which it arises". Mostofi and Price (1973) defined testicular teratoma as a "complex tumor with recognizable elements of more than one germ layer in various stages of maturation, often arranged in such a manner as to suggest abortive organ formation". These authors also mention a number of historic synonyms and related terms, as follows: dysembryoma, embryoma, teratoblastoma, teratoid tumor, malignant teratomas, intermediate A and B.

Scully (1979) writing about ovarian teratomas was more precise, stating that "most teratomas contain several types of tissue that recapitulate the development of two or three embryonic layers (endoderm; mesoderm; ectoderm). The neoplastic components may be entirely mature, entirely immature or both mature and immature. In occasional cases, differentiation is monodermal, or almost so, as evidenced by the exclusive or predominant formation of a single highly specialized type of tissue". British pathologists nevertheless remained unconvinced by these American efforts and retained their own classification, in which they used the term teratoma with different prefixes for all testicular germ cell tumors except for seminoma, (Pugh, 1976) (Table 1).

\section{TABLE 1}

\section{COMPARISON OF THREE MAJOR CLASSIFICATIONS OF HUMAN TESTICULAR TUMORS}

\begin{tabular}{lll} 
AFIP (Dixon and More,1951) & British Testicular Tumour Panel (Pugh,1976) & World Health Organization (Moch et al, 2016) \\
\hline Seminoma & Seminoma & Seminoma \\
Embryonal carcinoma & Malignant teratoma, undifferentiated & Embryonal carcinoma \\
Teratoma with embryonal carcinoma (teratocarcinoma) & Malignant teratoma, intermediate & Nonseminomatous germ cell tumor(NSGCT) \\
& & -Mixed germ cell tumor \\
Teratoma, adult & Teratoma, differentiated & Teratoma, postpubertal type \\
Choriocarcinoma & Malignant teratoma, trophoblastic & Choriocarcinoma \\
\hline
\end{tabular}

AFIP-Armed Forces Institute of Pathology, Washington, DC

*Only the part of the WHO classification pertaining to germ cell tumors derived from germ cell neoplasia in situ and corresponding to the tumors in the AFIP and British Testicular Tumour Panel was included in this table.

\section{Pragmatic definition of teratoma}

For researchers dealing with hPSC, teratoma (without any additional qualifier) is best defined as a benign tumor composed of mature somatic tissues arranged in a disorderly manner. All standard textbooks of human pathology define teratomas in oncologic and developmental biology terms. From the oncologic point of view there is no doubt that teratomas are true neoplasms; the haphazard arrangement of tissues, "recapitulating" or "resembling" various somatic derivatives, points to an abnormal development of tissues inside the tumor. Experimental teratomas produced in rodents re-emphasize this dual developmental/oncologic nature of teratomas (Solter, 2006). Teratomas produced in mice from xenografted hPSC can be identified by the naked eye as tumors that grow on their own, and thus escape any growth inhibitory mechanisms in the host. They are thus "real tumors", readily recognized by the examiner as being different from other tissues or organs of the host.

\section{Comments}

Issue of three germ layer derivatives

Most human teratomas contain derivatives of all three embryonic germinal layers, although in practical terms this is 
not a sine qua non for diagnosing a tumor as teratoma. Those tumors that have derivatives of all three germ layers are also known as "tridermomas". Some tumors contain only derivatives of two germ layers and are thus also known as "bidermomas". Tumors predominantly or exclusively composed of cells or a tissue derived from a single germ layer (e.g. thyroid goiter of the ovary) are called "monodermal or monophyletic teratomas". Xenografts produced in mice injected with hPSC typically contain tissues derived from all three germ layers, although in some instances a certain tissue may predominate forming over $90 \%$ of the entire graft. This is most prominently seen in teratomas composed of neural tissue. "Monodermal" or "highly specialized" teratomas composed of a single cell type, can be produced in mouse xenografts from committed stem cells generated in vitro from undifferentiated hPSC, such as islet cell precursors (Schultz,2015).

\section{Location}

Although Willis (1951) defined teratomas in terms of location ("multiple tissues foreign to the part in which it arises"), experimental data show that teratomas can be experimentally produced in any site (Solter, 2006). The same holds true for the teratomas produced by xenografting of hPSC in immunodeficient mice (Adewumi,et al., 2007). Teratomas can be produced from hPSC xenografted to any anatomic site in immunodeficient mice (reviewed by Hentze et al.,2009).

\section{Benign versus malignant}

These terms refer to the clinical presentation of various tumors and the final outcome of the neoplastic disease. Ovarian teratomas composed of mature somatic tissues are almost all benign and do not endanger the life of the host. On the other hand, in the testis, even the pathologically diagnosed "benign" teratomas may clinically behave as malignant, metastasize and kill the host. Hence, many authorities suggest that the extra-ovarian teratomas should be clinically observed for possible malignancy that cannot be recognized histologically. Experimentally produced and spontaneous teratomas of mice are benign and can be readily distinguished from malignant teratocarcinomas (Solter, 2006). The biological nature of teratomas produced from hPSC xenografted into immunodeficient mice cannot be determined with certainty. In part this relates to the limited time of observation of grafted animals, and in part it is related to the nature of the experiments that have been performed so far, not allowing us to address properly the nature of possible malignancy in the xenografts.

\section{Immature teratomas}

Teratomas composed of mature and immature tissues are classified as immature teratomas. The significance of this distinction is best seen in the ovary: $99 \%$ of teratomas of the ovary are composed of mature tissue, and $1 \%$ are considered to be immature (Scully, 1979). In contrast to teratomas composed of mature somatic tissues, which are by definition clinically benign, immature ovarian teratomas are malignant tumors, which can metastasize and endanger the life of the host. The immaturity of other somatic tissues is clinically of no significance.

\section{Comment}

\section{Presence of immature tissues}

The issue of immature tissue in teratomas produced from xenografted hPSC is a conundrum that cannot be solved readily. Neural rosettes and neural tube-like tissue are very common in xenografts and sometimes they represent the predominant tissue in such tumors. On the basis of the experience with immature ovarian teratomas which also contain neural tube like tissues and neural rosettes, one could assume that such graft are potentially malignant and could disseminate. A simple experiment in which one would remove such a graft, dice it and inject these small pieces into the abdominal cavity of another mouse could answer, at least in part, the question of whether such tumors have the capacity to spread through the body or body cavities of immunosuppressed mice.

\section{Malignant transformation of benign teratomas}

Benign ovarian teratomas which are left in situ for many years without surgical intervention may undergo malignant transformation. (Most often such malignant tumors are classified as squamous cell carcinomas (Hackethal et al.,2008) but other tissues may undergo malignant transformation as well. There are reports of adenocarcinomas, various sarcoma and gliomas originating in benign teratomas.

\section{Comment}

\section{Malignant transformation}

Transformation of benign teratomas into somatic malignant tumors, such as carcinoma, sarcoma or lymphoma, has not been observed in teratomas produced from xenografted hPSC. Such transformation occurs in human ovarian teratomas over a prolonged period of time, and thus it seems unlikely for it to occur in mice bearing hPSC-derived teratomas during the short they are typically observed. 


\section{Teratocarcinoma-malignant teratoma}

Teratocarcinoma is a term used predominantly by scientists working on mouse germ cell tumors and embryo derived teratoid tumors (Damjanov and Andrews, 2012). The term was initially introduced by Friedman and More (1946) to denote malignant germ cell tumors composed of embryonal carcinoma cells and teratoma components. The term teratocarcinoma was, however, abandoned by clinical pathologists to be replaced by terms such a mixed germ cell tumor or non-seminoma, or nonseminomatous germ cell tumor (NSGCT).

According to the teaching of Friedman and Moore (1946), which was included in the AFIP Atlas on testicular tumors (Dixon and Moore, 1952), undifferentiated ECC are the malignant stem cells of teratocarcinomas. ECCs are capable of rapid growth and metastasis, but at the same time they can differentiate into somatic tissues and lose their malignancy. This concept of reversible malignancy was proven operational in clinical cases with metastases; under the influence of chemotherapy such metastases lost the ECC component and transformed into well differentiated teratomas (Ulbright, 1999). In vitro studies with human embryonal carcinoma cells confirmed, in principle, the notion that ECC can differentiate and lose their malignancy (Andrews et al., 2002). Comparison of human ECC and hPSC grown in vitro revealed many similarities, including their immunoprofile and developmental pluripotency (Andrews et al., 2002).

\section{Comment}

The significance of embryonal carcinoma cells

The presence of undifferentiated ECC in a clinically diagnosed teratoma automatically changes its diagnosis from benign to malignant. The same principle is used to diagnose malignant teratoid tumors in mice, and all tumors containing identifiable ECC are labeled as teratocarcinomas (Lin, et al., 2015). The obvious question, applied mutatis mutandis to hPSC grafted to immunosuppressed mice, is as follows: Are tumors that contain undifferentiated cells resembling ECC benign or malignant? The answer is: Nobody knows.

\section{Malignancy of $h P S C$ derived teratomas}

Without proper experimental proof of malignancy of teratomas that contain undifferentiated hPSC 6-8 weeks after xenografting, all discussions are moot. Nevertheless, the presence of such undifferentiated hPSC in 6-8 week old grafts is at least a topic that needs to be explored. In view of the potential (but not proven) malignancy residing in these undifferentiated hPSC that resemble human ECC ("human ECC-like cells"), more experiments are indicated. For example, parts of the tumors obtained from xenografted hPSC could be retransplanted into other mice to see if the tumor stem cells will form new tumors faster and contain more undifferentiated or human ECC-like cells, invade host tissue or even metastasize, thus proving that the tumors are malignant indeed.

\section{Teratocarcinoma}

This term has been rejected by clinical pathologists, although it is commonly used by laboratory scientists working with mice (Solter, 2006). Should one use this term for malignant teratomas produced from xenografted hPSC? No consensus has been reached so far, although it seems logical to use a specific term for malignant tumors proven to be malignant by established biomedical criteria (Damjanov and Andrews,2007).

\section{ISCI Steering Committee}

Peter W Andrews ${ }^{1}$, Nissim Benvenisty ${ }^{2}$, Oliver Brustle ${ }^{3}$, Barbara B. Knowles ${ }^{4}$, Christine Mummery ${ }^{5}$, Steven Oh ${ }^{6}$, Martin Pera ${ }^{7}$, Benjamin Reubinoff ${ }^{8}$, Janet Rossant ${ }^{9}$ and Glyn Stacey ${ }^{10}$

${ }^{1}$ Centre for Stem Cell Biology, Dept. Biomedical Science, University of Sheffield, UK; ${ }^{2}$ The Azrieli Center for Stem Cells and Genetic Research, Institute of Life Sciences, The Hebrew University of Jerusalem, Israel; ${ }^{3}$ Institute of Reconstructive Neurobiology, LIFE \& BRAIN Center, University of Bonn, Germany; ${ }^{4}$ The Jackson Laboratory, Bar Harbor, Main, USA; ${ }^{5}$ Dept. of Anatomy \& Embryology, Leiden University Medical Center, The Netherlands; ${ }^{6} A^{*}$ Star Bioprocessing Technology Institute, Stem Cell Group, Singapore; ${ }^{7}$ Melbourne Brain Centre, The University of Melbourne, Victoria, Australia; ${ }^{8}$ The Sidney and Judy Swartz Embryonic Stem Cell Research Center of The Goldyne Savad Institute of Gene Therapy \& The Department of Obstetrics and Gynecology, Hadassah University Medical Center, Jerusalem, Israel; ${ }^{9}$ Program for Developmental Biology, The Hospital for Sick Children, Toronto, Ontario, Canada; ${ }^{10}$ The UK Stem Cell Bank, National Institute for Biological Standards and Control, Hertfordshire, UK.

\section{Xenograft tumors were provided by}

Andre Choo ${ }^{1}$, Chris Denning ${ }^{2}$, Andrew G. Elefanty ${ }^{3}$, Lyn Healy ${ }^{4}$, Tenneille Ludwig, Pablo Menendez ${ }^{6}$, Milla Mikkola ${ }^{7}$, Norio Nakatsuji ${ }^{8}$, Orla O'Shea ${ }^{9}$, Timo Otonkoski ${ }^{10}$, Daniela F.C. Santori ${ }^{11}$, Edouard G. Stanley ${ }^{12}$ and Hirofumi Suemori ${ }^{13}$

${ }^{1}$ Bioprocessing Technology Institute, A*STAR; Singapore; '2Department of Stem Cell Biology, Centre for Biomolecular Sciences, 
University of Nottingham, UK; ${ }^{3}$ Murdoch Childrens Research Institute, The Royal Children's Hospital, Victoria, Australia; ${ }^{4}$ The UK Stem Cell Bank, National Institute for Biological Standards and Control, Hertfordshire, UK; Present address: The Francis Crick Institute, Mill Hill Laboratory, London, UK; ${ }^{5}$ WiCell, Madison, WI, USA; ${ }^{6}$ Josep Carreras Leukemia Research Institute, Institucio Catalana de Recerca i Estudis Avancats (ICREA), Barcelona, Spain; ${ }^{7}$ Research Programs Unit, Molecular Neurology and Biomedicum Stem Cell Centre, University of Helsinki, Finland; ${ }^{8}$ Institute for Integrated Cell-Material Sciences, Kyoto University, Kyoto, Japan; ${ }^{9}$ The UK Stem Cell Bank, National Institute for Biological Standards and Control, Hertfordshire, UK; ${ }^{10}$ Research Programs Unit, Molecular Neurology and Biomedicum Stem Cell Centre, University of Helsinki, Finland; "1 Dept. of Anatomy \& Embryology, Leiden University Medical Center, Leiden, The Netherlands; ${ }^{12}$ Murdoch Childrens' Research Institute, The Royal Children's Hospital, Victoria, Australia; ${ }^{13}$ Department of Embryonic Stem Cell Research, Institute for Frontier Medical Sciences, Kyoto University, Kyoto, Japan.

\section{Acknowledgements}

This work was funded by the International Stem Cell Forum and the Medical Research Council, UK.

\section{References}

ADEWUMI O, AFLATOONIAN B, AHRLUND-RICHTER L, AMIT M, ANDREWS PW, BEIGHTON G, BELLO PA, BENVENISTY N, BERRY LS, BEVAN S, BLUM B, BROOKING J, CHEN KG, CHOO AB, CHURCHILL GA, CORBEL M, DAMJANOV I, DRAPER JS, DVORAK P, EMANUELSSON K, FLECK RA, FORD A, GERTOW K, GERTSENSTEIN M, GOKHALE PJ, HAMILTON RS, HAMPL A, HEALY LE, HOVATTA O, HYLLNER J, IMREH MP, ITSKOVITZ-ELDOR J, JACKSON J, JOHNSON JL, JONES M, KEE K, KING BL, KNOWLES BB, LAKO M, LEBRIN F, MALLON BS, MANNING D, MAYSHAR Y, MCKAY RD, MICHALSKAAE, MIKKOLA M, MILEIKOVSKY M, MINGER SL, MOORE HD, MUMMERY CL, NAGYA, NAKATSUJI N, O'BRIEN CM, OH SK, OLSSON C, OTONKOSKI T, PARK KY, PASSIER R, PATEL H, PATEL M, PEDERSEN R, PERA MF, PIEKARCZYK MS, PERA RA, REUBINOFF BE, ROBINS AJ, ROSSANT J, RUGG-GUNN P, SCHULZ TC, SEMB H, SHERRER ES, SIEMEN H, STACEY GN, STOJKOVIC M, SUEMORI H, SZATKIEWICZ J, TURETSKY T, TUURI T, VAN DEN BRINK S, VINTERSTEN K, VUORISTO S, WARD D, WEAVER TA, YOUNG LA, ZHANG W. (2007) Characterization of human embryonic stem cell lines by the International Stem Cell Initiative. Nat Biotechnol. 25: 803-816.

AMPS K, ANDREWS PW, ANYFANTIS G, ARMSTRONG L, AVERY S, BAHARVAND H, BAKER J, BAKER D, MUNOZ MB, BEIL S, BENVENISTY N, BEN-YOSEF D, BIANCOTTI JC, BOSMAN A, BRENA RM, BRISON D, CAISANDER G, CAMARASA MV, CHEN J, CHIAO E, CHOI YM, CHOO AB, COLLINS D, COLMAN A, CROOK JM, DALEY GQ, DALTON A, DE SOUSA PA, DENNING C, DOWNIE J, DVORAK P, MONTGOMERY KD, FEKI A, FORD A, FOX V, FRAGA AM, FRUMKIN T, GE L, GOKHALE PJ, GOLAN-LEV T, GOURABI H, GROPP M, GUANGXIU L, HAMPL A, HARRON K, HEALY L, HERATH W, HOLM F, HOVATTA O, HYLLNER J, INAMDAR MS, IRWANTO AK, ISHII T, JACONI M, JIN Y, KIMBER S, KISELEV S, KNOWLES BB, KOPPER O, KUKHARENKO V, KULIEV A, LAGARKOVA MA, LAIRD PW, LAKO M, LASLETT AL, LAVON N, LEE DR, LEE JE, LI C, LIM LS, LUDWIG TE, MA Y, MALTBY E, MATEIZEL I, MAYSHAR Y, MILEIKOVSKY M, MINGER SL, MIYAZAKI T, MOON SY, MOORE H, MUMMERY C, NAGY A, NAKATSUJI N, NARWANI K, OH SK, OH SK, OLSON C, OTONKOSKI T, PAN F, PARK IH, PELLS S, PERA MF, PEREIRA LV, QI O, RAJ GS, REUBINOFF B, ROBINS A, ROBSON P, ROSSANT J, SALEKDEH GH, SCHULZ TC, SERMON K, MOHAMED JS, SHEN H, SHERRER E, SIDHU K, SIVARAJAH S, SKOTTMAN H, SPITS C, STACEY GN, STREHL R, STRELCHENKO N, SUEMORI H, SUN B, SUURONEN R, TAKAHASHI K, TUURI T, VENU P, VERLINSKY Y, OOSTWAARD DW, WEISENBERGER DJ, WU Y, YAMANAKA S, YOUNG L, ZHOU Q. (2011) Screening ethnically diverse human embryonic stem cells identifies a chromosome 20 minimal amplicon conferring growth advantage. Nat Biotechnol. 29: $1132-1144$.

ANDREWS, P.W. (2002). From teratocarcinomas to embryonic stem cells. Phil. Trans. R. Soc. Lond. B 357: 405-417.

ANDREWS,P.W, BRONSON,D.L.,BENHAM,F.,STRICKLAND, S. and KNOWLES,B.B. (1980). A comparative study of eight cell lines derived from human teratocarcinoma. Int. J. Cancer 26: 269-280.

ANDREWS P.W., DAMJANOV I., SIMON D., BANTING G., CARLIN C., DRACOPOLI N.C. and FOGH J. (1984) Pluripotent embryonal carcinoma clones derived from the human teratocarcinoma cell line Tera-2: Differentiation in vivo and in vitro. Lab. Invest. 50: 147-162.

ANDREWS,P.W., MATIN,M.M., BAHRAMI, A.R., DAMJANOV,I. GOKHALE,P.and DRAPER,J.S.(2005). Embryonic stem (ES) cells and embryonal carcinoma (EC) cells: opposite sides of the same coin. Biochem Soc Trans. 33:1526-1530.

DAMJANOV, I. and ANDREWS,P.W. (2007) The terminology of teratocarcinomas and teratomas. Nat. Biotechnol. 25: 1212.

DAMJANOV, I. and WEWER-ALBRECHTSEN,N. (2013) Testicular germ cell tumors and related research from a historical point of view. Int.J. Dev. Biol. 57: 197-200.

DIXON, F.J. and MOORE, R.A. (1952). Tumors of the Male Sex Organs. Fascicles 31b and 32.Atlas of Tumor Pathology, Armed Forces Institute of Pathology, Washington.

EWING, J. (1911) Teratoma testis and its derivatives. Surg. Gynecol. Obstet. 12: 230-261.

EWING, J. (1919) Neoplastic Diseases. A Treatise on Tumors. W.B. Saunders, Philadelphia.

FRIEDMAN, N.B. and MOORE, R.A. (1946) Tumors of the testis. Military Surg. 99: 573-593.

HACKETHAL, A., BRUEGGMANN, D., BOHLMANN,M.K., FRANKE,F.E., TINNEBERG,H.R.and MüNSTEDT, K.(2008) Squamous-cell carcinoma in mature cystic teratoma of the ovary: Systemic review and analysis of published data. Lancet Oncol.9: 1173-1180.

HENTZE H,SOONG,P.L.,WANG,S.T.,PHILLIPS,B.W.,PUTTI,T.C. and DUNN,N.R. (2009) Teratoma formation by human embryonic stem cells: evaluation of essential parameters for future safety studies. Stem Cell Res.2: 198-210.

KLEINSMITH,L.J, and PIERCE,G.B.(1964).Multipotentiality of single embryonal carcinoma cells. Cancer Res. 24: 1544-1551.

LIM, C.Y., SOLTER, D., KNOWLES,B.B. and DAMJANOV, I. (2015). Development of teratocarcinomas and teratomas in severely immunodeficient NOD. Cg-Prkdc (scid) II2rg(tm1Wj)/Szj (NSG) mice. Stem Cells Dev. 24: 1515-1520.

MOSTOFI, F.K. and PRICE, E.B. (1973). Tumors of the Male Genital System, Atlas of Tumor Pathology, second series, Armed Forces Institute of Pathology, Washington.

PERA, M.F., COOPER, S., MILLS, J., PARRINGTON, J.M. (1989) Isolation and characterization of a multipotent clone of human embryonal carcinoma cells. Differentiation 42: 10-23.

PUGH, R.C.B.,editor (1976) Pathology of the Testis. Blackwell, Oxford.

SCHULZ,T.C.(2015). Concise Review: Manufacturing of Pancreatic Endoderm Cells for Clinical Trials in Type 1 Diabetes. Stem Cells Transl. Med. 4: 927-931. 


\section{I. Damjanov and P. W. Andrews}

SCULLY,R.E. (1979). Tumors of the Ovary and Maldeveloped Gonads, second series, Armed Forces Institute of Pathology, Washington.

SOLTER, D. (2006) From teratocarcinomas to embryonic stem cells and beyond: a history of embryonic stem cell research. Nature Rev. Genet. 7:319-327.

TAKAHASHI, K. and YAMANAKA, S. (2006) Induction of pluripotent stem cells from mouse embryonic and adult fibroblast cultures by defined factors. Cell 126: 663-676.

TAKAHASHI, K. TANABE, K, OHNUKI, M, NARITA, M, ICHISAKA, T, TOMODA, K. and YAMANAKA, S. (2007) Induction of pluripotent stem cells from adult human fibroblasts by defined factors, Cell 131: 861-872.

THOMSON, J.A., ITSKOVITZ-ELDOR, J., SHAPIRO, S.S., WAKNITZ, M.A., SWIERGIEL, J.J., MARSHALL, V.S., and JONES, J.M. (1998). Embryonic stem cell lines derived from human blastocysts. Science 282: 1145-1147.

ULBRIGHT,T.M. (1999) Testis risk and prognostic factors. The pathologist's perspective. Urol. Clin. North Am. 26: 611-626.

VIRCHOW, R. (1863).Die Krankhafte Geschwülste, Bd I, p96, Hirschwald, Berlin.

WILLIS, R.A. (1951). Teratomas. Atlas of Tumor Pathology, first series, Armed Forces Institute of Pathology, Washington.

YU, J, VODYANIK, M.A. SMUGA-OTTO, K. ANTOSIEWICZ-BOURGET, J. FRANE, J.L. TIAN, S. NIE, J. JONSDOTTIR, G.A. RUOTTI, V. STEWART, R. SLUKVIN, I.I. and THOMSON, J.A. (2007) Induced pluripotent stem cell lines derived from human somatic cells. Science 318: 1917-1920. 


\section{SEGTIONS}

Synoptic view of xenografts

$\begin{array}{ll}\text { Ectodermal derivatives } & 365\end{array}$

$\begin{array}{lr}\text { Endodermal derivatives } & 379\end{array}$

$\begin{array}{ll}\text { Mesodermal derivatives } & 387\end{array}$

Human PSCs, early embryonic and extraembryonic tissues

Abbreviations used in this Atlas: B, bone; Bv, blood vessel; C, cartilage; Cp, choroid plexus; End, endodermal; EB, embryoid body; ECC, embryonal carcinoma cell; F, fat; hPSC, human pluripotent cell; iPSC, induced pluripotent stem cell; M, muscle; Mes, mesenchymal stroma; Neu, neural cell; Np, neural plate; Nt, neural tube; O, osteoid; Pig, pigmented; Sm, smooth muscle; Sc, stratified cylindrical epithelium; Sq, squamous epithelium; $\mathrm{V}$, vacuolated.

Note: Except for Fig. 33, all sections in this Atlas are conventionally stained with hematoxylin and eosin (H\&E). 



\section{Synoptic view of xenografts}


346 I. Damjanov and P. W. Andrews

Fig. 1. Representative whole mount sections of nine xenografts. (A-J) The samples (E,F,G) were bisected in half and thus contain much more tissue for examination. Magnification: $4 x$. Specimens $(\mathbf{I}, \mathbf{J}, \mathbf{K})$ appeared larger in the mouse upon harvesting because the cystic spaces within the xenografts were expanded by the fluid, which has escaped upon sectioning. Magnification: (H) 120x; (I) 180x; (J) 180x. 

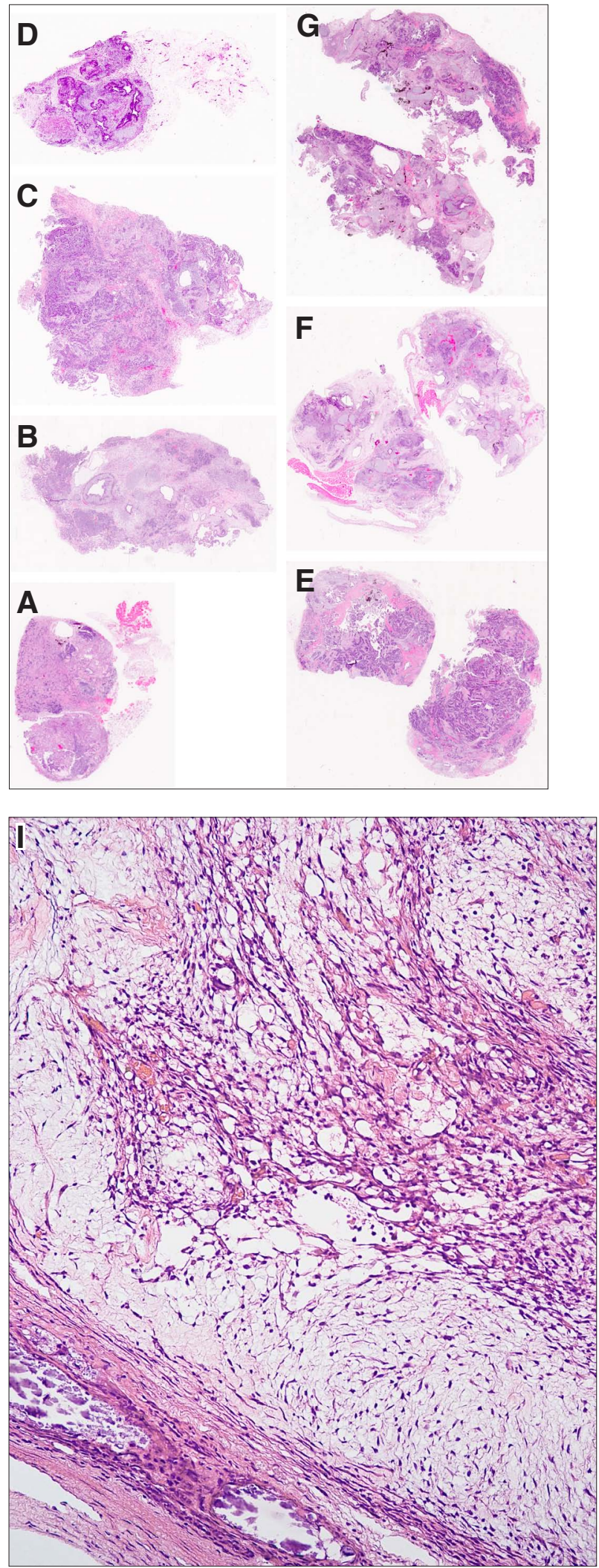
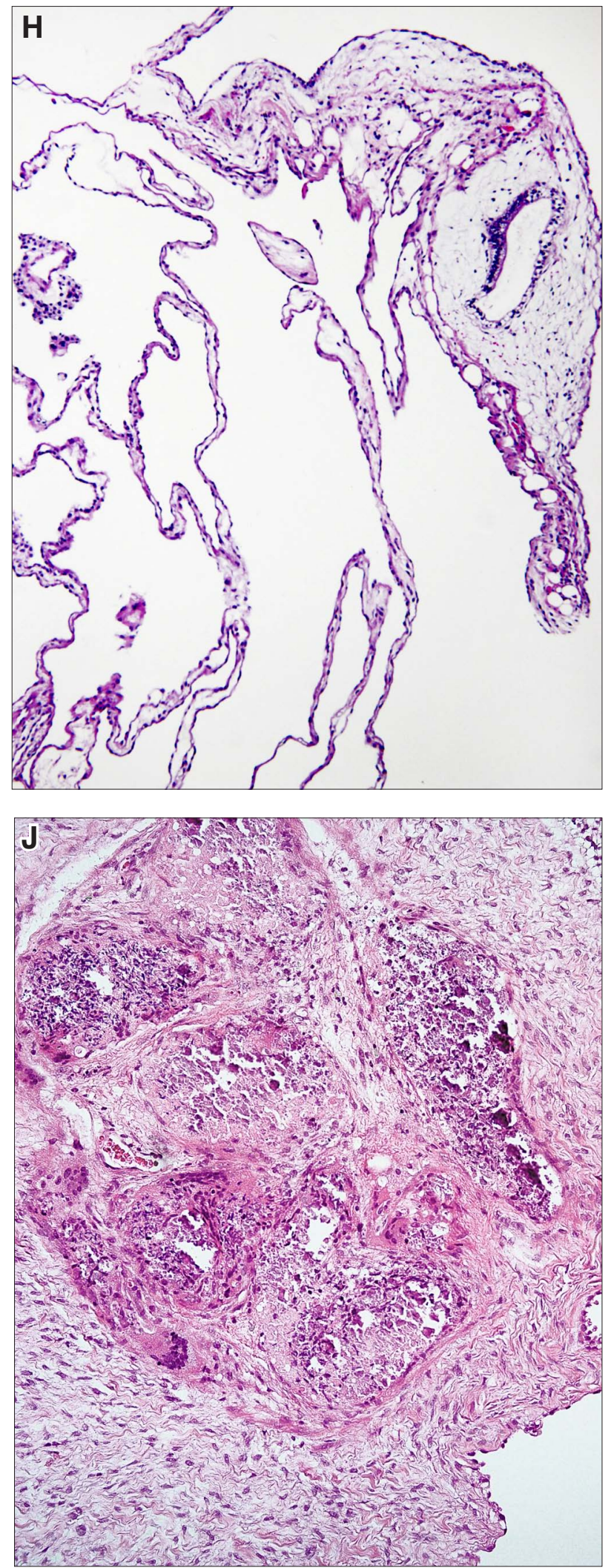
348 I. Damjanov and P. W. Andrews

Fig. 2. Xenograft presented in Fig. 1A photographed at higher magnifications. (A) 40x; (B) 80x. Abbreviations: Cp, choroid plexus; End, endodermal; Neu, neural. 

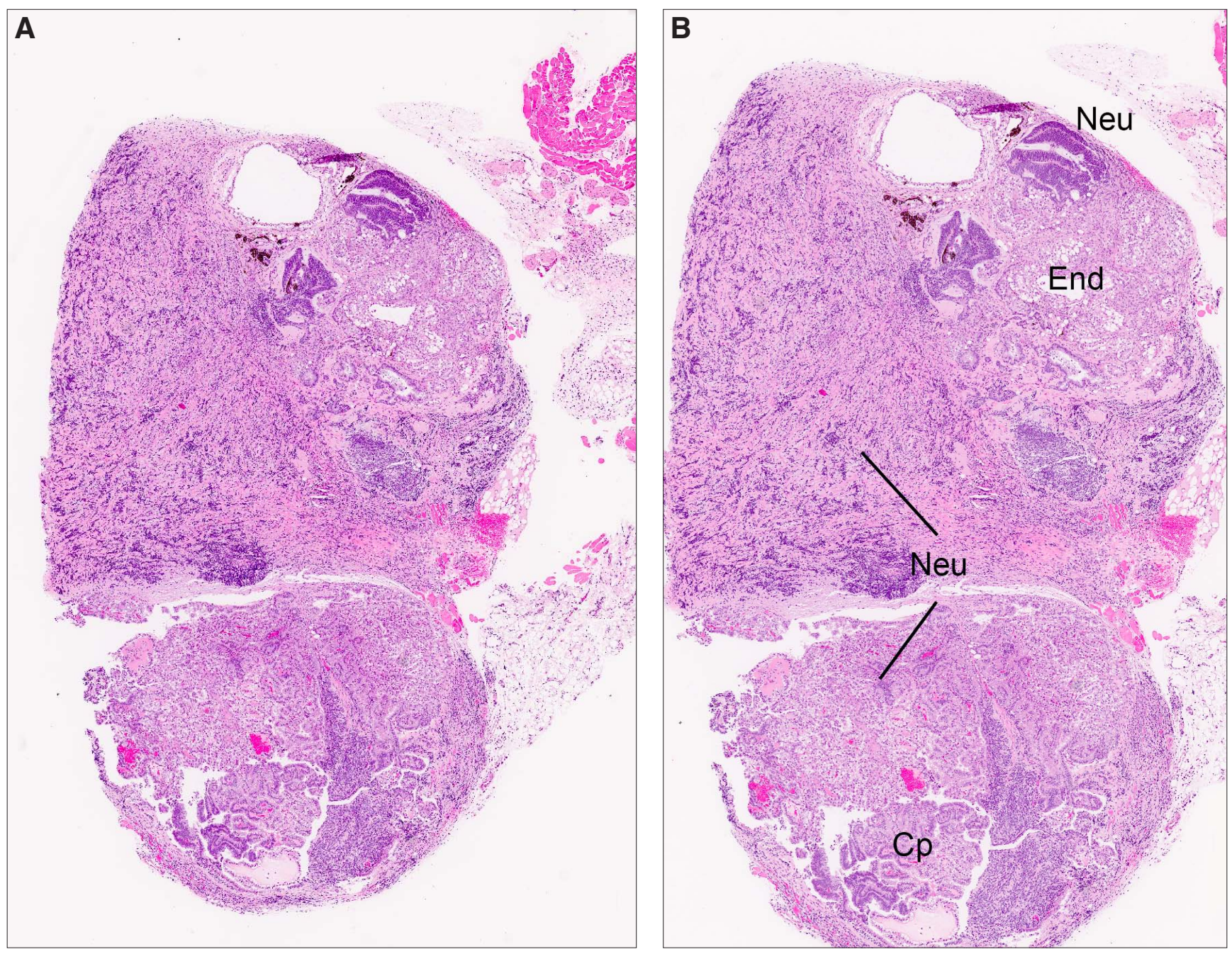
Fig. 3. Teratomas, panoramic view. (A) Higher magnification view of Fig. 1D. (B) A typical teratoma containing ectodermally derived neural tissue (Neu), mesodermally derived cartilage (C), muscle (M) and endodermal tubes (End). Magnification: (A) 80x; (B) 160x. 

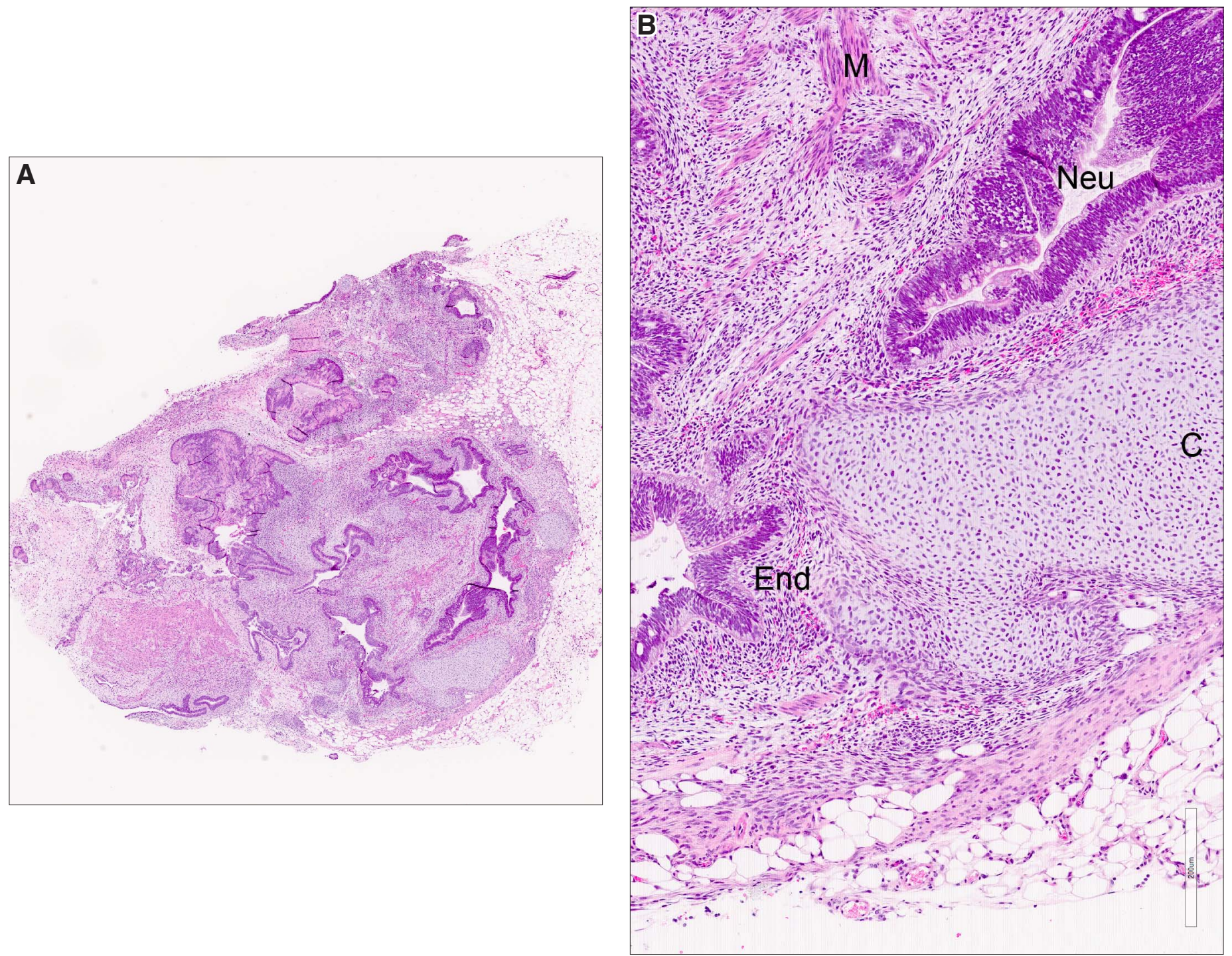
352 I. Damjanov and P. W. Andrews

Fig. 4. Teratoma, panoramic view. (A) The xenograft is composed predominantly of immature neural tissue (Neu), some choroid plexus (Cp), a few endodermal tubes (End) surrounded by mesenchymal stroma (Mes). (B) Higher magnification view of the neural component in the right sided part the teratoma. Magnification: (A) 80x; (B) 120x. 

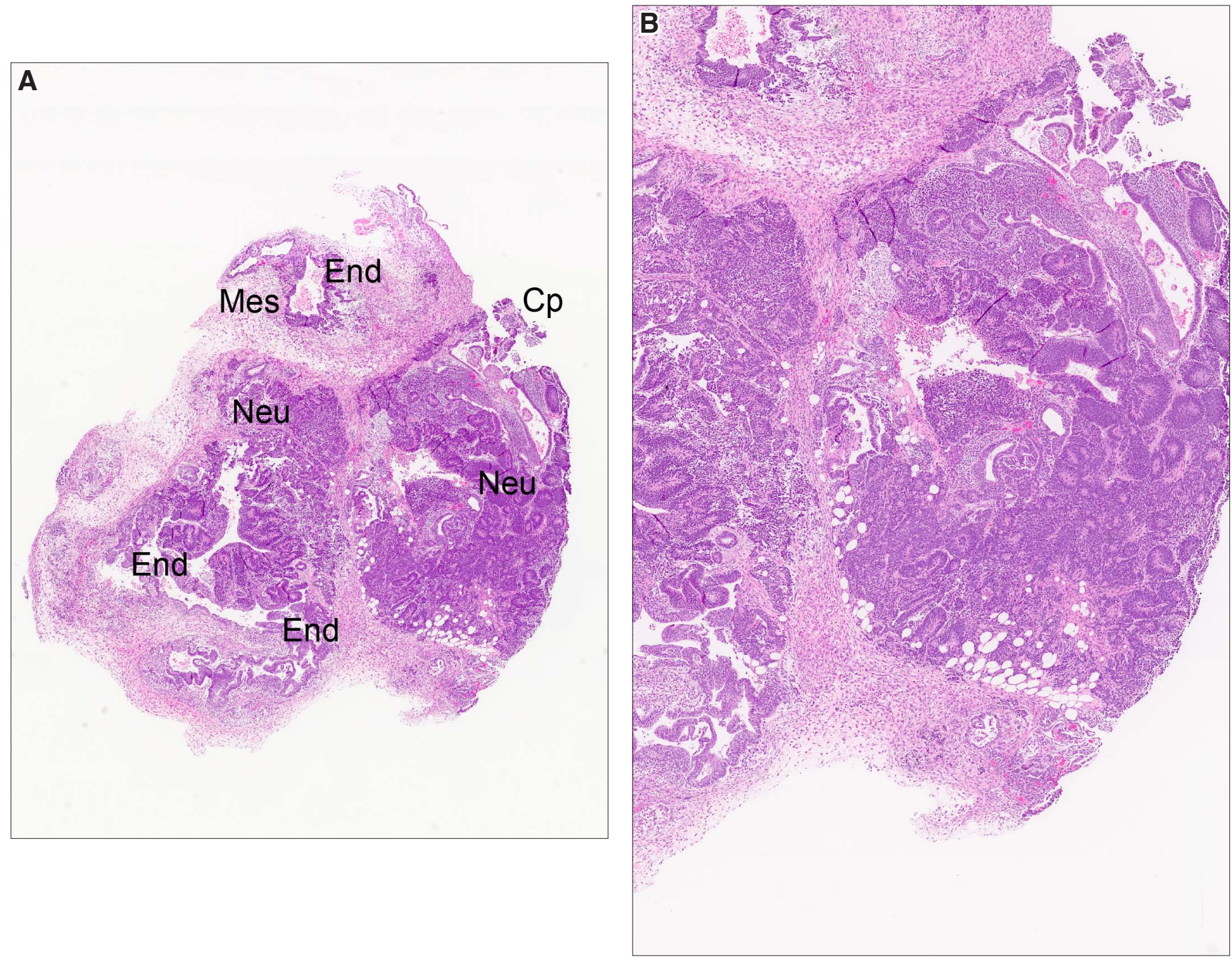
354 I. Damjanov and P. W. Andrews

Fig. 5. Teratoma, panoramic view. (A) This xenograft is composed of approximately equal parts of endodermal (End), mesodermal derivative (Mes) including bone (B) and cartilage (C), and ectodermal derivative, such as neural tissue(Neu). (B) Another teratoma showing equal representation of derivatives of all 3 germ layers. Magnification: $(A, B) 120 x$. 

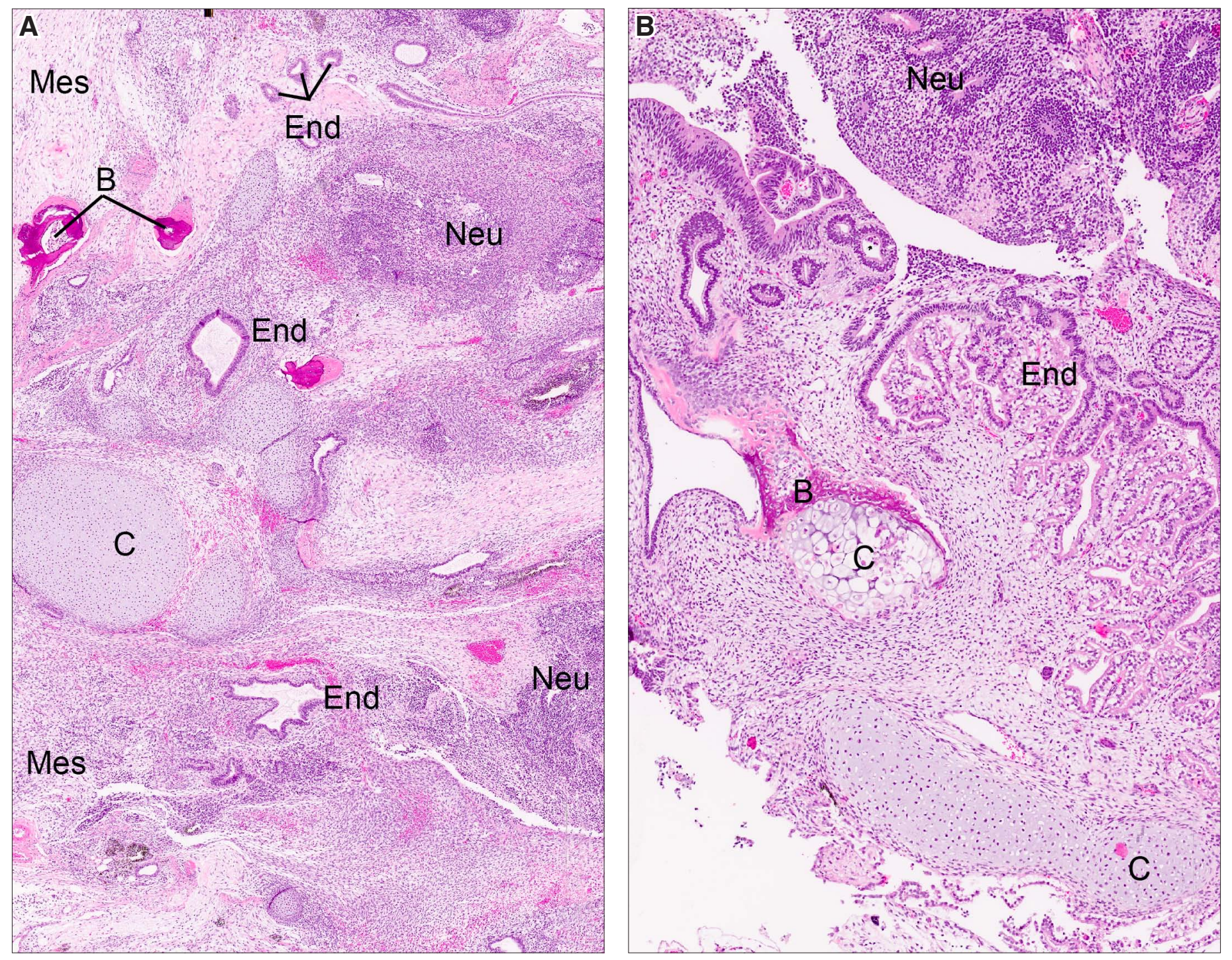
Fig. 6. Teratomas containing derivatives of all three germ layers. (A) Teratoma contains endodermal tubes (End), and ectodermal tissues, including squamous epithelium (Sq) and neural tissue (Neu). Mesoderm derived stroma is seen between these elements. (B) In this teratoma, ectodermal derivatives are represented by neural tissue (Neu), endodermal derivatives by the liver, and mesodermal derivatives by the stroma. (C) In this teratoma, ectodermal derivatives are represented by dispersed immature neural tissue and neural rosettes (Neu), endodermal derivatives by a endodermal tube (End) with subnuclear vacuoles, and the mesodermal derivatives by cartilage (C) and loose stroma. (D) Higher magnification of neural tissue focally forming rosettes (Neu) and vacuolated endodermal tube(End). The mesodermal stroma in the upper part is loose and in the lower part of the figure dense. Magnification: (A) 180x; (B) 200x; (C) 180x; (D) 280x. 

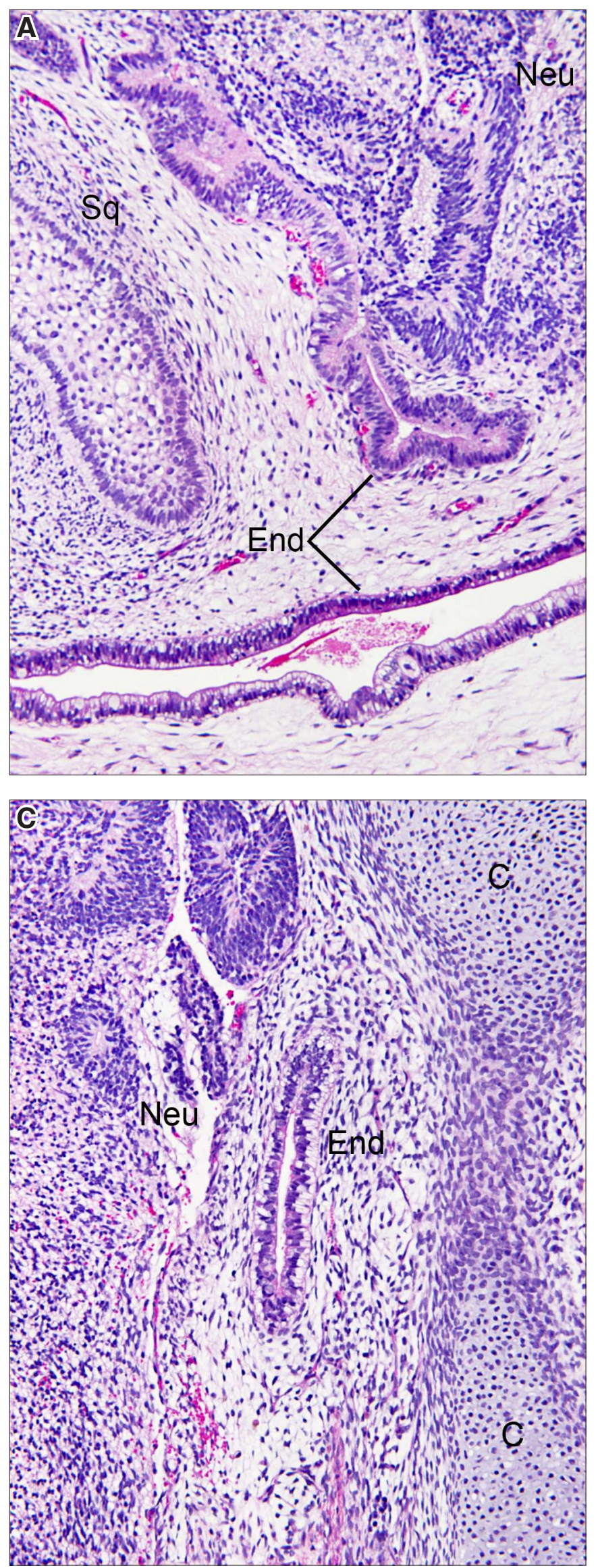
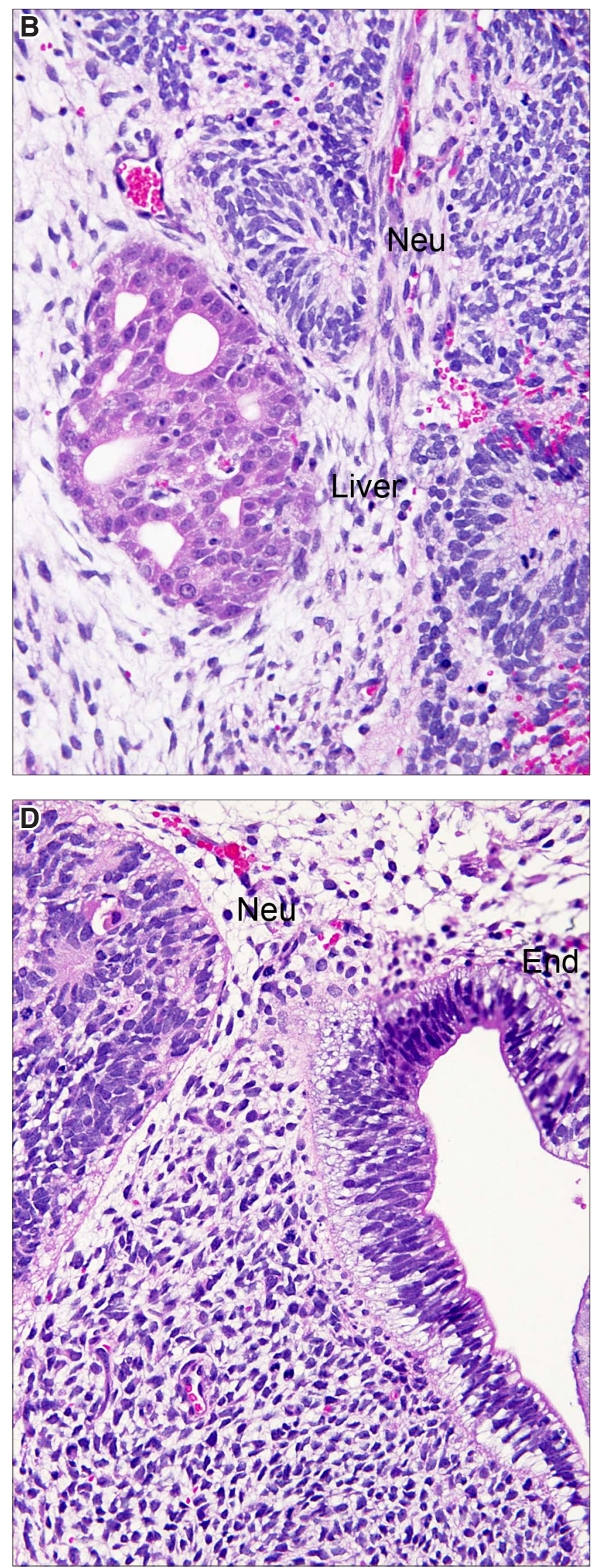
Fig. 7. Teratomas containing yolk sac (YS) components intermixed with hPSC. (A) In this teratoma YS and hPSC form just a very small component (framed). Immature neural tissue is the most prominent component, and it is focally admixed with mesenchymal stroma. (B) Yolk sac components admixed with hPSC account for the entire photographed part of this teratoma. Magnification: (A,B) 120x. 

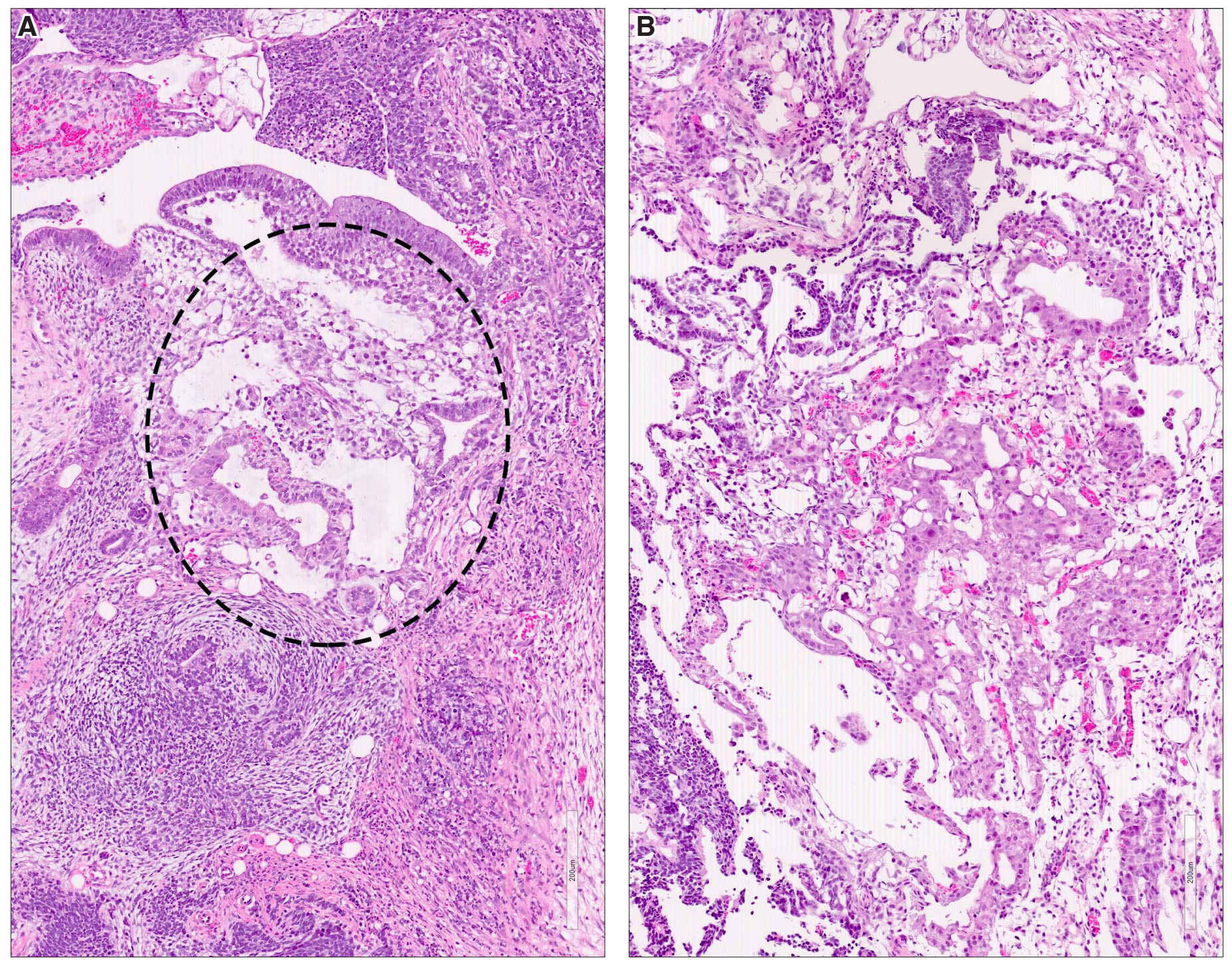
Fig. 8. Teratomas composed of undifferentiated cells that cannot be further classified. (A) This tumor contains numerous cystic and tubelike structures formed of undifferentiated cells which have condensed nuclei and scant cytoplasm. It is possible that these cells represent precursors of neural cells or endodermal structures, such as intestines and bronchi. However without additional studies, these cells cannot be properly identified. Magnification: (A) 120x; (B) 220x. 

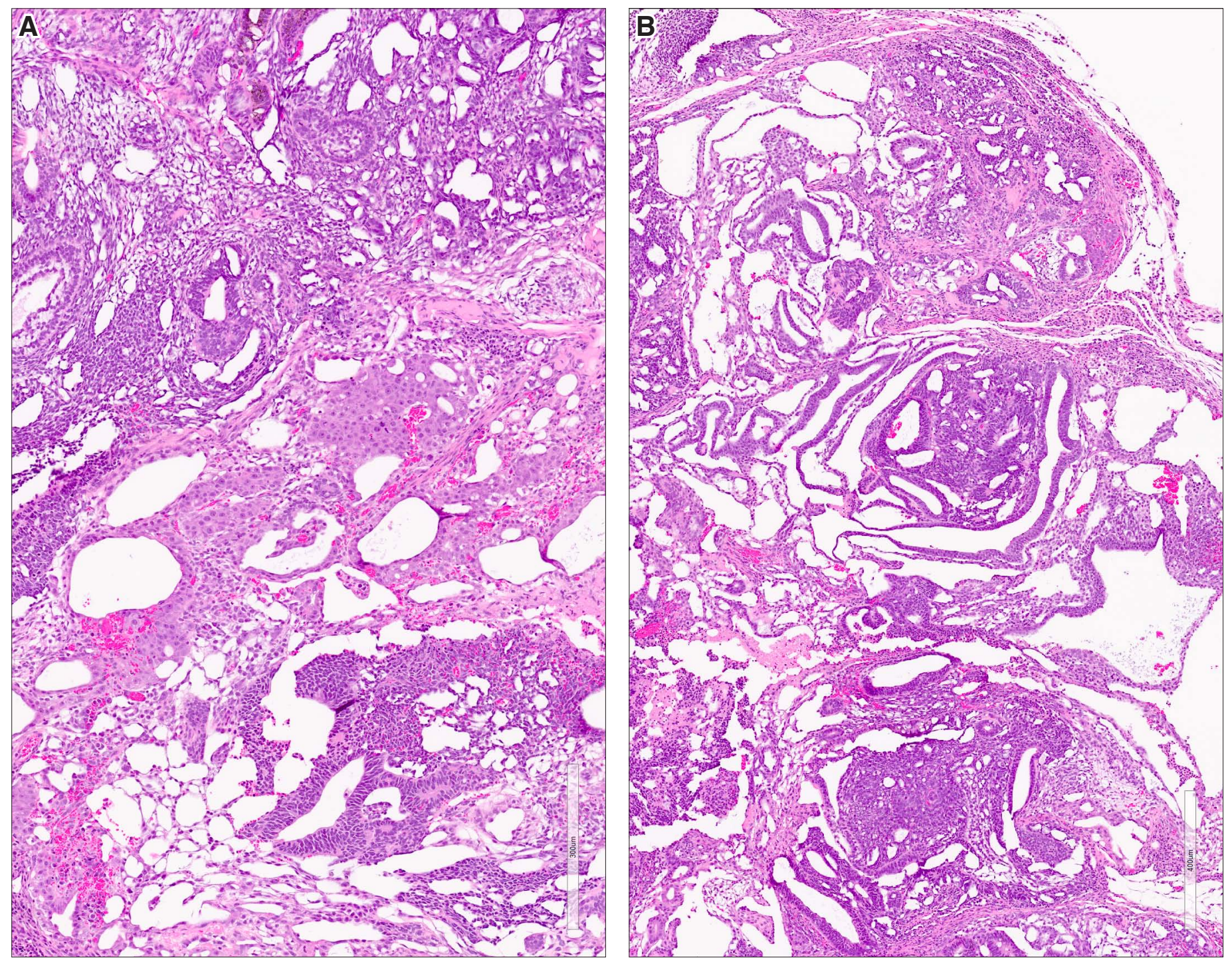
362 I. Damjanov and P. W. Andrews

Fig. 9. Teratomas composed of cells which cannot be further classified. (A) Teratoma composed of ducts and tubules lined by undifferentiated cells with condensed nuclei and scant cytoplasm. (B) Teratoma composed of the same cells as shown in (A). However this one has more stroma between the tubes formed of unidentified cells. (C) Teratoma made up of duct like structures surrounded by hyaline stroma. (D) Irregular spaces lined by flattened epithelium which cannot be further characterized. Magnification: $(A, B)$ 80x; (C,D) 180x. 


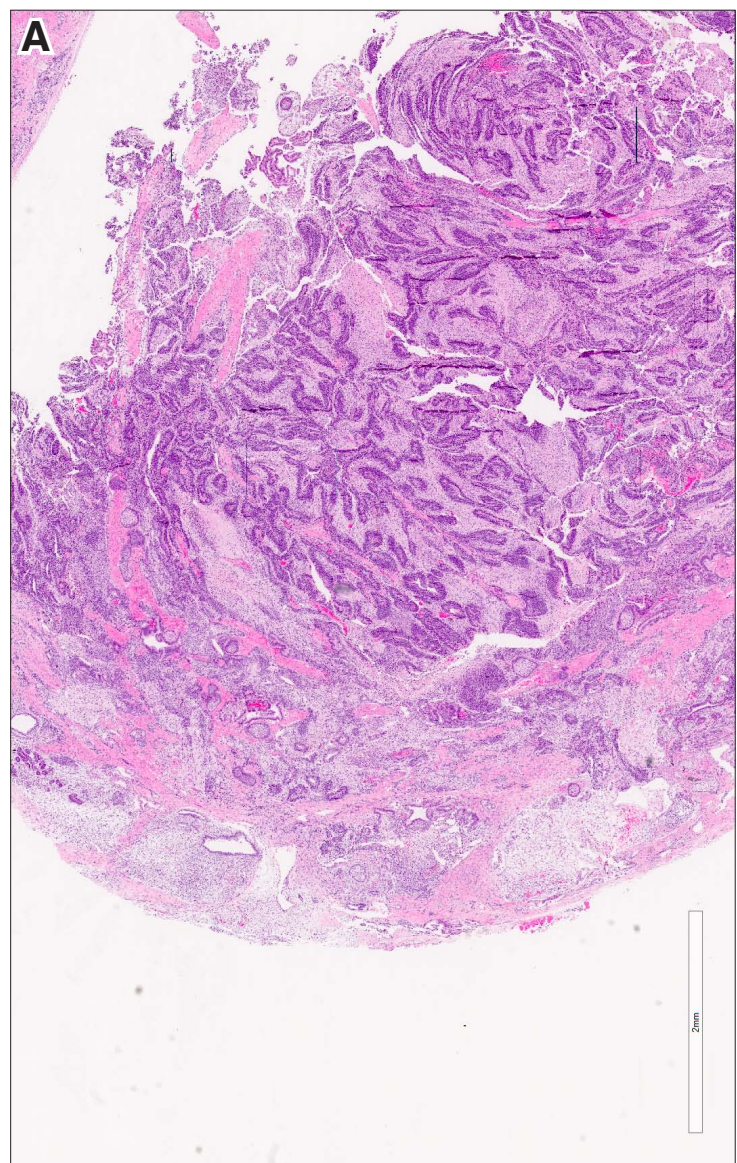

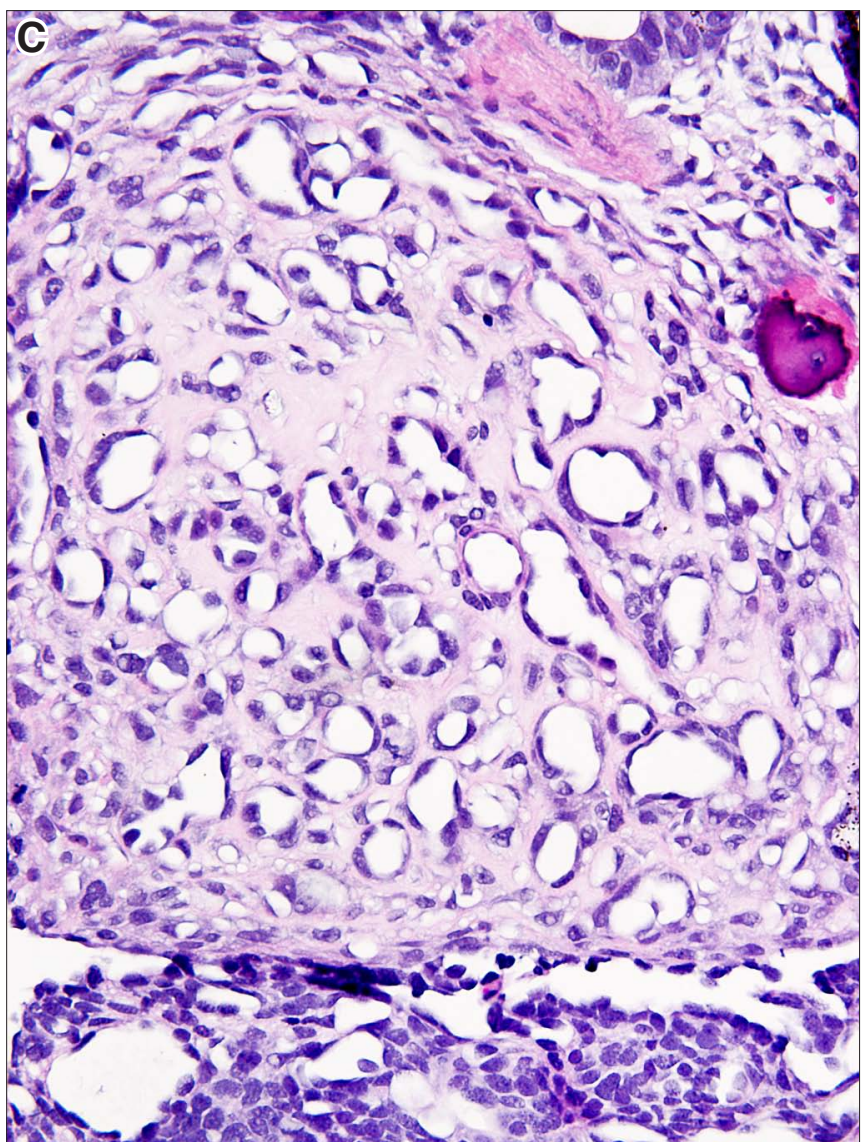
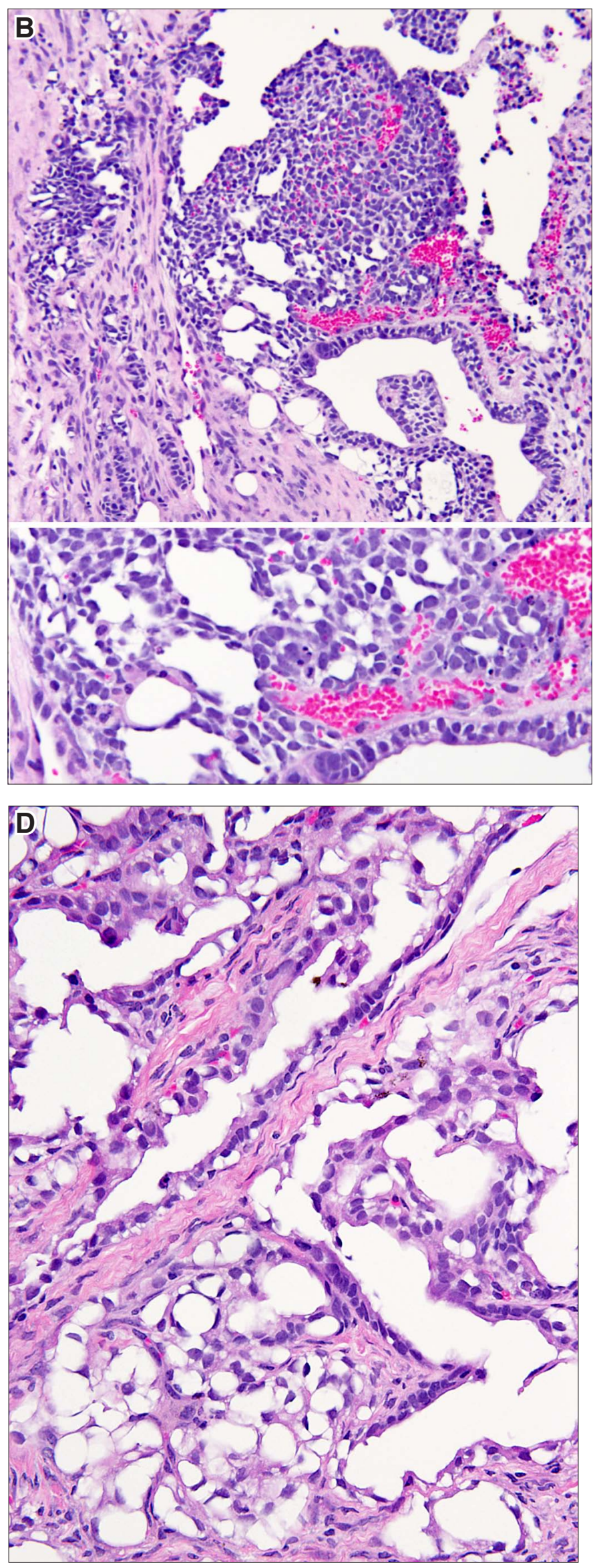



\section{Ectodermal derivatives}


Fig. 10. Neural tissue. (A) Neural rosettes forming a distinct nodule delimited from the empty space by layer of cells lying on a membrane. These rosettes seem to converge toward a virtual center left of the midfield (asterisk). (B) Neural tubes resemble neural rosettes, but in contradistinction to them, they have a central slit lumen. (C) Confluent neural tubes and rosettes. (D) Neural tubes surrounded by sheets of small neural precursor cells arranged without any discernible structure. Magnification: $(A, B) 160 x ;(C, D) 120 x$. 

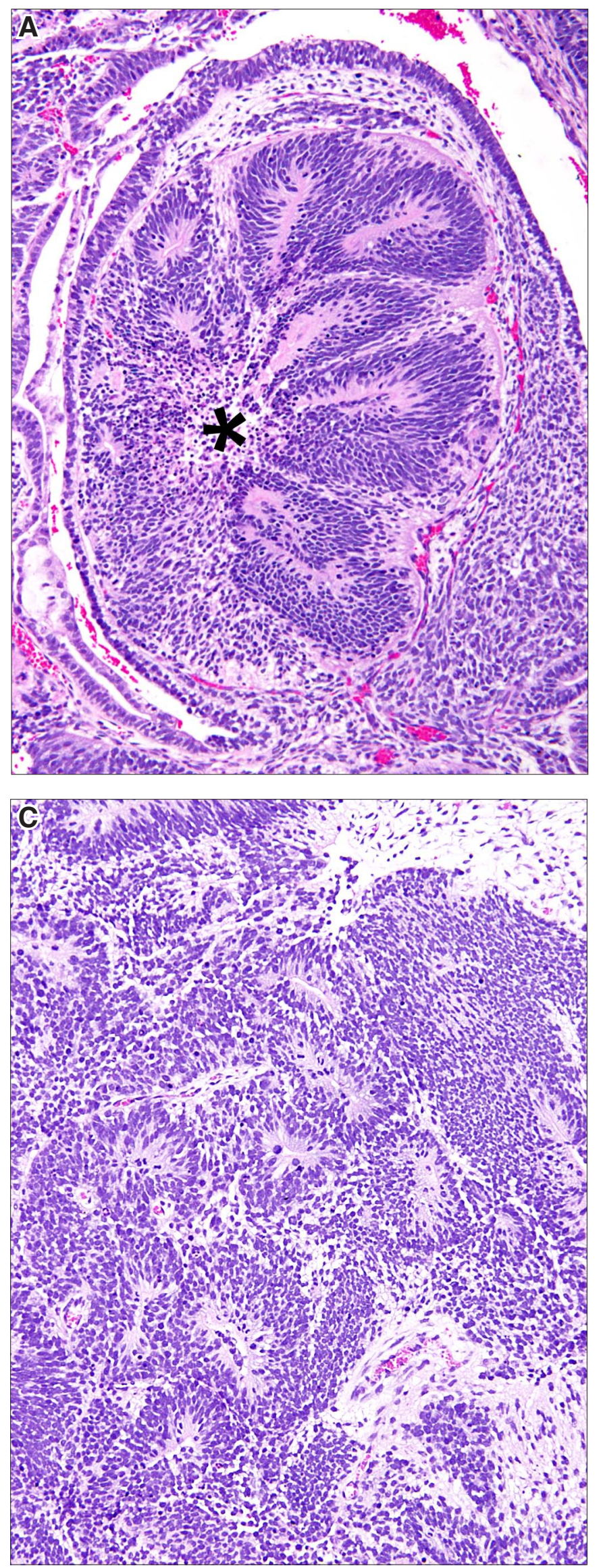

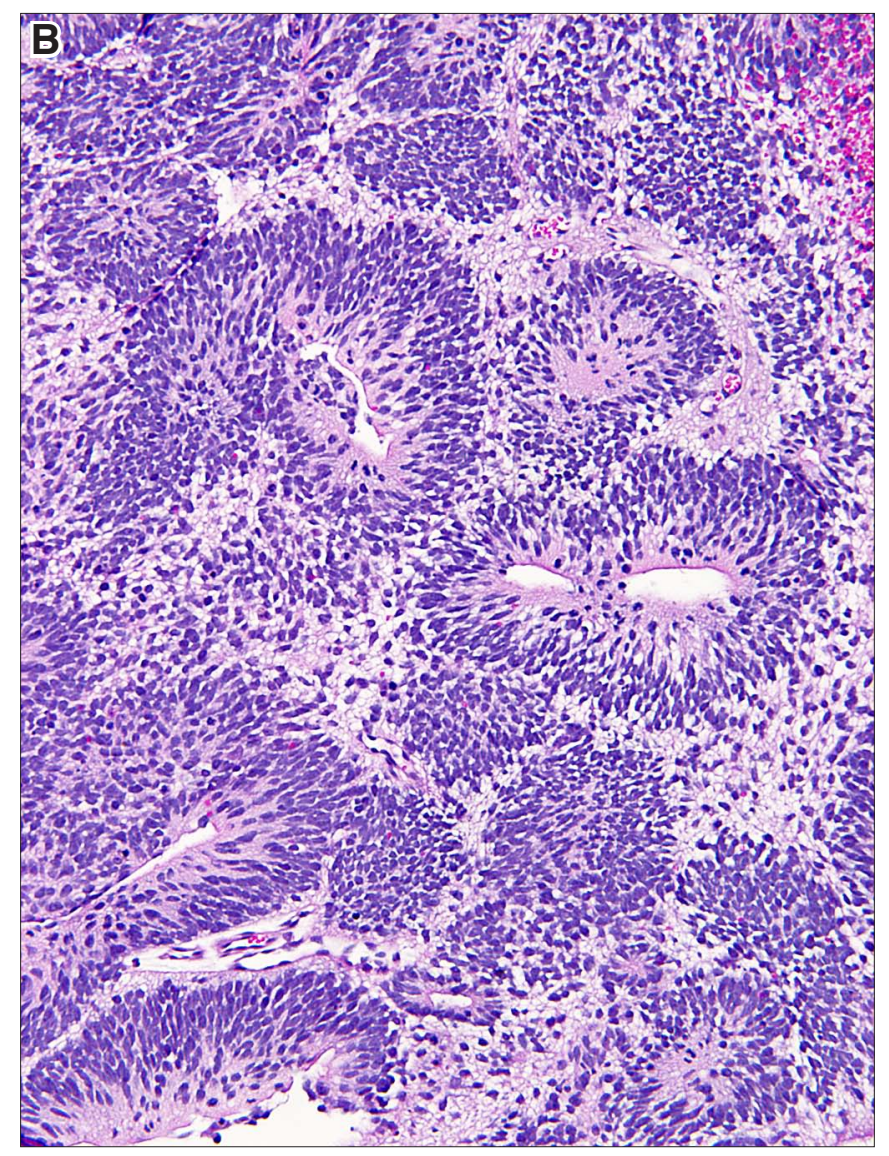

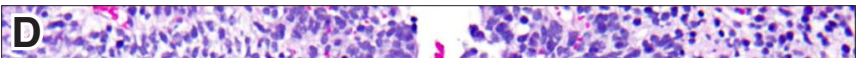

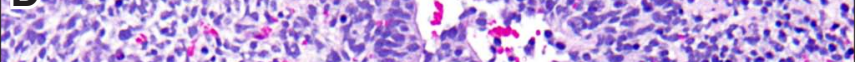

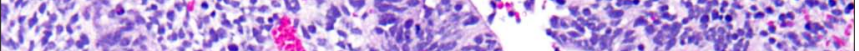
3.

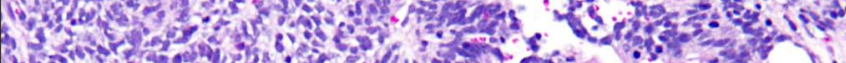
H.

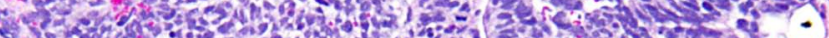

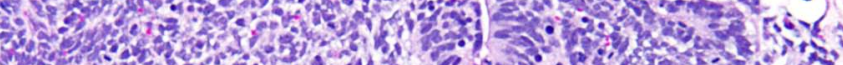

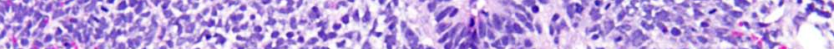

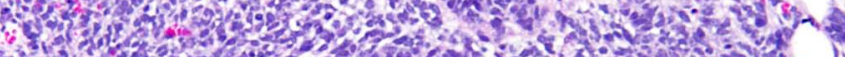
30 \% 1 .

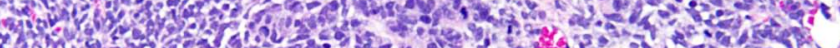
37 . 45 .

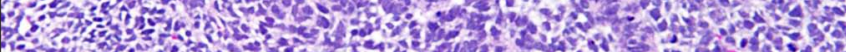

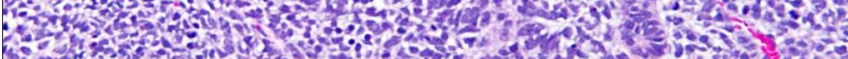

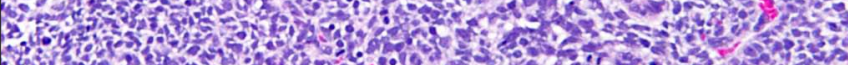
(1)

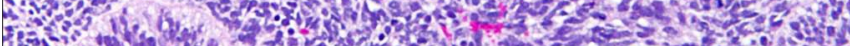

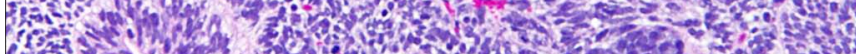

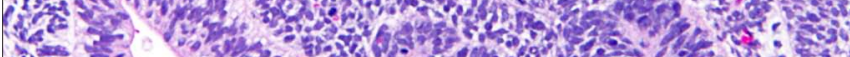
1.

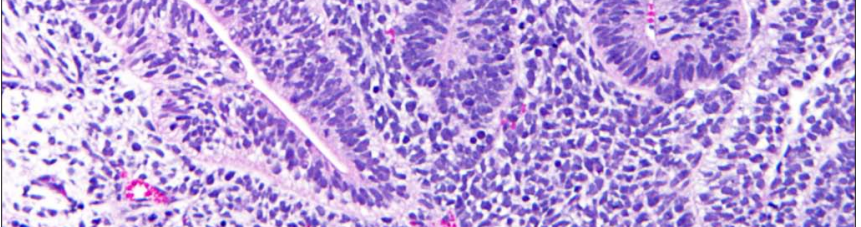

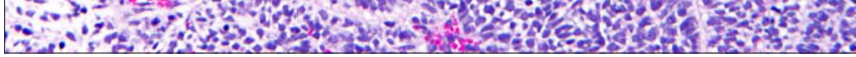


Fig. 11. Neuropil formed around neural tubes. (A) Neural tubes surrounded with eosinophilic neuropil reflecting the fact that these neural and glial cells have more cytoplasm that their immature precursor cells which appear blue. (B) Neuropil in the left upper corner appears more eosinophilic than the neuropil next to it in the lower left side. The cells forming the neuropil have in either case more cytoplasm then the immature neural cells to the left of the rosettes, and along the lower edge of the figure. (C) Neural rosettes surrounded with rather pale neuropil. (D) Variegated cellularity and eosinophilia, probably reflecting the level of maturation of neuropil. Two bluish cell nests in the midline are composed of immature neural cell precursors. Magnification: (A) 220x; (B) 180x. 

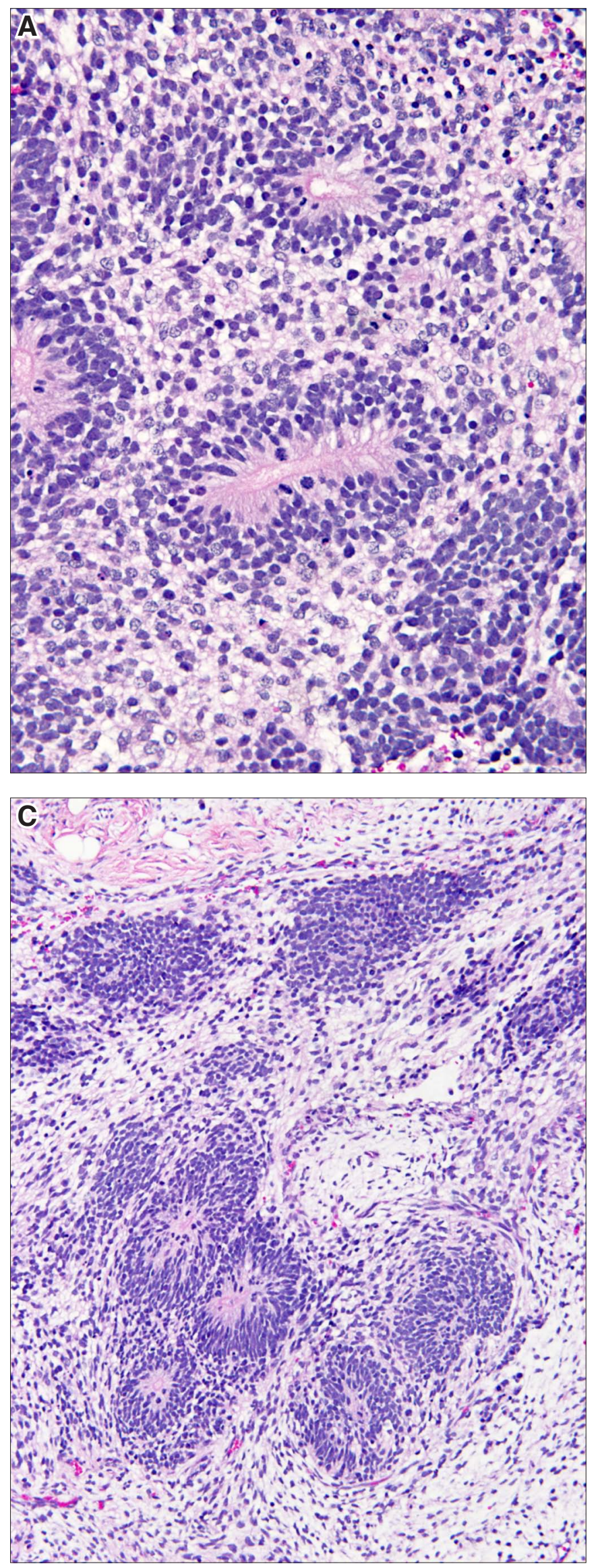

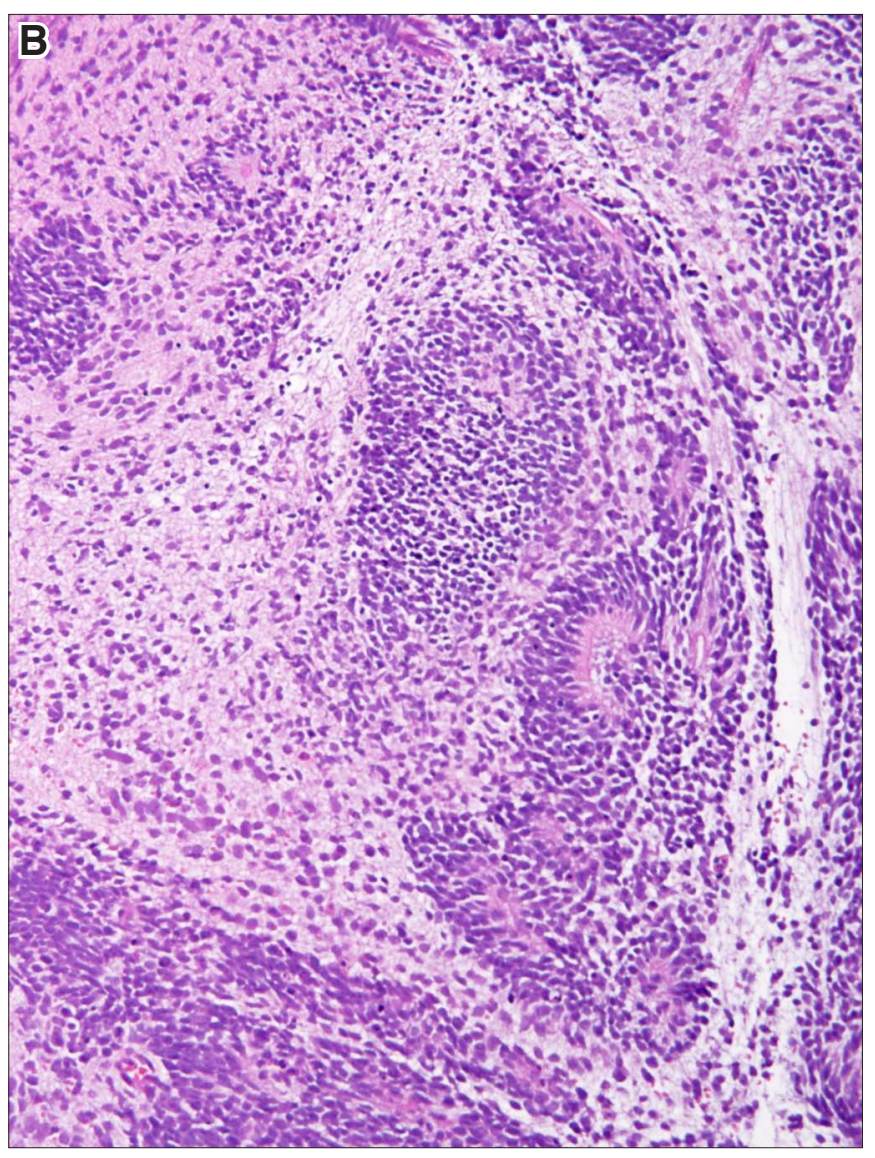

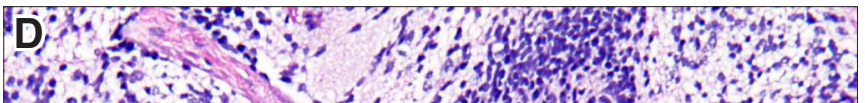

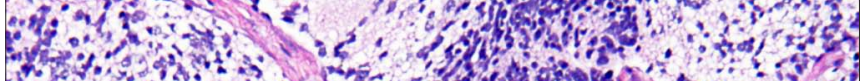

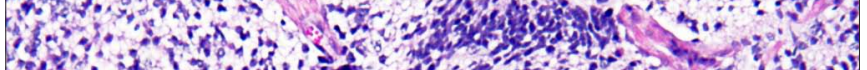

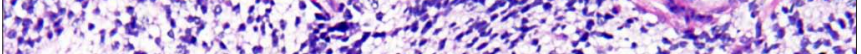

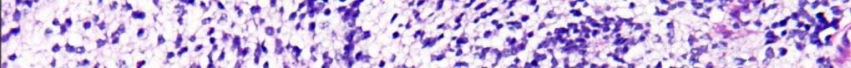

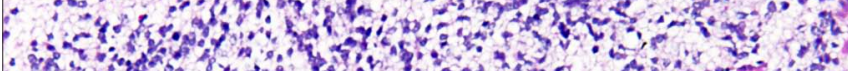

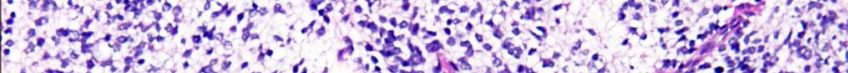

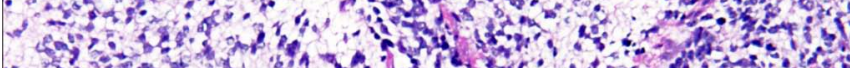
H.

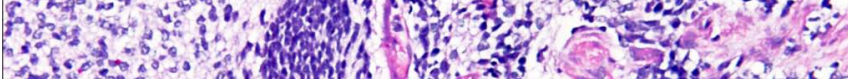

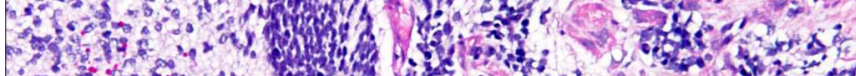

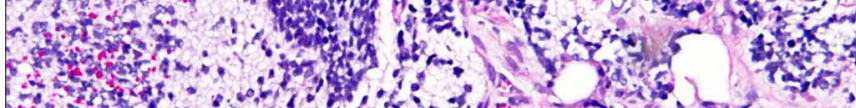

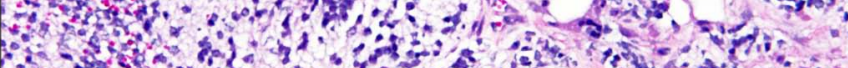

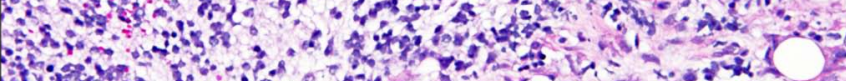

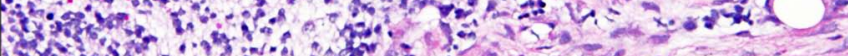

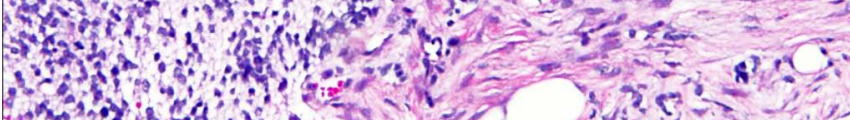
*7.

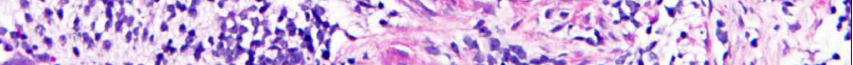

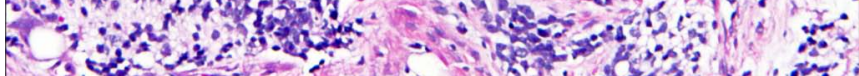

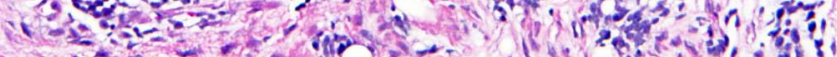

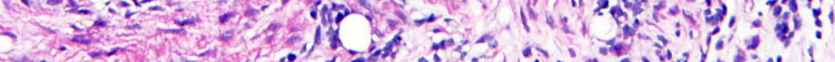

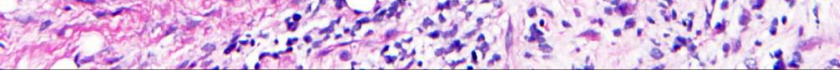


Fig. 12. Neural tube and derivatives. (A) Dilated neural tubes filled with choroid plexus forming confluent papillary structures in the right upper hand corner. (B) Choroid plexus composed of clear cells. At the margins of the nest of choroid plexus there are pigmented cells (Pig). (C) Choroid plexus composed of vacuolated cuboidal cells forming papillae. (D) Choroid plexus papillae projecting into a cystic space. Magnification: (A) 120x; (B) 160x; (C) 180x; (D) 220x. 

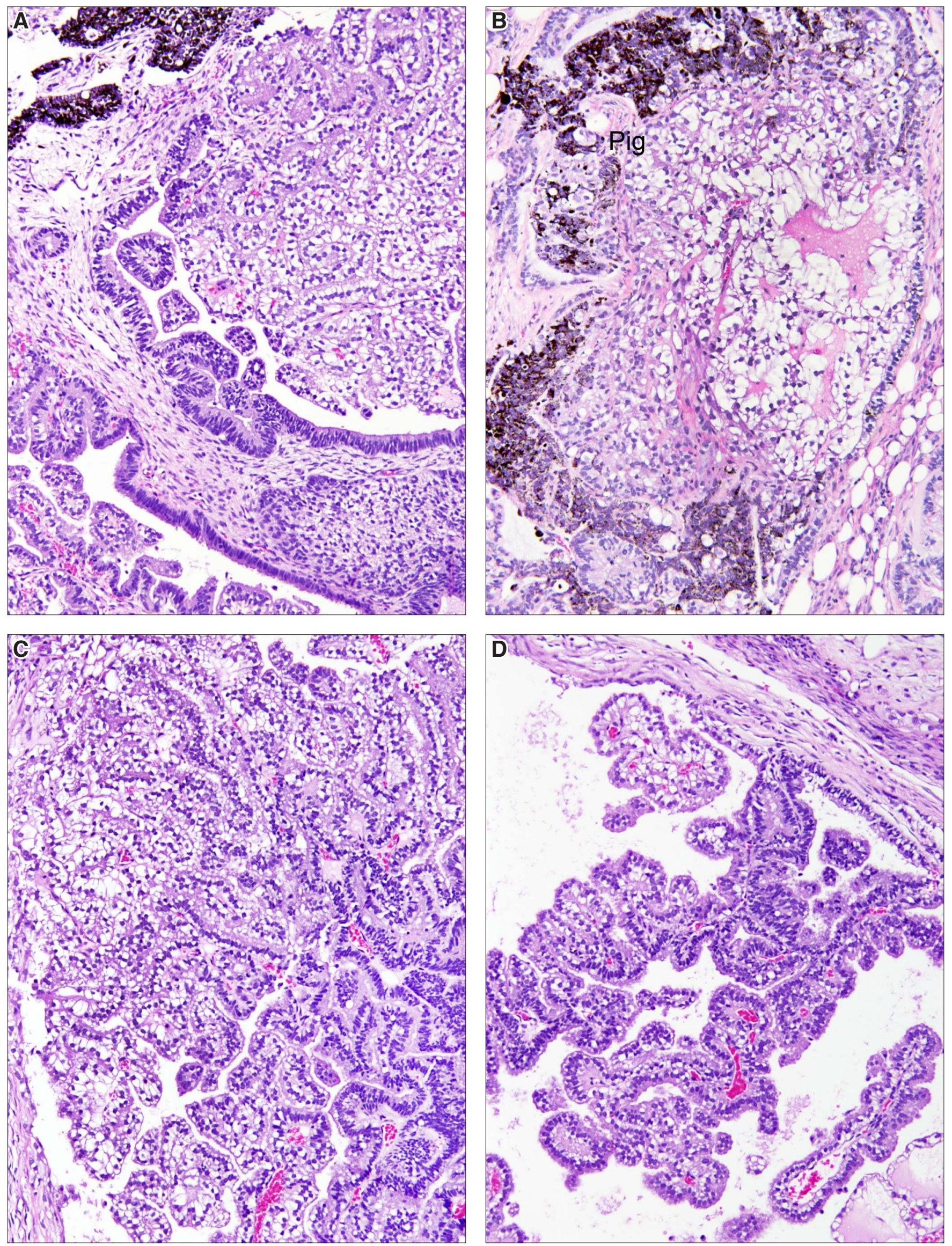
372 I. Damjanov and P. W. Andrews

Fig. 13. Neural tissue and eye structures. (A) Pigmented cells forming a layer that is partially enclosing a nest of lentoid cells. These cells with small round nuclei and abundant eosinophilic cytoplasm are precursors of the lens in the eye. (B) Lentoid cells forming a protrusion in the attenuated epithelium of the neural tube, reminiscent of eye formation. Magnification: (A) 160x; (B) 280x. 

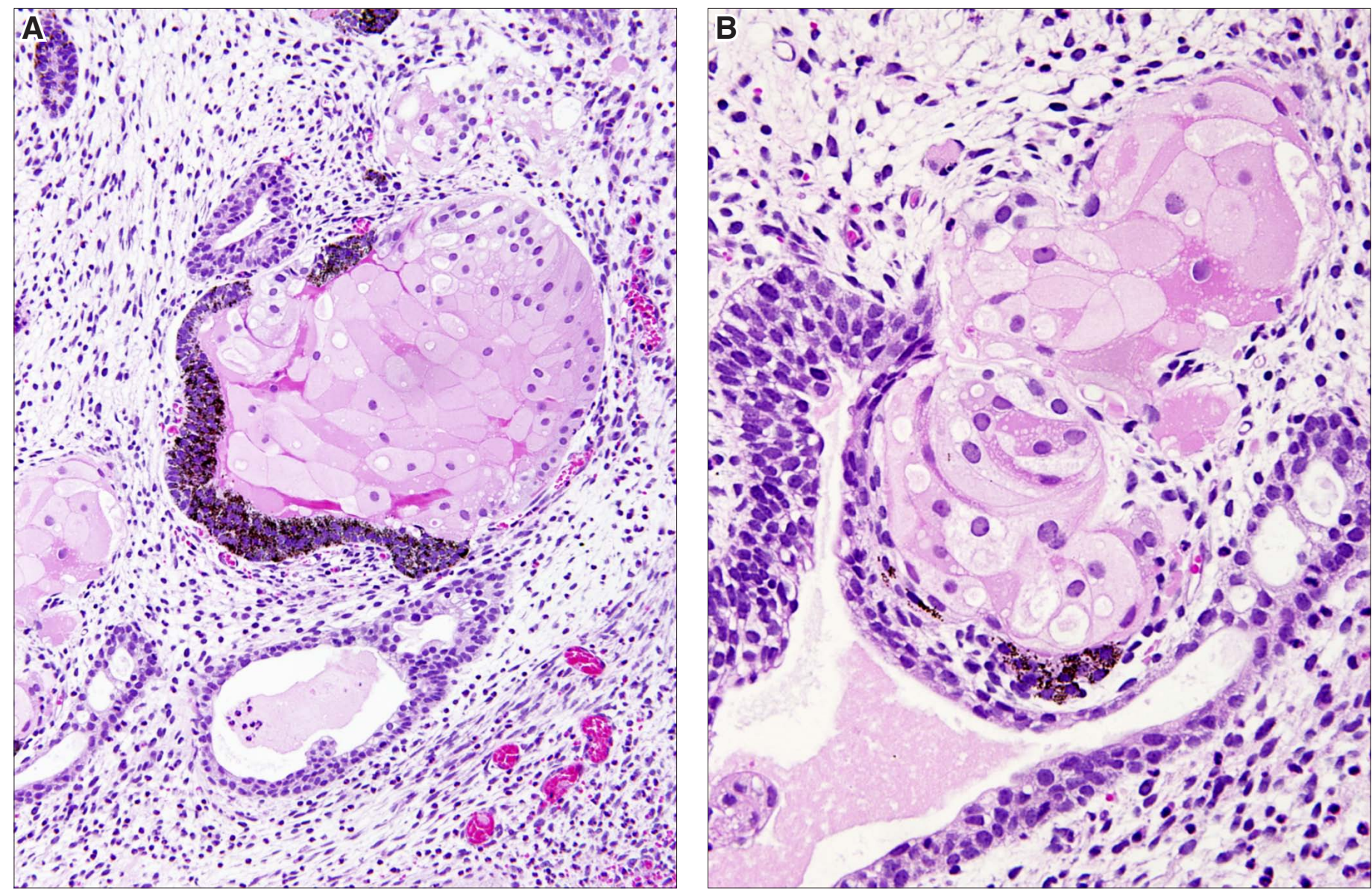
374 I. Damjanov and P. W. Andrews

Fig. 14. Pigmented cells. (A) Cells containing brown pigment are in continuity with neural rosettes or form rosette-like structures, best seen at the lower margin of the figure. (B) Overgrowth of pigmented cells which occupy a large part this tumor. Magnification: (A) 160x; (B) 100x. 

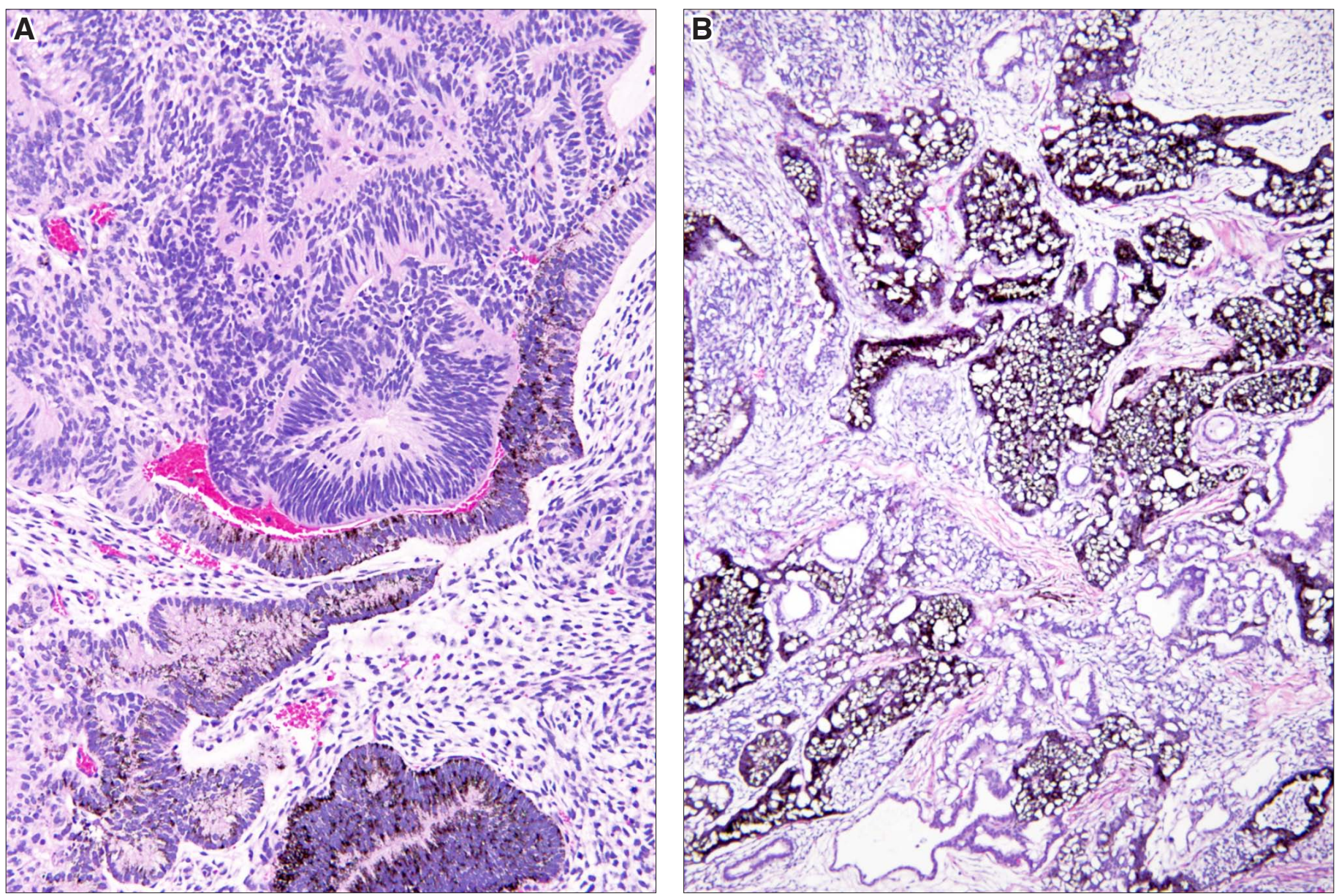
376 I. Damjanov and P. W. Andrews

Fig. 15. Squamous epithelium. (A) Nest of immature squamous cells, which contain glycogen in their cytoplasm, thus appearing clear. The nest is rimmed by a basal layer of smaller darker cells lying on a basement membrane delimiting the squamous cells from the surrounding stroma. (B) Nascent squamous nests attached to a tube, which is surrounded by dense stroma. (C) Squamous cell nest originating from nondescript columns of epithelial cells on the lower side of the figure. The squamous cells show focal keratinization (red). (D) Squamous nest next to a nidus of cartilage. This squamous epithelial nest lacks the distinct basal layer. Magnification: $(A, B, C, D) 180 x$. 

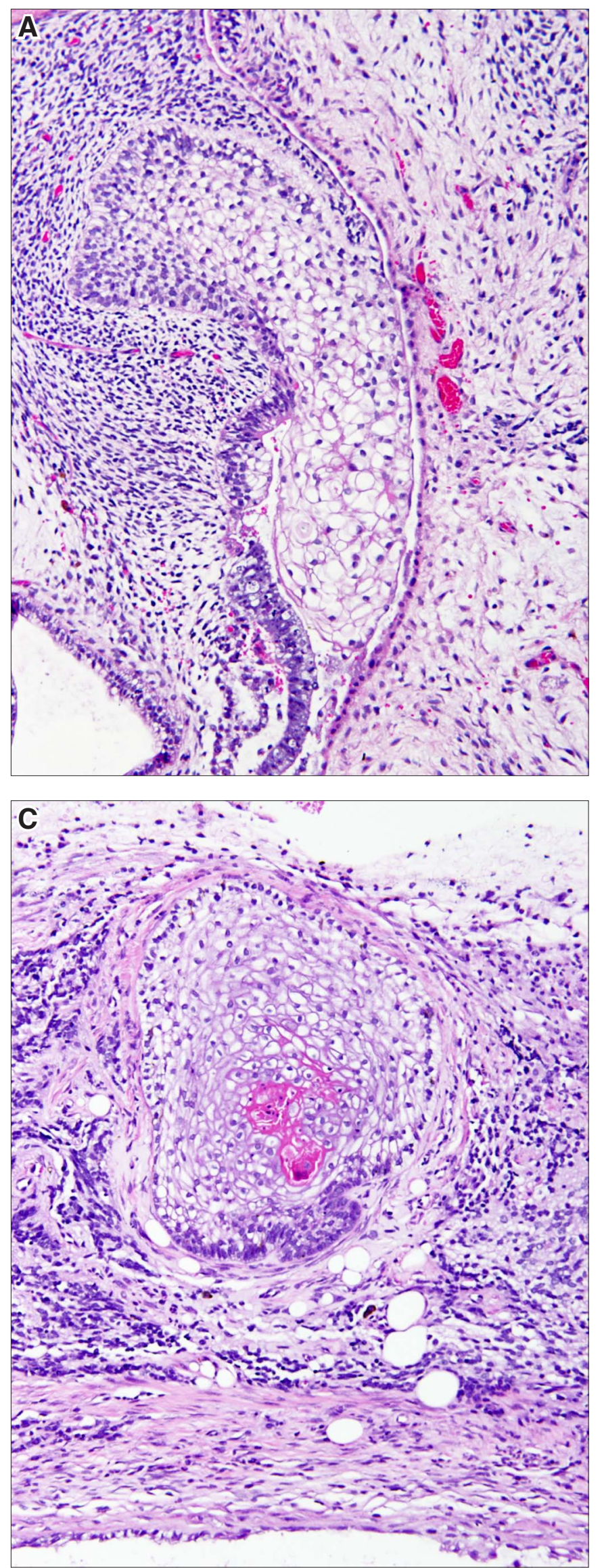
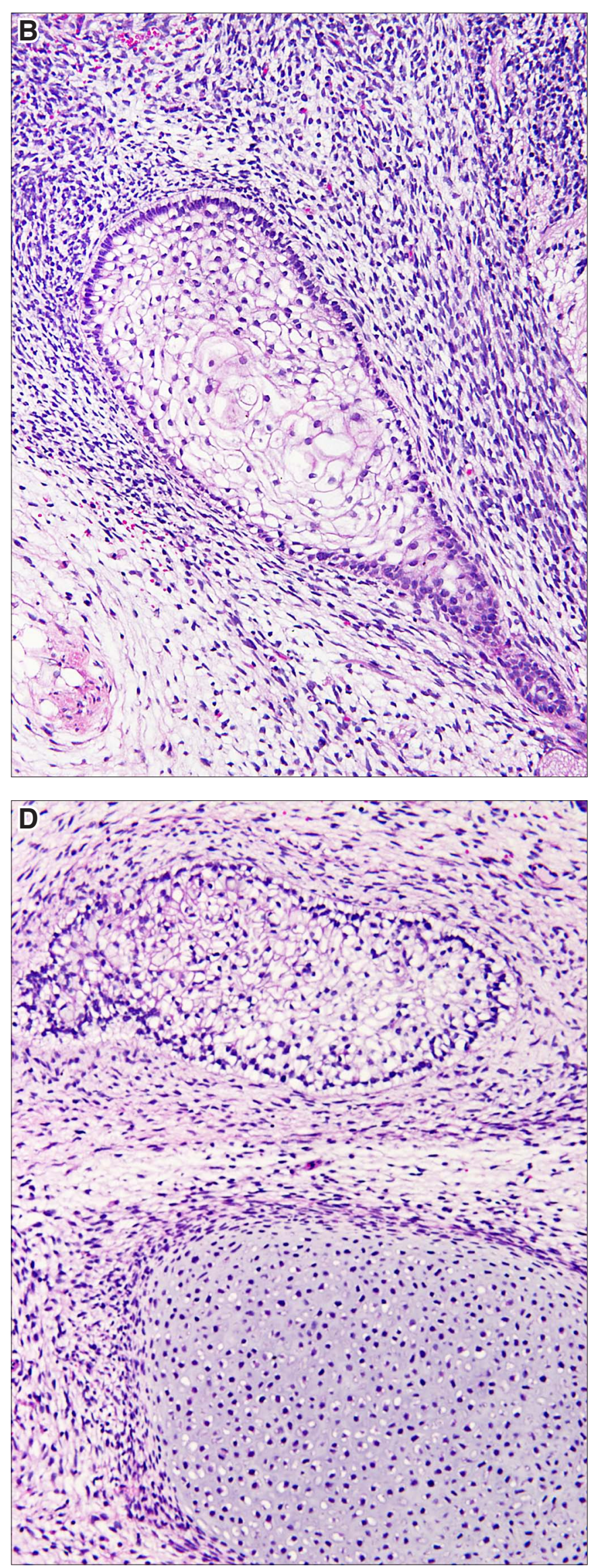



\section{Endodermal derivatives}


Fig. 16. Endodermal tubes. (A) Duct-like structures lined by polarized columnar cells which have basally located nuclei and well developed eosinophilic cytoplasm. The apical pole of these cells delimits a central lumen. Many cells are vacuolated. These cells cannot be further characterized, but most likely they represent precursors of the tubular part of the gastrointestinal tract or bronchial tree. The stroma surrounding these tubules appears "very blue," indicating that the stromal cells represent fetal-like mesenchyme, as seen during early stages of normal organogenesis. Compare this dense stroma with the loosely structured stroma in the left upper quadrant. (B) An endodermal tubule, composed of cells that show subnuclear vacuolization, is surround by concentrically layered stromal cells. (C) Tubules lined by mucus-secreting cells. (D) Dilated tubular structures lined by several types of epithelium, such as stratified cylindrical epithelium (Sc), cuboidal vacuolated epithelium(V), and focal squamous epithelium (Sq). Magnification: (A,C,D) 160x; (B) 280x. 

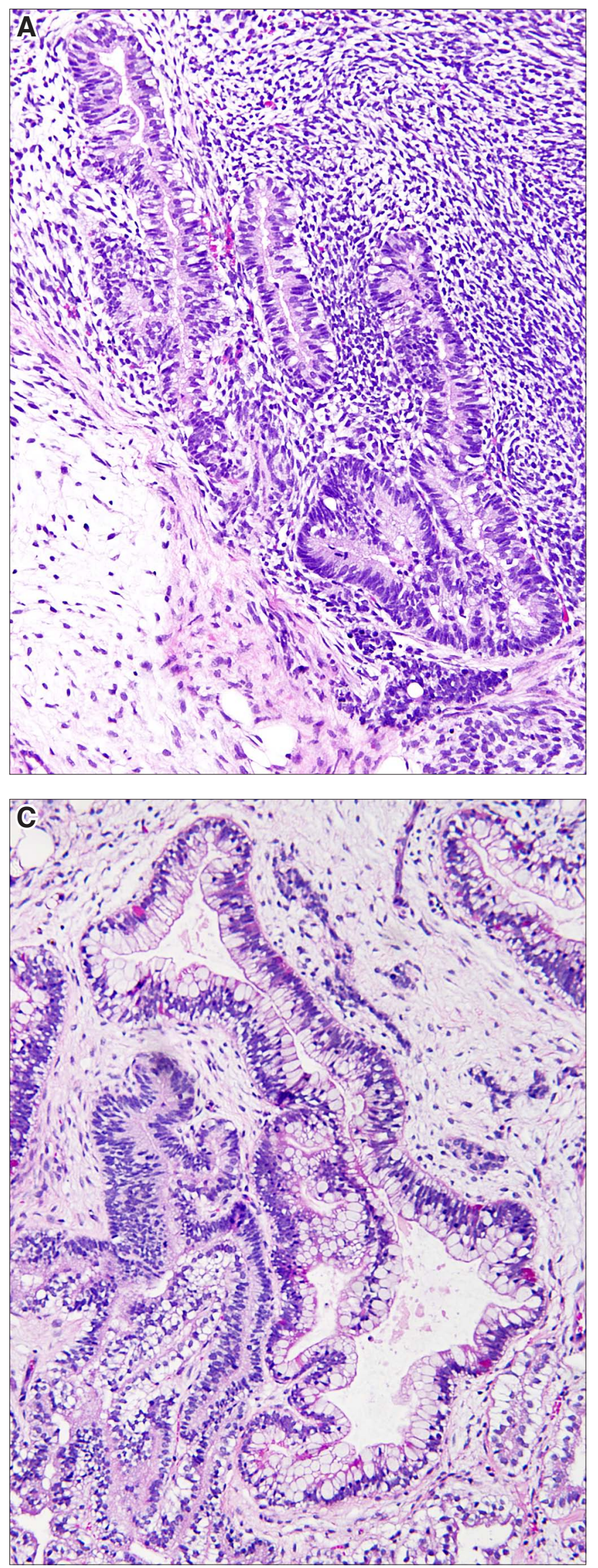
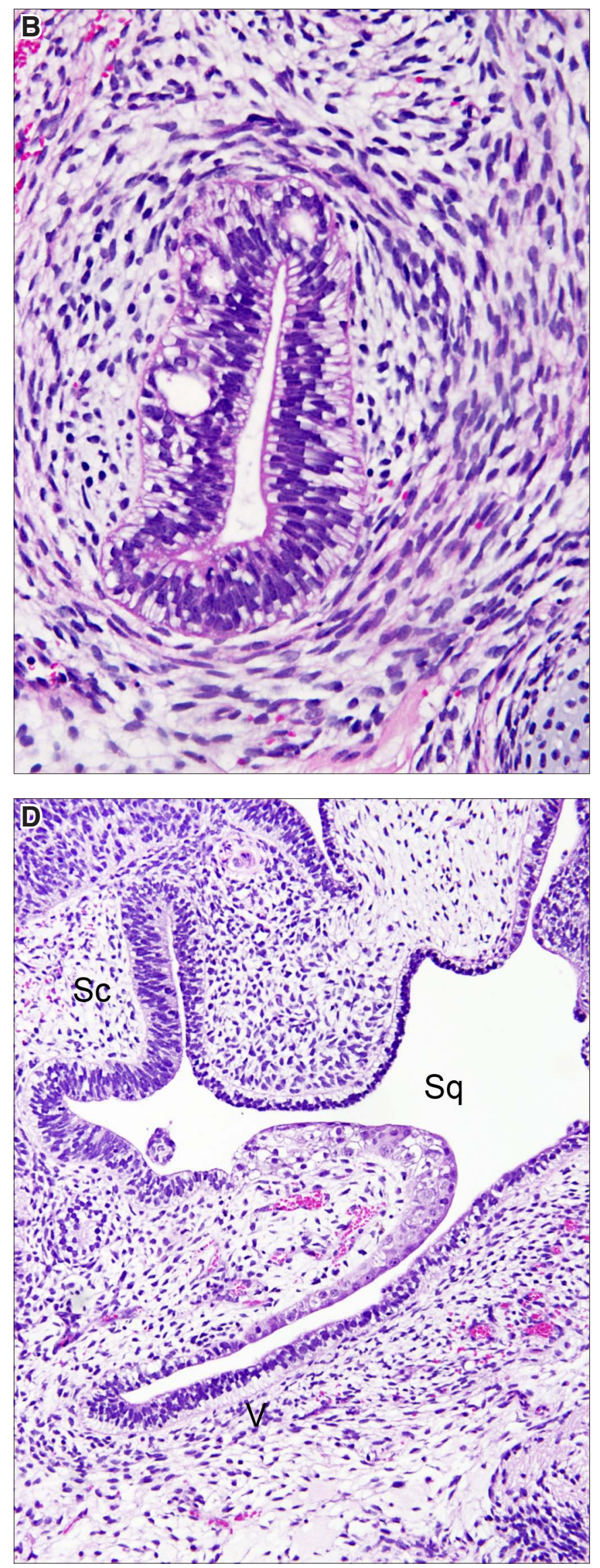
382 I. Damjanov and P. W. Andrews

Fig. 17. Endodermal tube with condensation of stroma. (A) Several endodermal tubes, two of which show condensation of the stroma surrounding them. (B) Endodermal tube with condensation of stroma in a promontory pushing into the tube and invaginating it (arrow). (C) Intestine formation with concentric layering of loose stroma composed of spindle cells which also start forming smooth muscle cells. (D) Intestine formation with a distinct eosinophilic smooth muscle layer encircling the submucosa. Magnifications (A,B) 120x; (C) 160x; (D) 80x. 

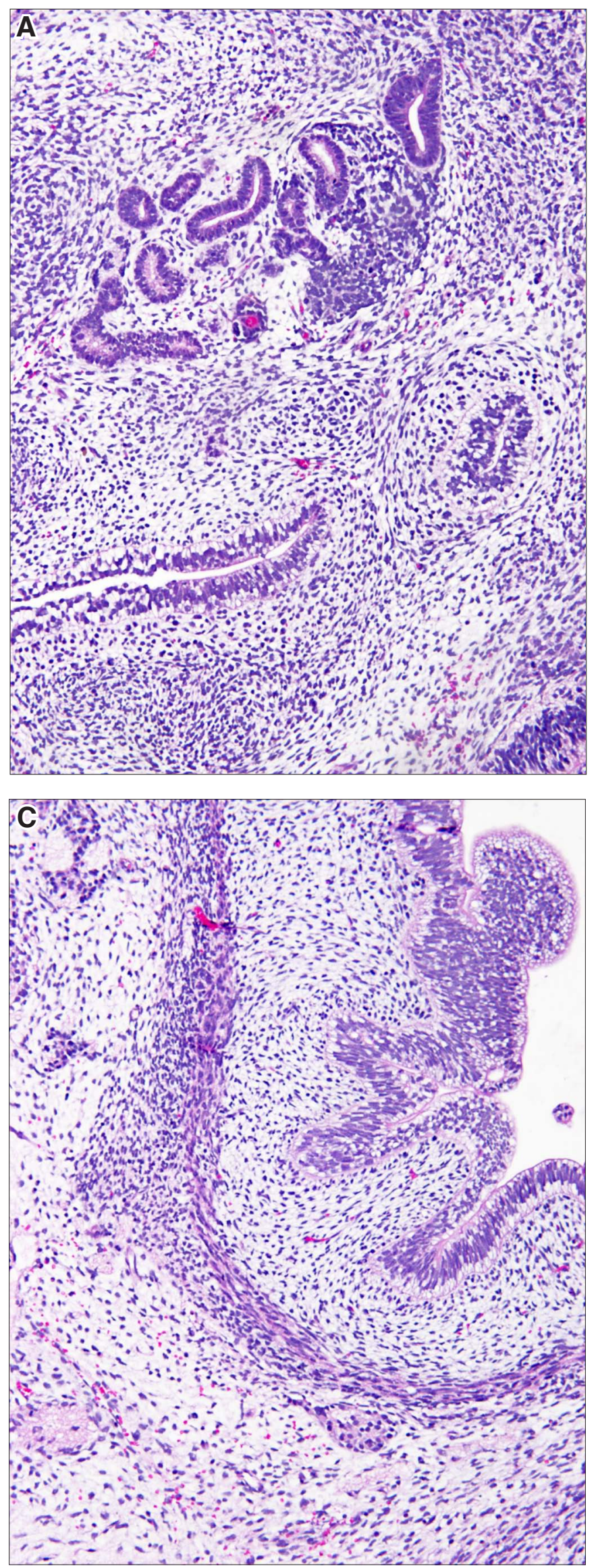
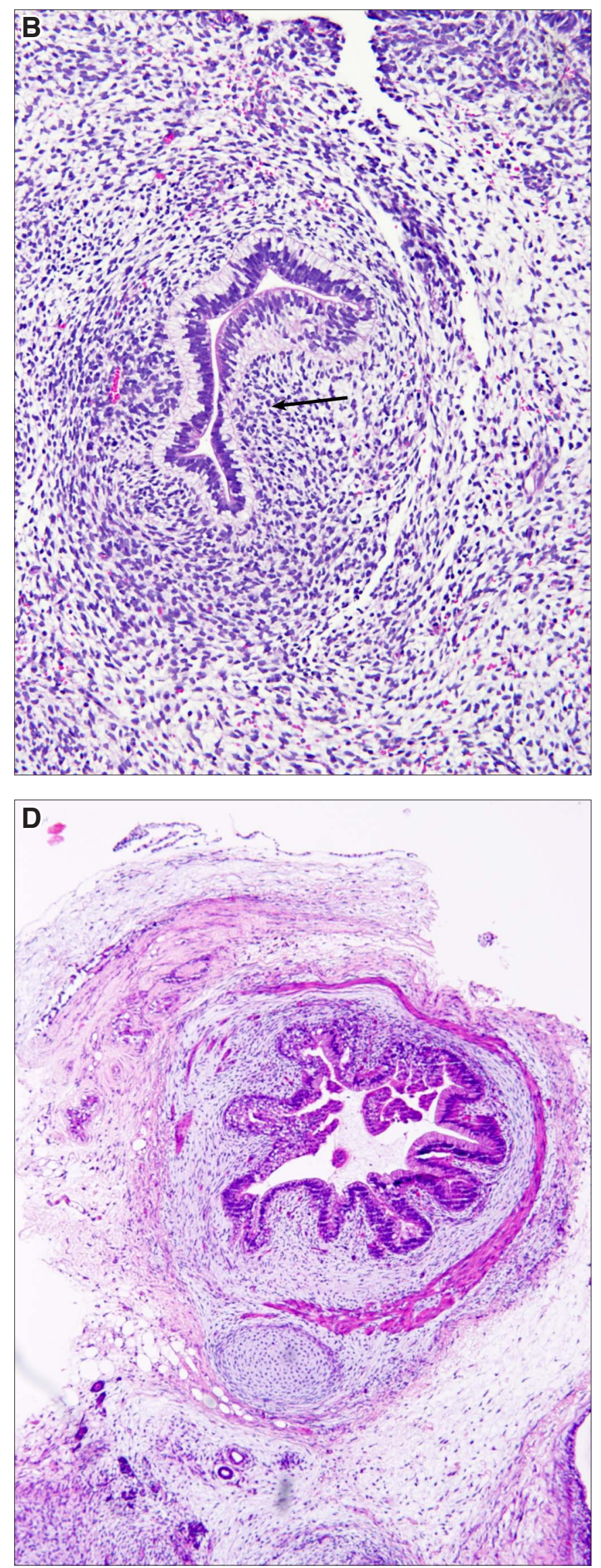
384 I. Damjanov and P. W. Andrews

Fig. 18. Endodermal tube with liver cells. (A) Endodermal tube with a nidus of liver tissue attached to it (arrow). (B) Endodermal tube and liver tissue. (C) Endodermal cells and liver cells admixed with blood cell precursors, which appear as small dark round cells in the central lumen. (D) Cords and nests of liver cells. Magnification: (A,B,C) 280x. 

A.

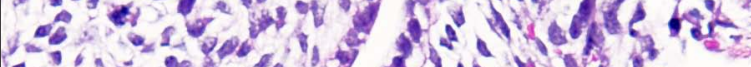

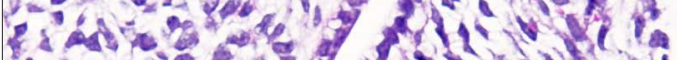

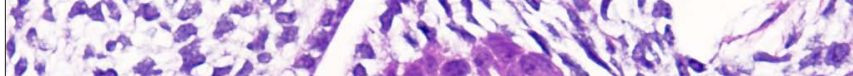

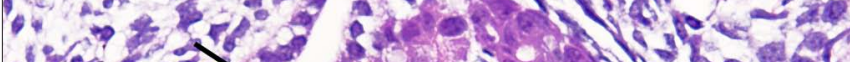

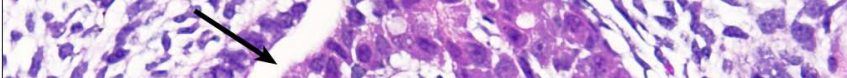

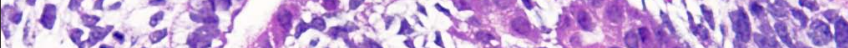

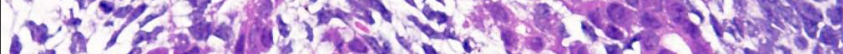

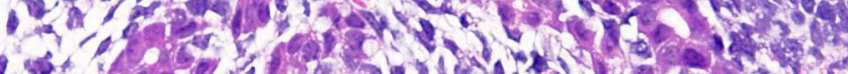

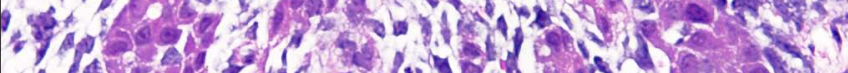

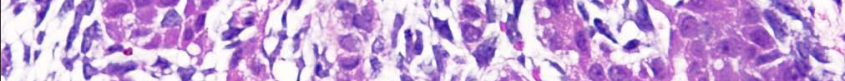

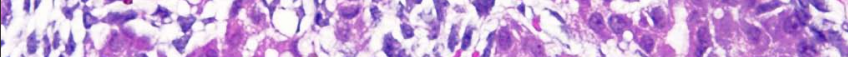

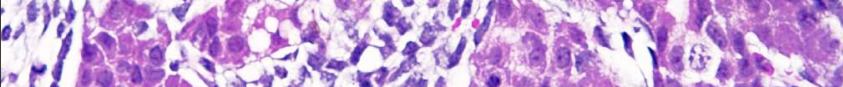

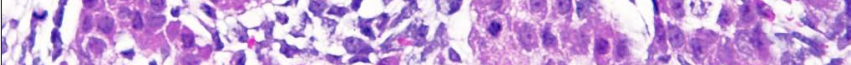

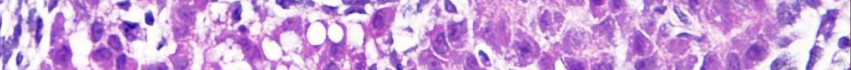

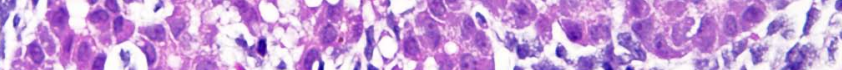

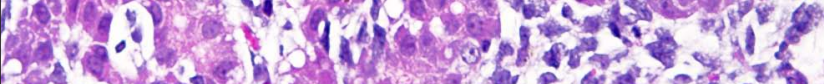

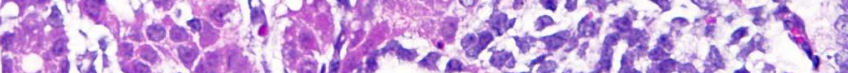

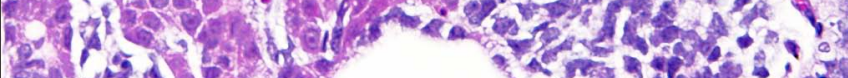

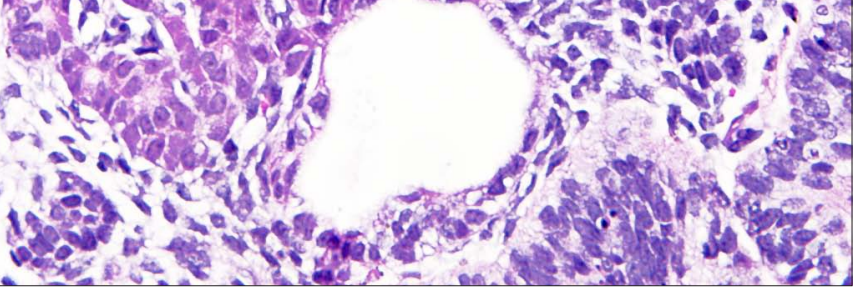

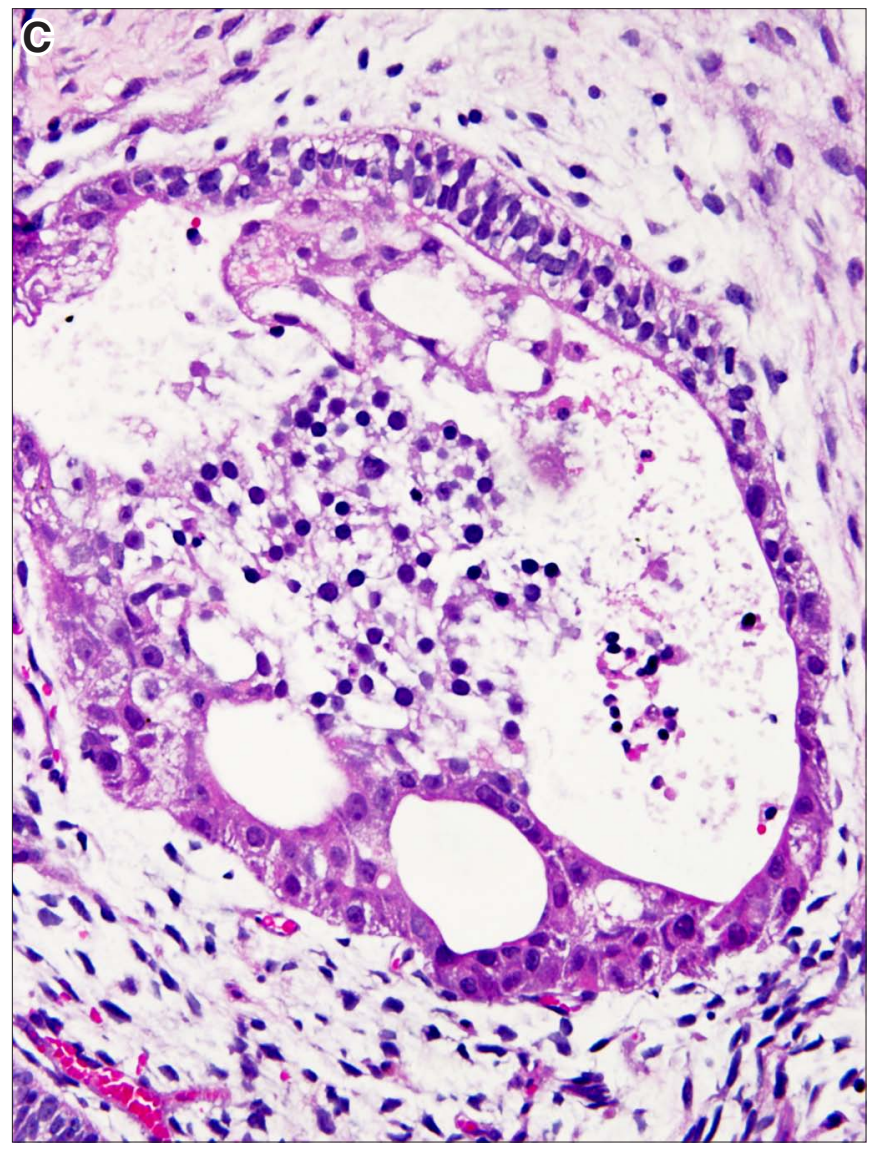

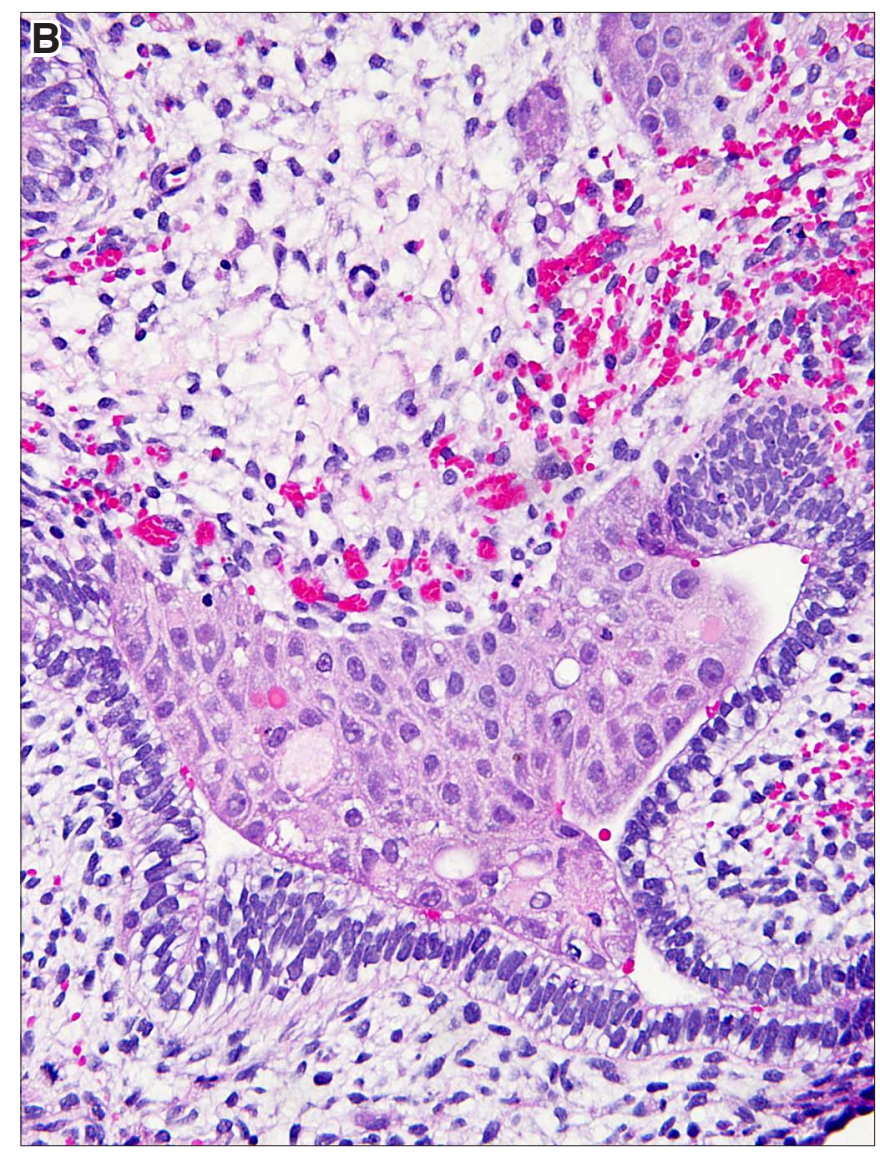

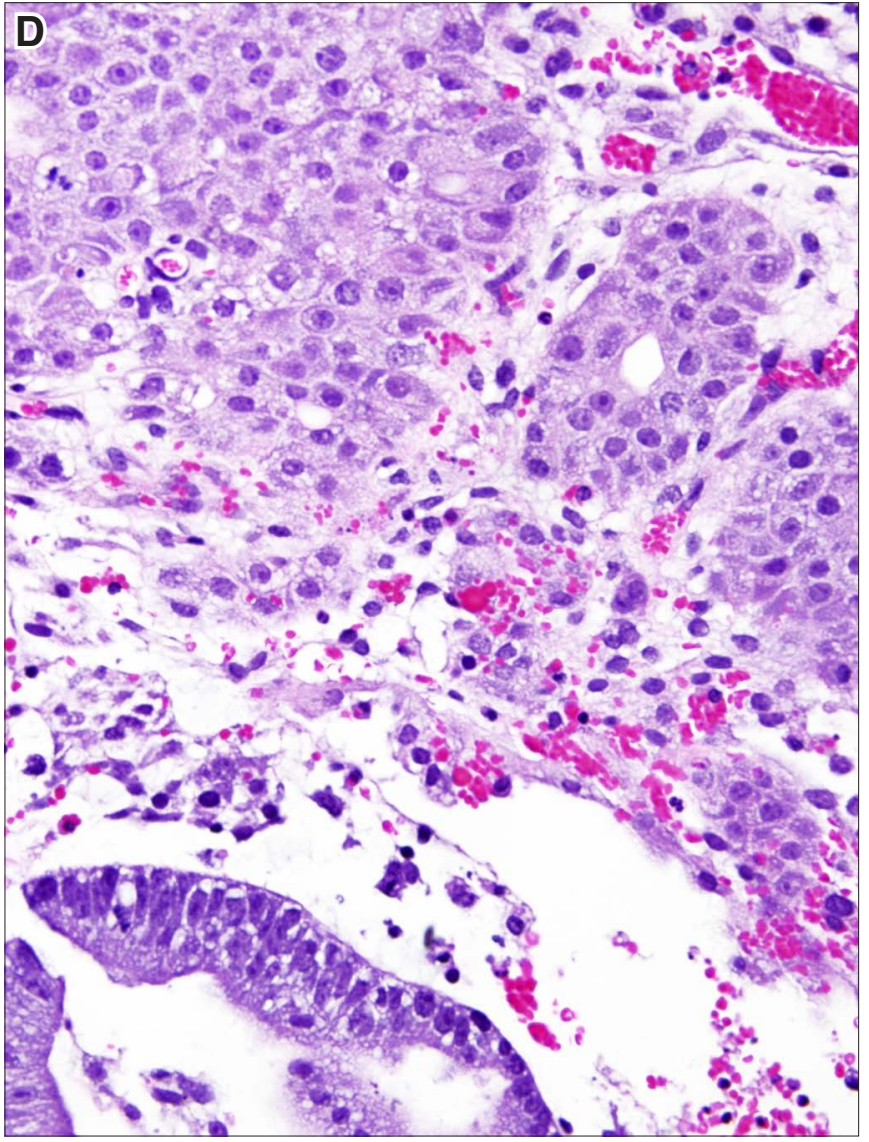





\section{Mesodermal derivatives}


Fig. 19. Cartilage and bone. (A) An aggregate of cartilage cells (C) and a small nidus of bone (B) in loosely structured stroma showing some condensation in the left upper part of the figure. (B) Bone rimming a nidus of immature cartilage. (C) Bone formation with peripheral calcification within a nidus of cartilage (enchondral ossification). (D) Bone formation comprising osteoid and calcified bone trabeculae within loose connective tissue (membranous ossification). Osteoids appear pink and the calcified bone is blue. Magnification: (A) 160x; (B,C,D) 220x. 

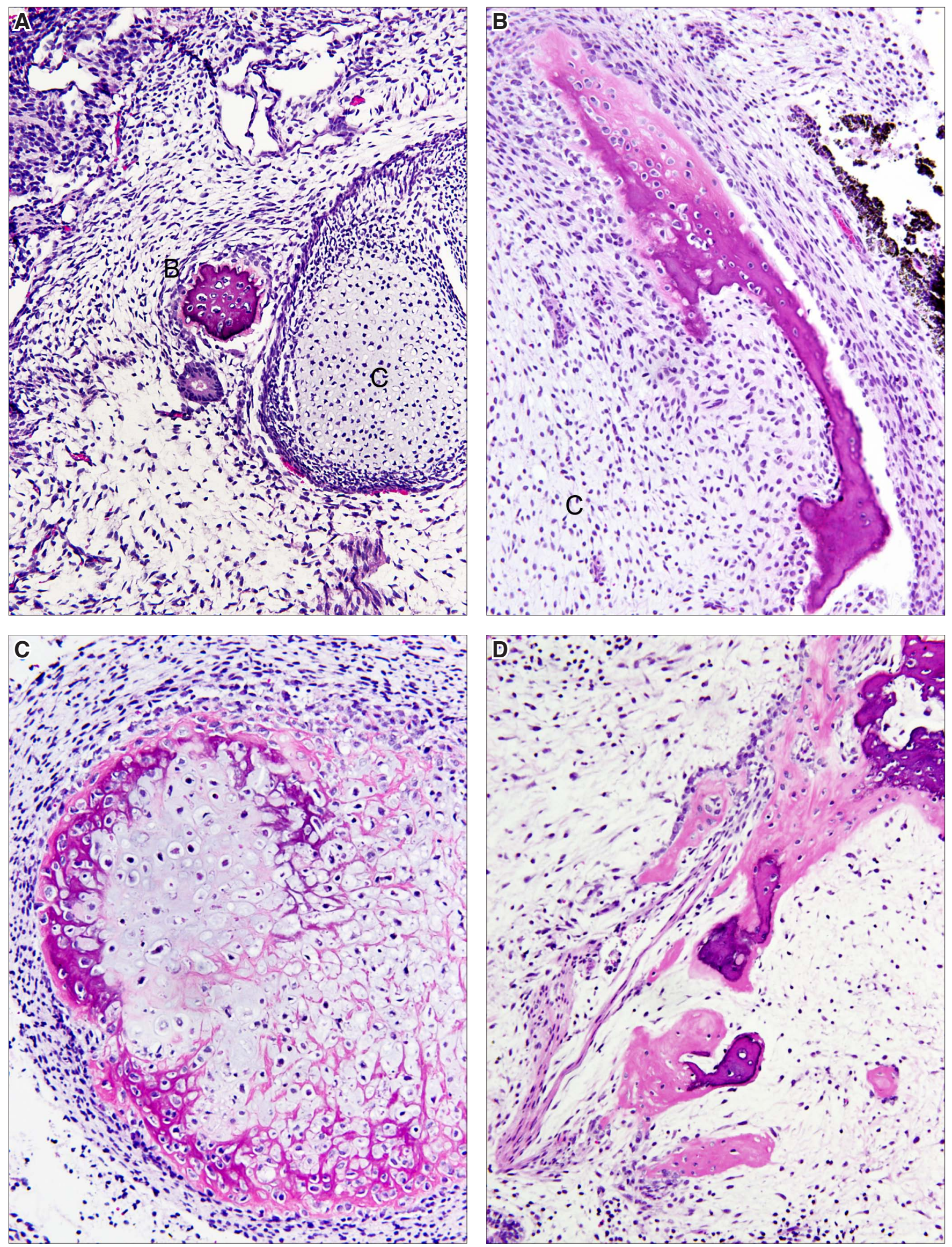
Fig. 20. Osteoid and cartilage formation. (A) An eosinophilic osteoid (O) is surrounded by fibroblast-like cells. (B) An osteoid surrounded by a layer of plump osteoblasts, most prominently on the left side. (C) Close juxtaposition of cartilage to neural, pigmented and lentoid epithelium. (D) Close juxtaposition of cartilage to an endodermal tube. Magnification: (A,B) 220x; (C,D) 160x. 

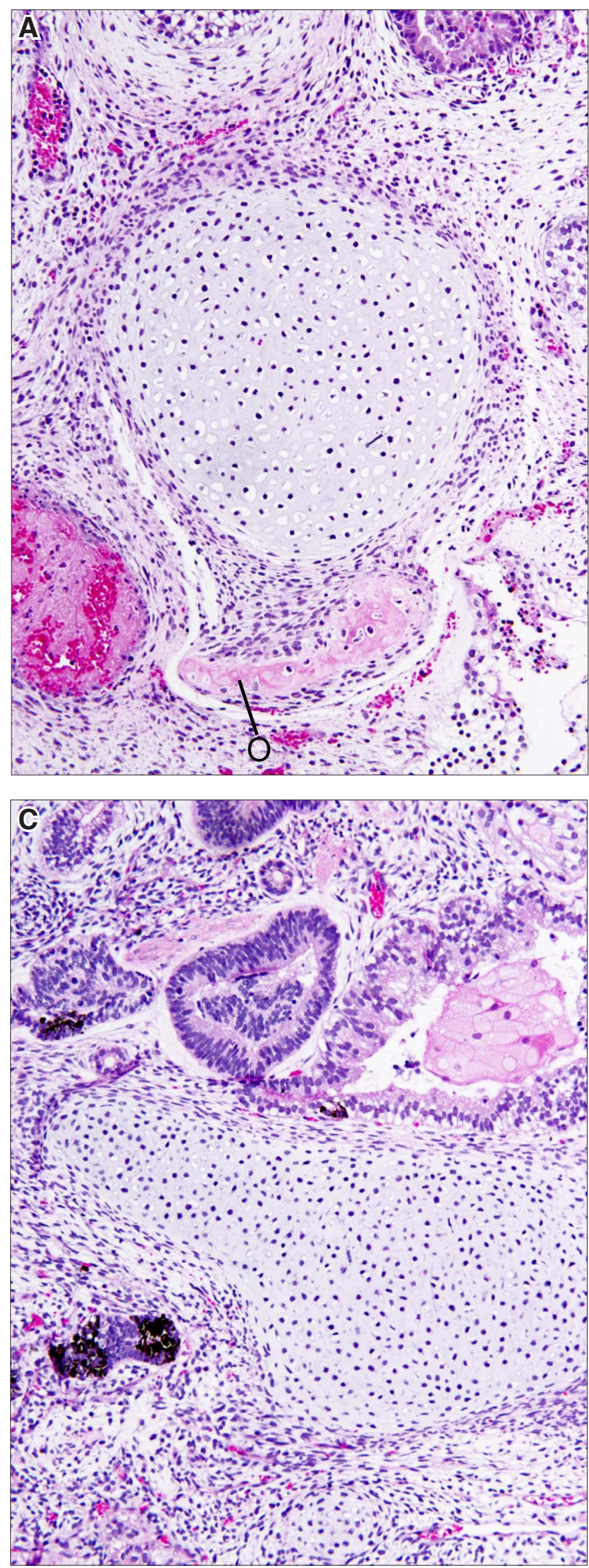
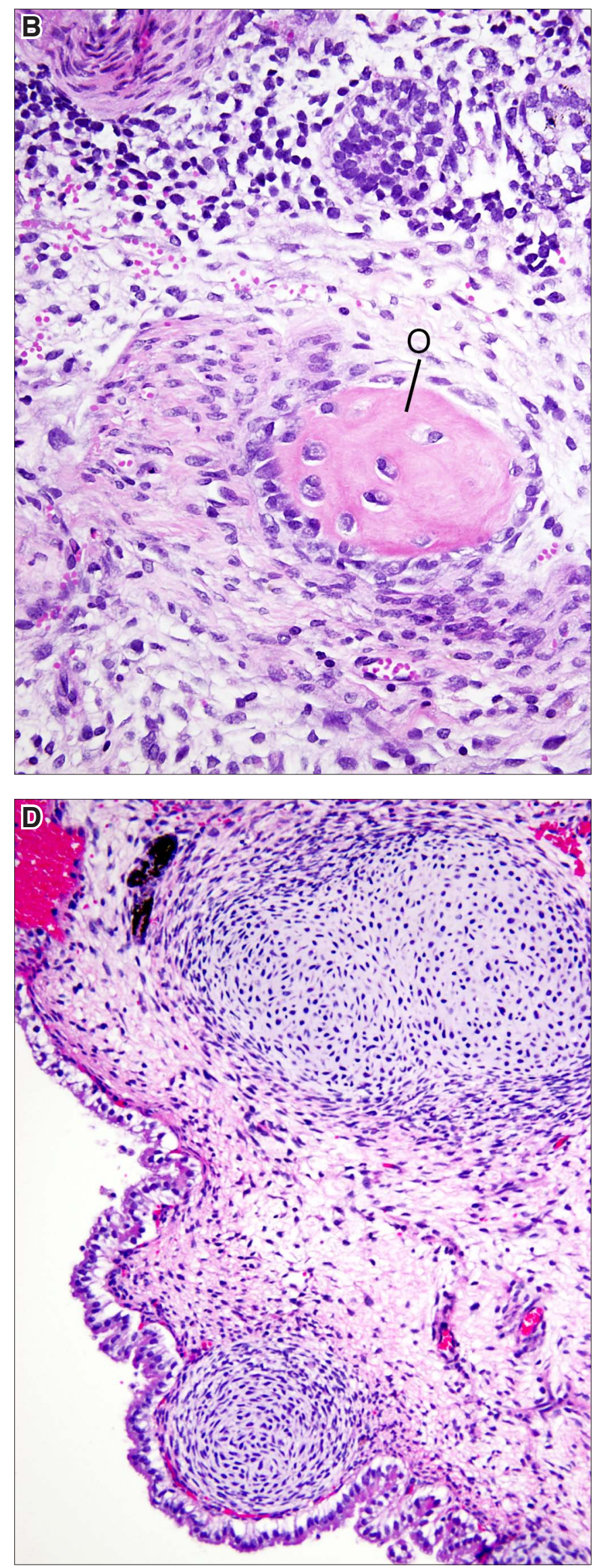
392 I. Damjanov and P. W. Andrews

Fig. 21. Mesenchymal cells showing structural changes. (A) Loosely textured connective tissue with central condensation, probably corresponding to the formation of cartilage. An endodermal tube is seen towards the top of the figure. (B) Higher magnification of a condensed area corresponding to early chondrogenesis. (C) Three nests of mesenchymal cells: one in the upper left part of the figure is composed of loosely structured cells, the one to the upper right contains a central nidus of cartilage, whereas the one in the lower mid-portion contains a central area of dark bluish cells which could not be further characterized. (D) An endodermal tube (End) is seen adjacent to a mesenchymal loose connective tissue area (to the left). Vascular or lymphatic spaces are seen along the left margin and are adjacent to an area containing smooth muscle (Sm). Magnification: (A) 120x; (B) 280x; (C) 180x; (D) 160x. 

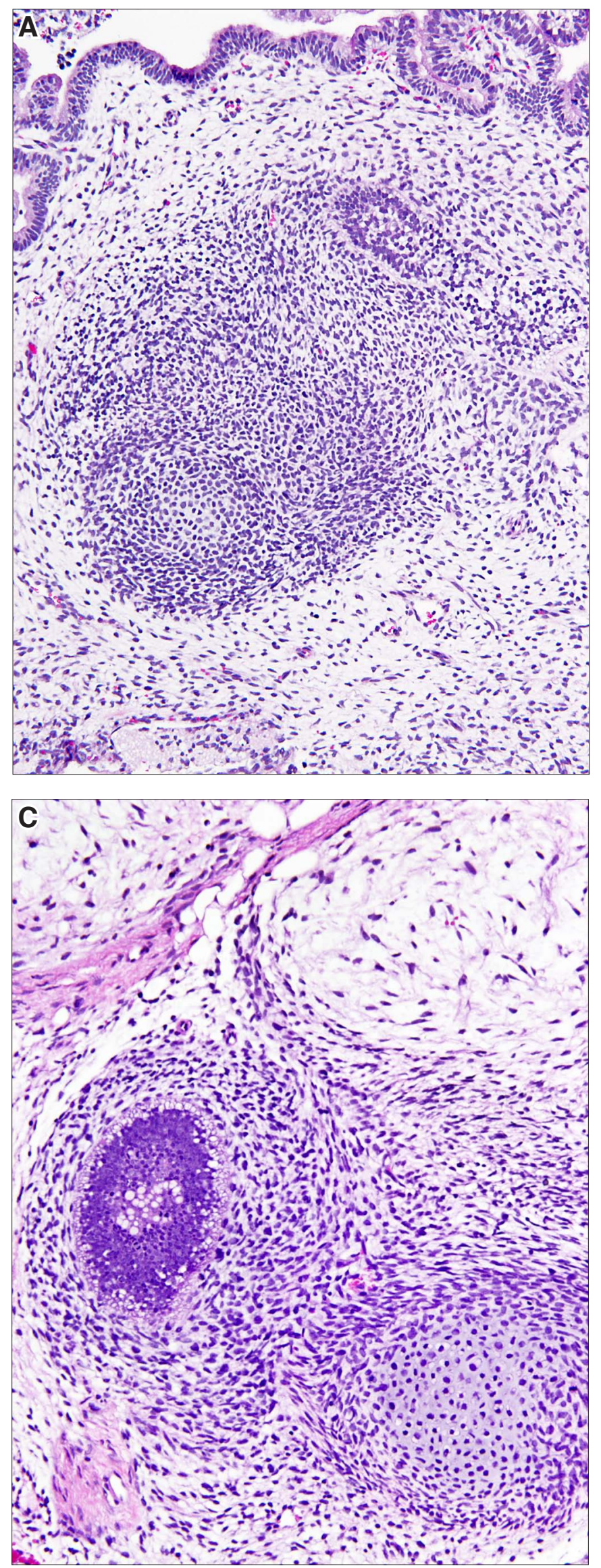

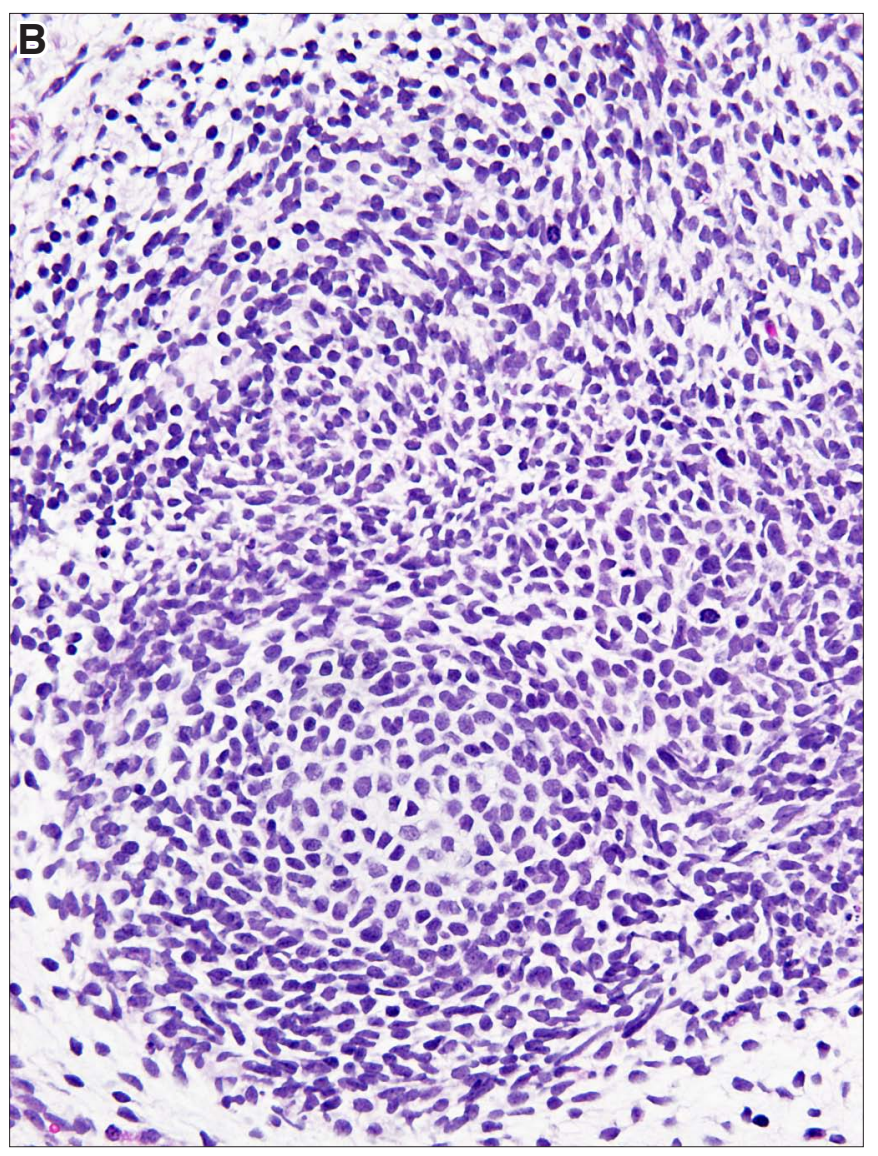

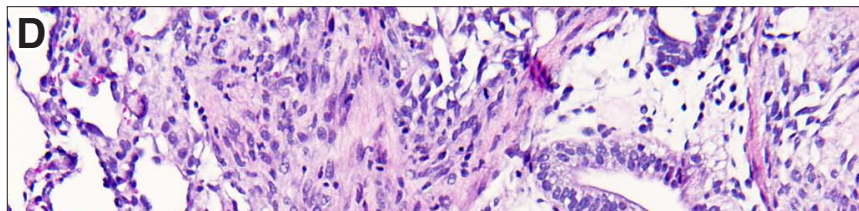

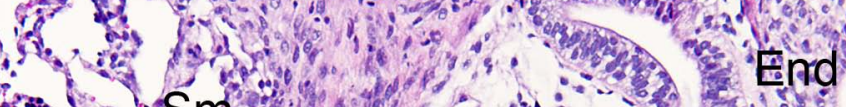

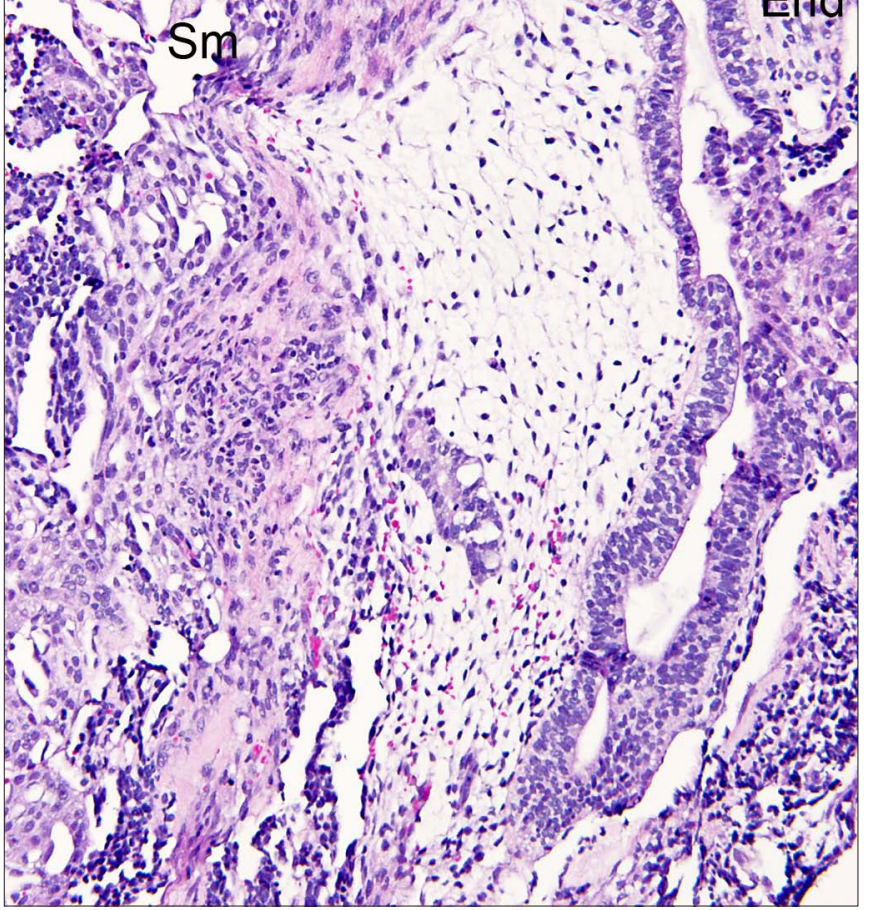


394 I. Damjanov and P. W. Andrews

Fig. 22. Mesenchymal stroma. (A) Stroma composed of spindle cells appears loose on one side of the endodermal tubule (above it), and condensed below. (B) Loose stroma on the right side is composed of cells with round or oval nuclei and scant if any cytoplasm, reminiscent of fetal mesenchyme. It appears focally to impinge on the tubule (arrow). Dense stroma on the left side is separated from the epithelium by a basement membrane. Magnification: $(A, B) 280 x$. 

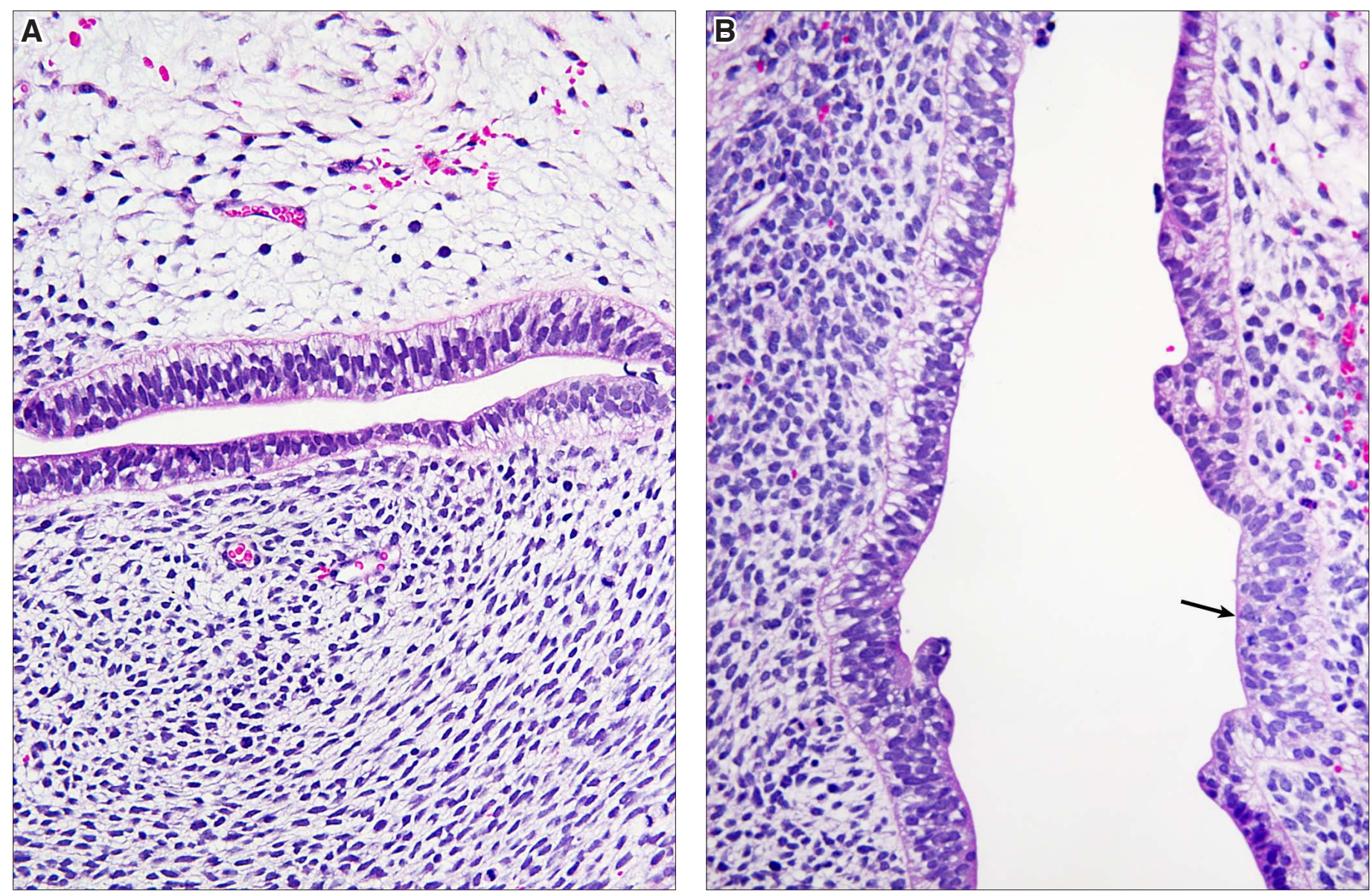
396 I. Damjanov and P. W. Andrews

Fig. 23. Mesenchymal epithelial transition. (A) In the center of a condensed mesenchyme, there are interconnected cells forming cords and small nests. (B) Higher magnification of the nascent epithelial cells. Magnification: (A) 160x; (B) 280x. 

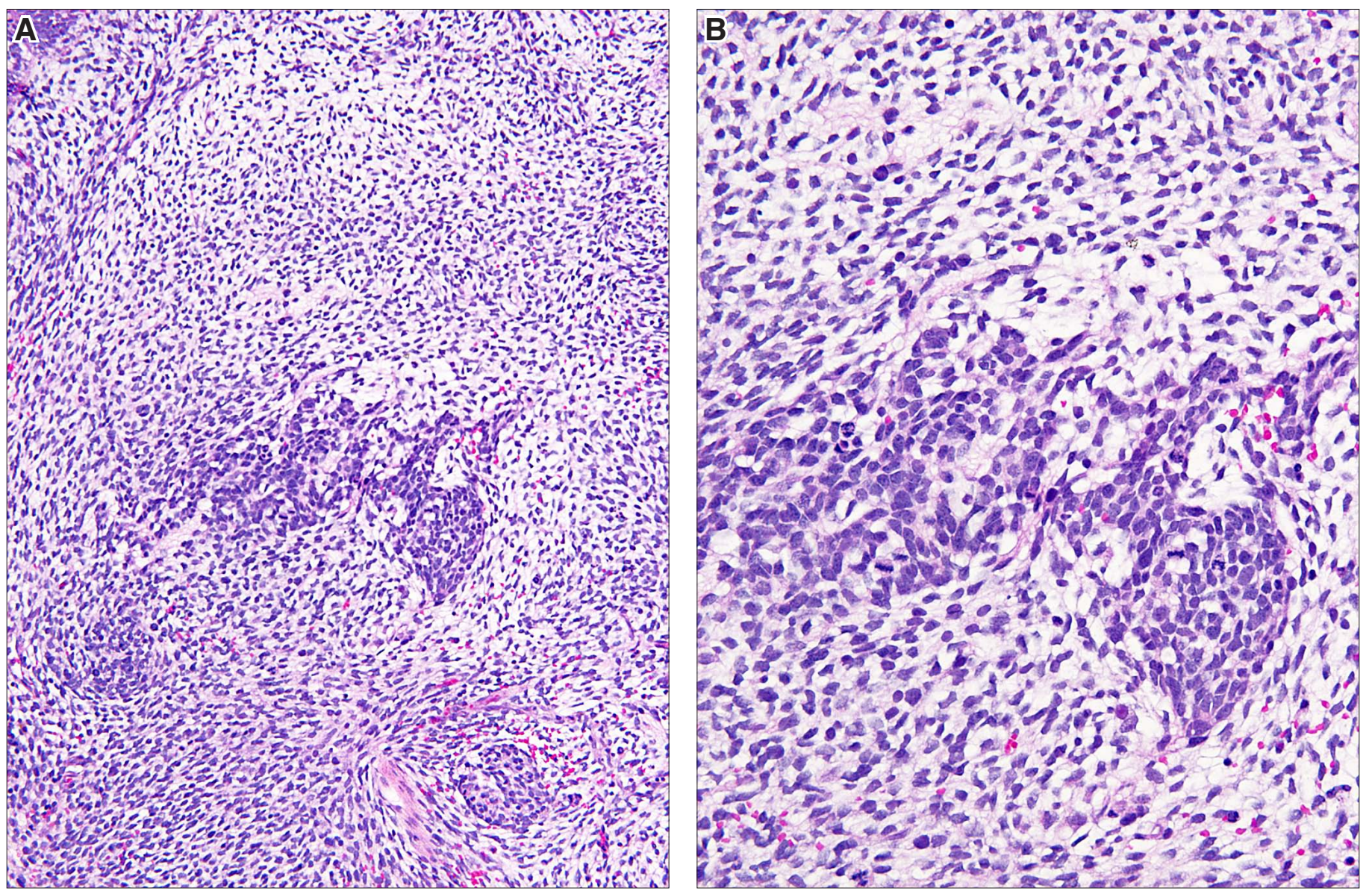
398 I. Damjanov and P. W. Andrews

Fig. 24. Angiogenesis. (A) Small inter-anastomosing blood vessels (Bv) filled with blood are seen next to an endodermal tube in the lower part of the figure. (B) Small blood vessels on the right upper side and larger blood vessels on the left and lower right side. (C) Dilated thin walled vessels (asterisks) surround an embryoid body with prominent apoptosis (arrow). (D) Large vessels (asterisks) and buds of small blood vessels in their walls. 

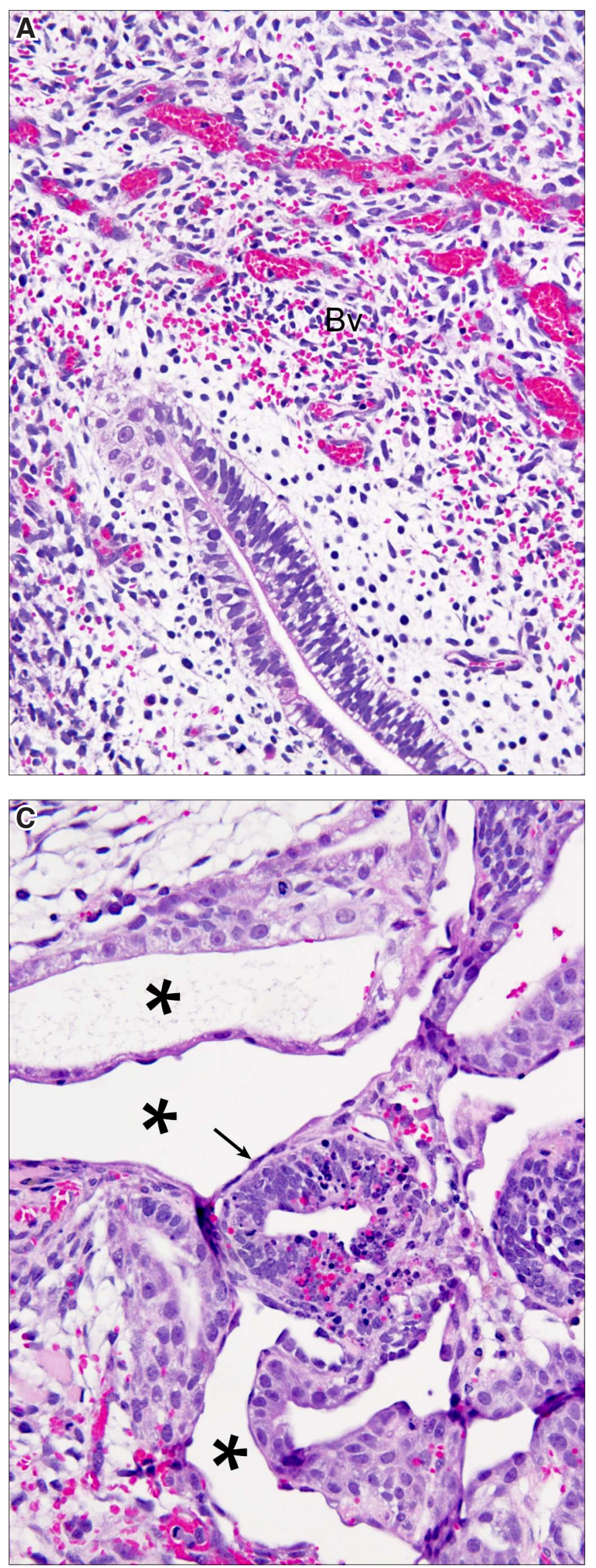
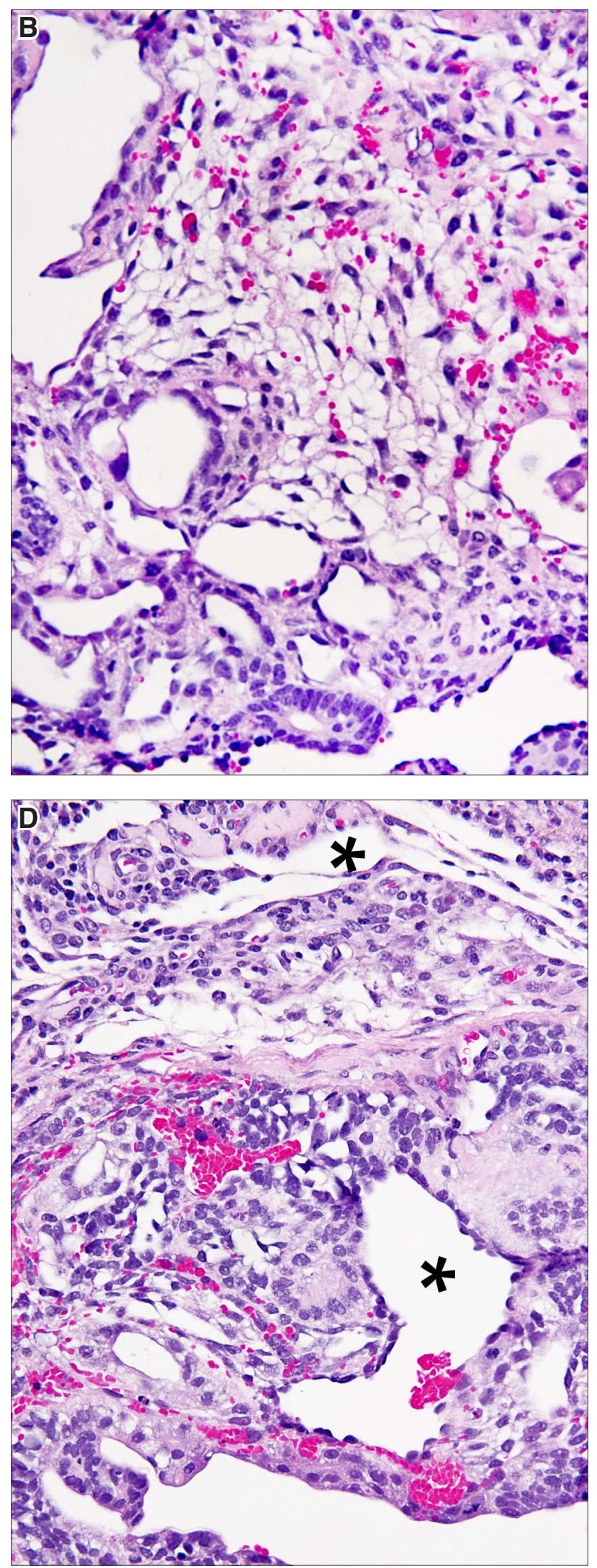
Fig. 25. Mesenchymal tissues. (A) Groups of fat cells (F) and smooth muscle cells (Sm) close to a field composed of neural tissue. (B) Fat tissue composed of mature fat cells and less mature (fetal) fat cells in the left lower portion of the figure. Neural tissue occupies the upper part of the field and forms a rim at the bottom. (C) Smooth muscle cell-rich stroma surrounding nests of squamous epithelium and neural tissue. (D) Hyaline intercellular matrix surrounding small groups of vacuolated cells that cannot be identified. The possibility that this hyaline rich tissue represents parietal yolk sac cannot be excluded. Magnification: (A, B,C) 160x; (D) 220x. 

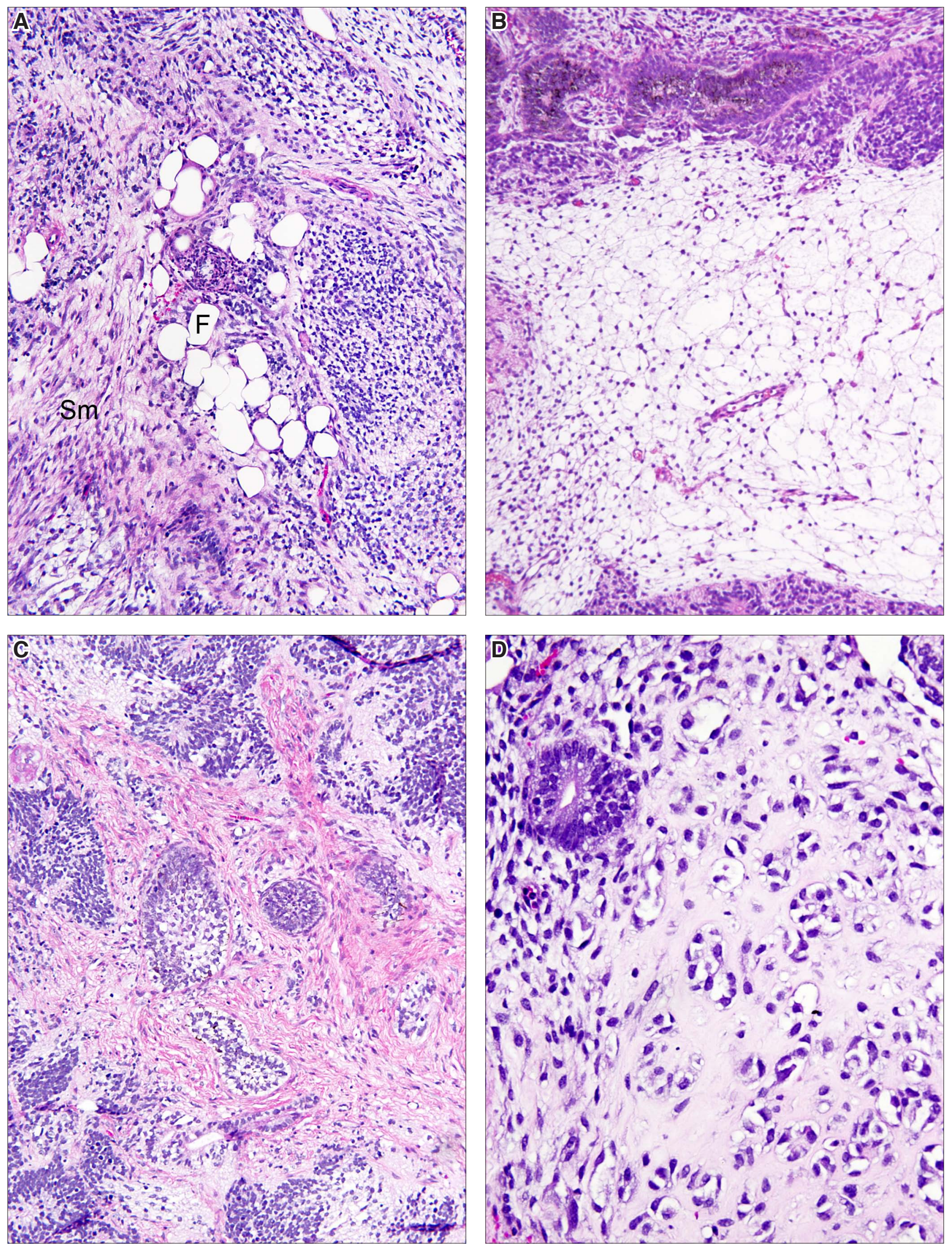



\section{Human PSCs \& early- and extra-embryonic tissues}


404 I. Damjanov and P. W. Andrews

Fig. 26. Embryoid bodies and yolk sac. (A) Embryoid body composed of human pluripotent stem cells (hPSC) is surrounded by loosely structured yolk sac, which in turn is surrounded by dense stroma. (B) Embryoid body surrounded by yolk sac that shows prominent angiogenesis, and contains small blood vessels filled with red blood cells. (C) Details of (B) photographed at higher magnification. (D) Tube composed of hPSCs, corresponding to a simple embryoid body, but lacking the typical yolk sac components around it. Yolk sac components can be seen in in the upper part of the figures. Magnification: (A) 80x; (B) 160x; (C) 220x; (D) 100x. 

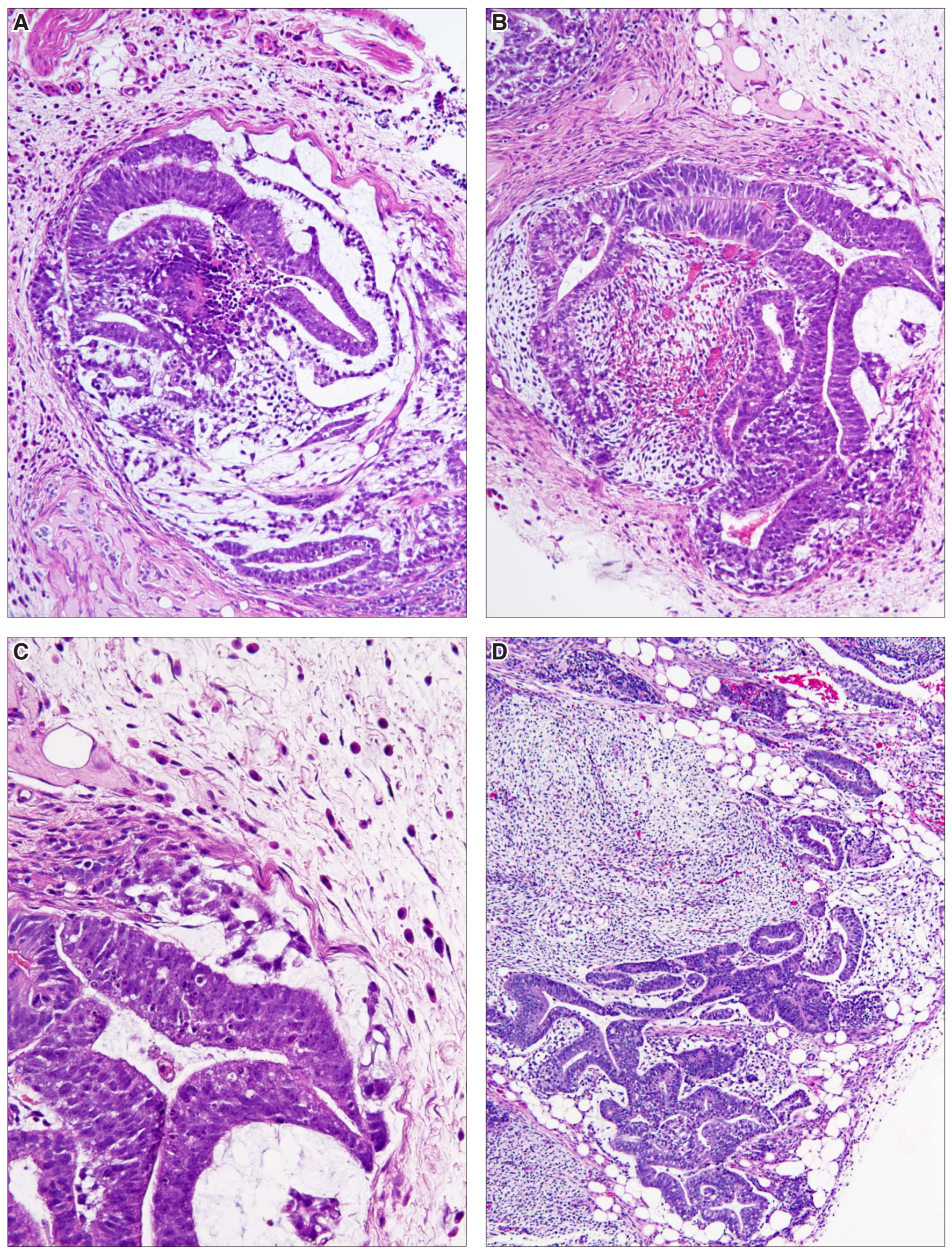
Fig. 27. Human pluripotent stem cells (hPSCs). (A) Inter-anastomosing cords of hPSCs surrounded by fat cells which have clear cytoplasm. (B) hPSCs forming cords or compact nests. Note the typical loosely structured nuclear chromatin and overlapping nuclei. (C) hPSCs forming nests of cells that are not clearly demarcated from the adjacent tissue. (D) An embryoid body adjacent to loosely structured yolk sac on the right side. Magnification: (A) 160x; (B,C,D) 280x. 


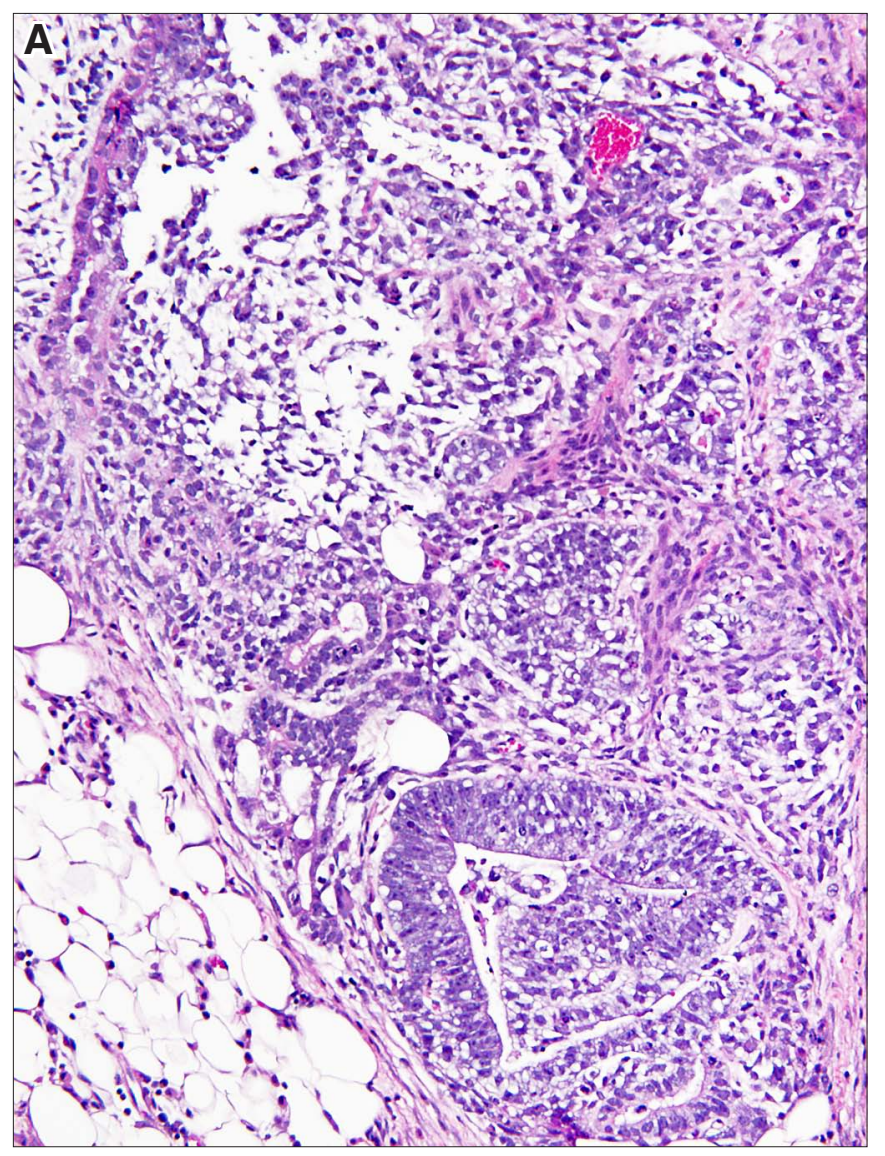

C)

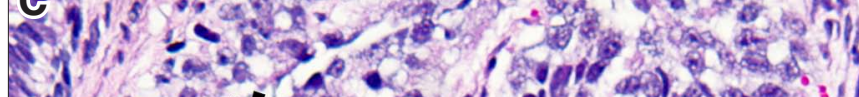

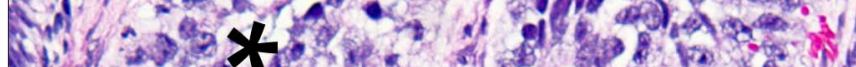

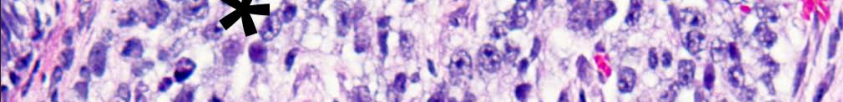

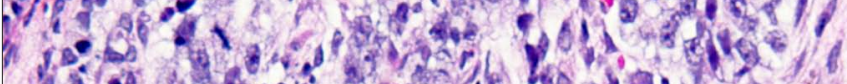

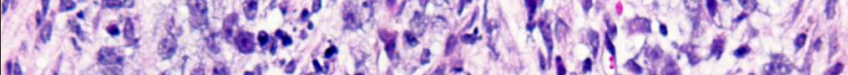

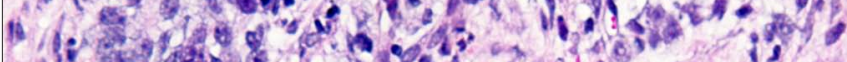

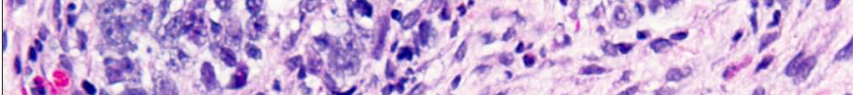

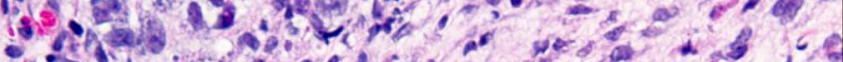

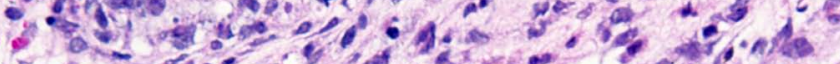

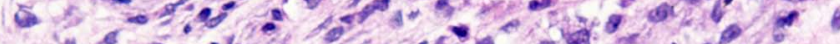

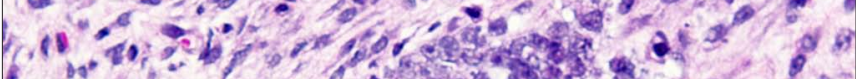

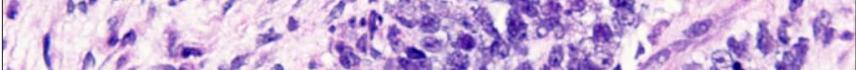

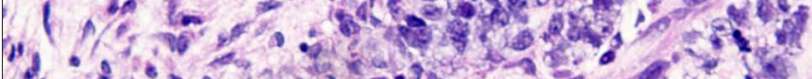

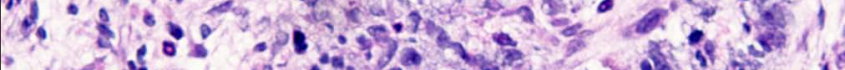

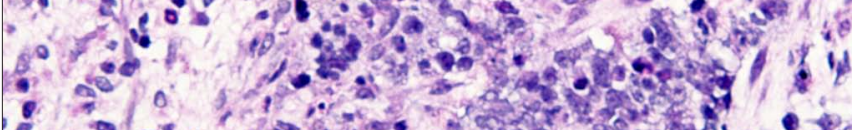

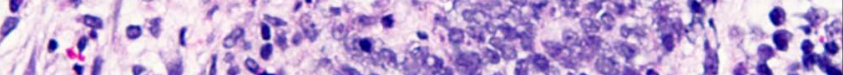

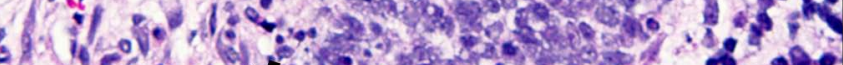

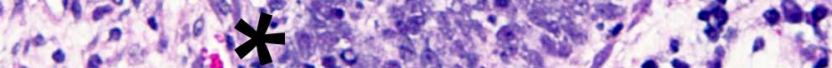

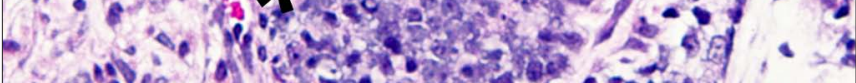

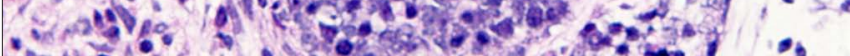

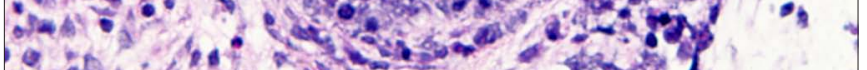

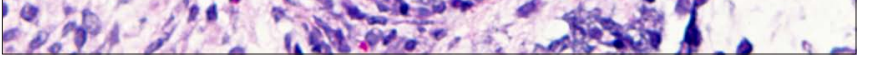
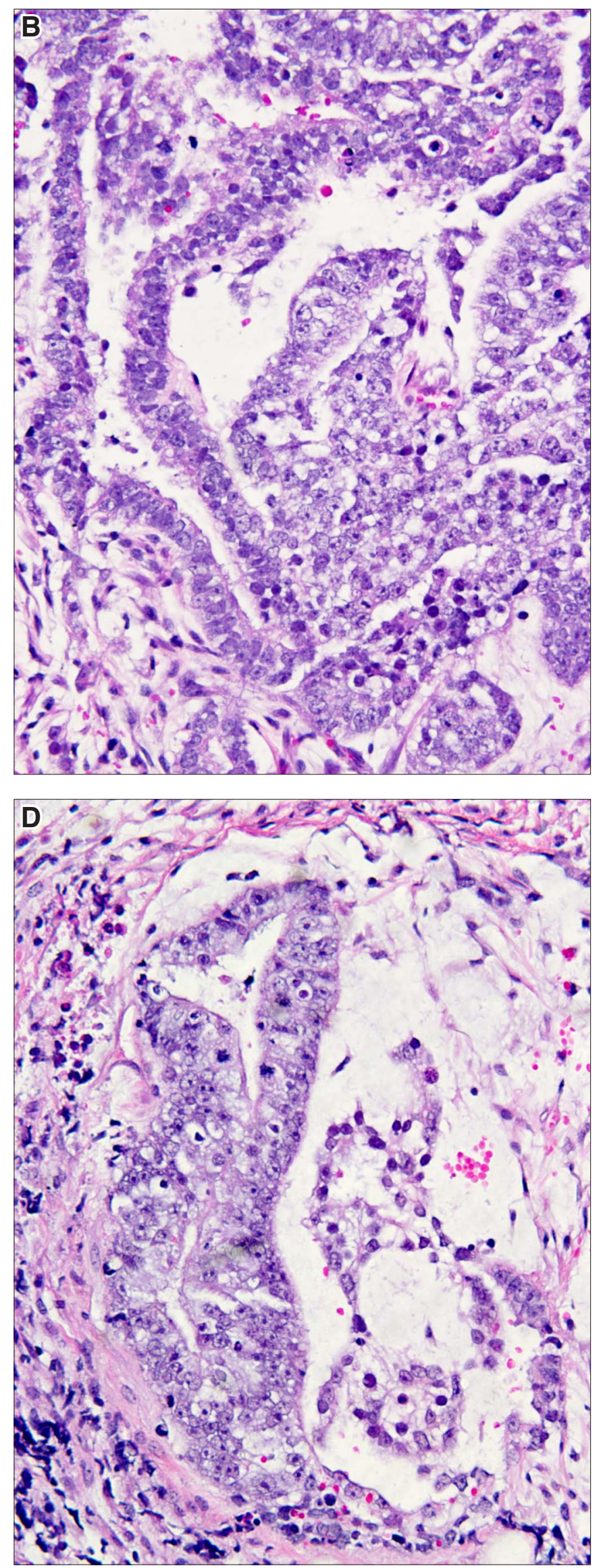
408 I. Damjanov and P. W. Andrews

Fig. 28. Human pluripotent stem cells (hPSCs). (A) hPSCs have typical nuclei with loosely structured chromatin and show focal apoptosis (upper part of the figure). Compare the nuclei of hPSC (asterisk) with those of the neural cells in the lower part of the figure. (B) hPSCs in this field cannot be definitively identified and are intermixed with other, possibly neural cell precursors. (C) hPSCs forming cords or plates (asterisk) surrounded by neural cells, which have more condensed nuclei. (D) Cords of hPSCs in continuity with neural cells occupying the upper part of the figure. Arrows indicate a areas of apoptosis. Neu, neural tissue. Magnification: $(A, B, C, D) 280 x$. 

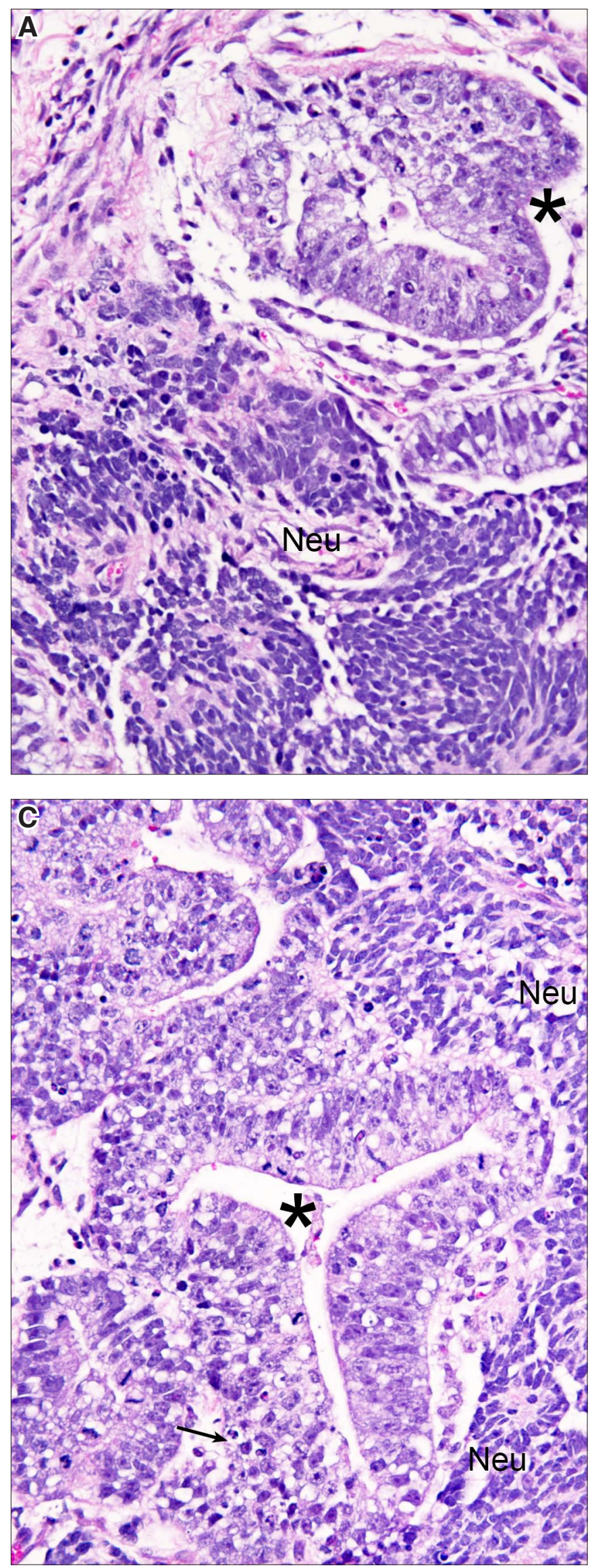

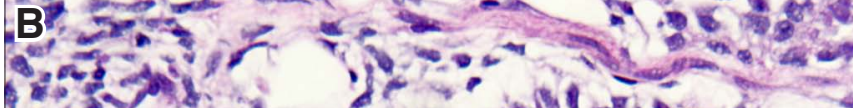

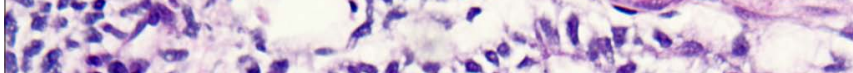

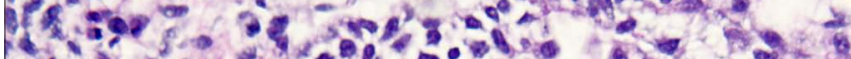

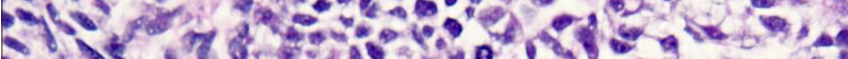

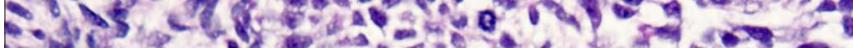

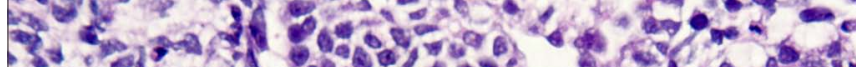

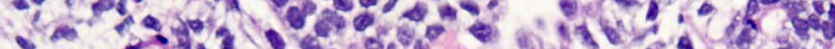

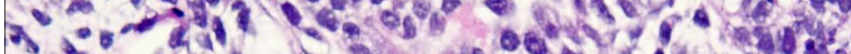

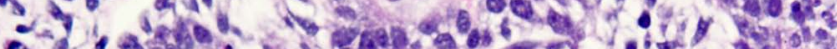

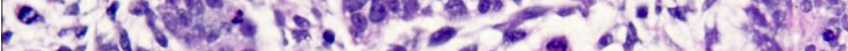

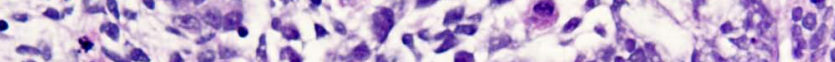
- J.

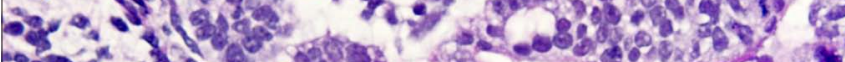

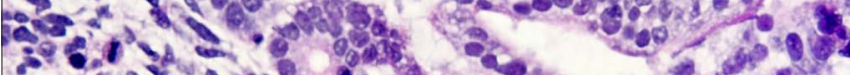

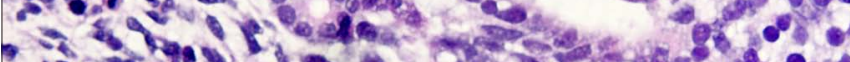

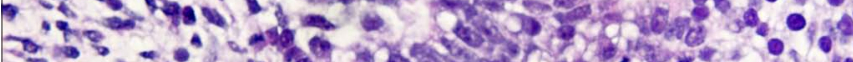

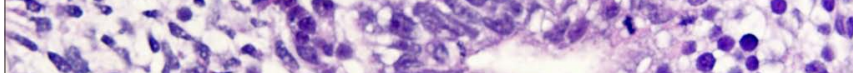

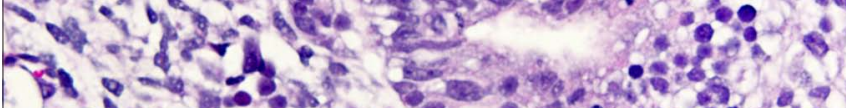

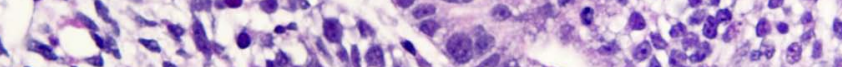

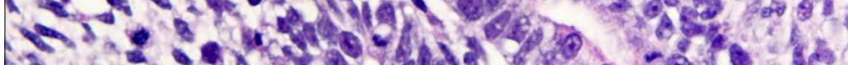

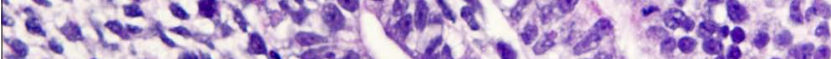

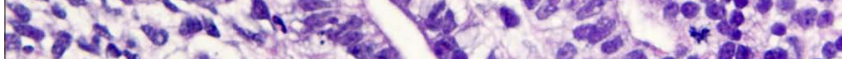

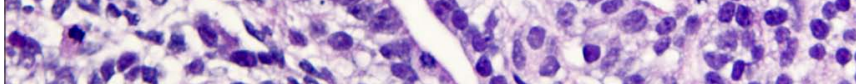

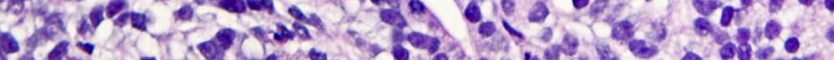

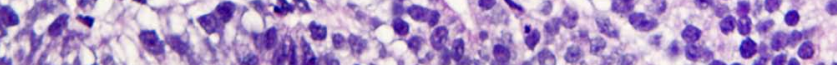

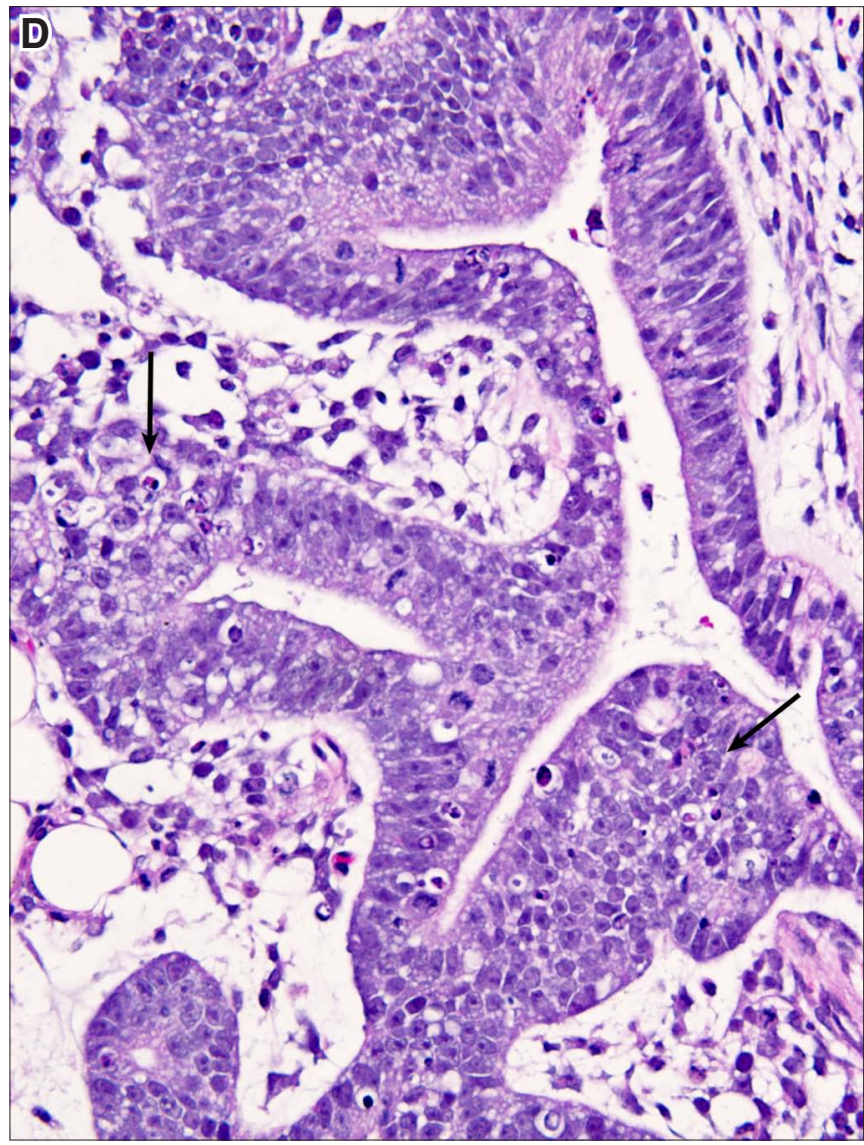


Fig. 29. Apoptosis of human pluripotent stem cells (hPSCs). (A) hPSCs forming cords and nests that are clearly separated from other cells. Occasional apoptotic cells with dark condensed nuclei are seen. (B) A nidus of hPSCs with prominent apoptosis. The nuclei of apoptotic cells appear dense, small and round. (C) hPSCs surrounding a cavity (asterisk) that most likely formed by apoptosis of centrally located cells. The lumen of the cavity contains single apoptotic cell nuclei. (D) Two layers composed of hPSCs showing prominent apoptosis. Magnification: $(A, B, C, D) 280 x$. 

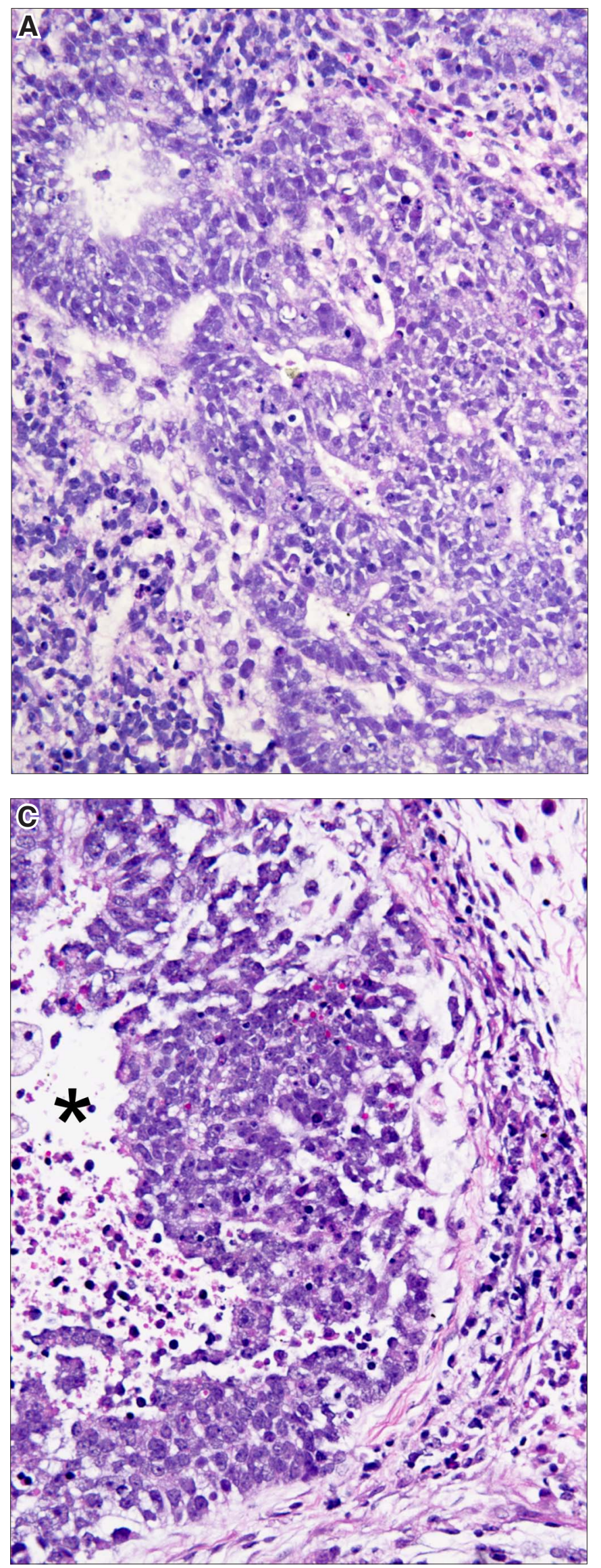
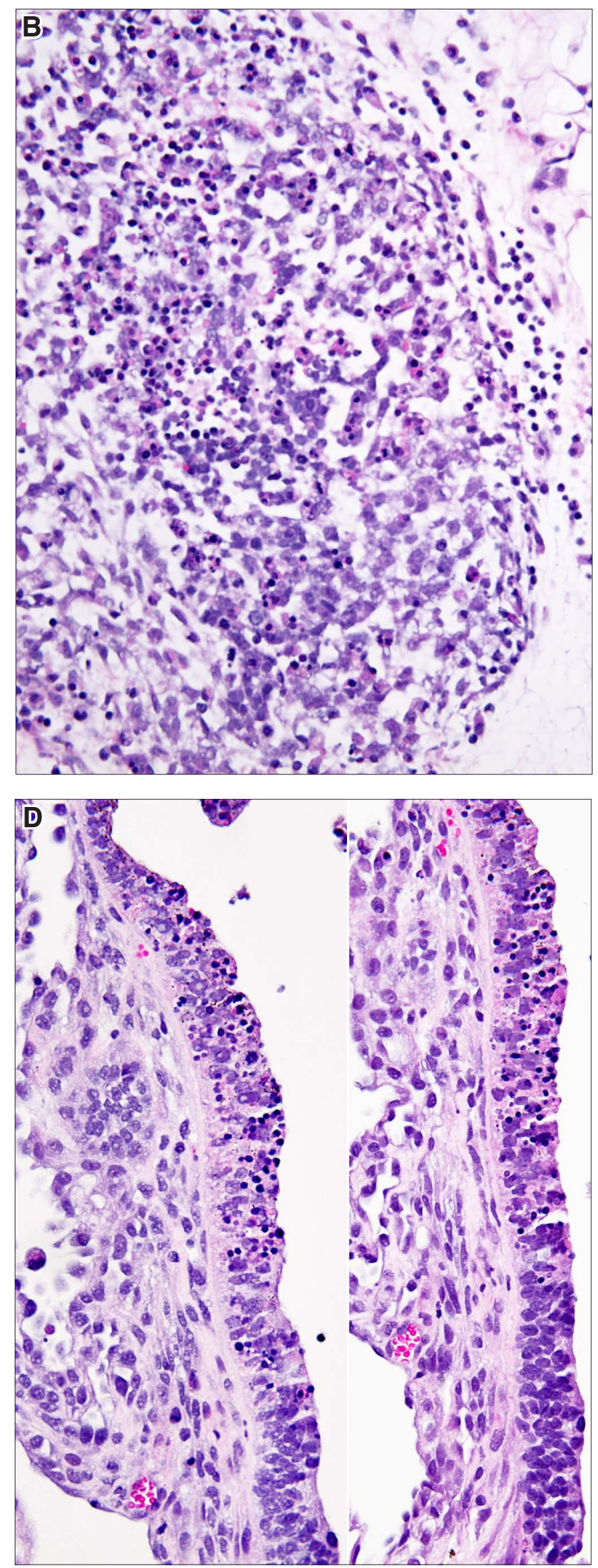
412 I. Damjanov and P. W. Andrews

Fig. 30. Yolk sac. (A) Yolk sac is composed of strands and cords and loosely structured stroma. (B) Focally within the yolk sac, one may see darker cells forming cords, but without immunohistochemistry one cannot tell if these cells are hPSCs. (C) In addition to darker cells, this yolk sac contains foci of liver cells which stand out due to their pink cytoplasm (arrow). (D) Foci of hematopoiesis next to liver cells. Magnification: $(A, B, C) 160 x ;(D) 240 x$ 

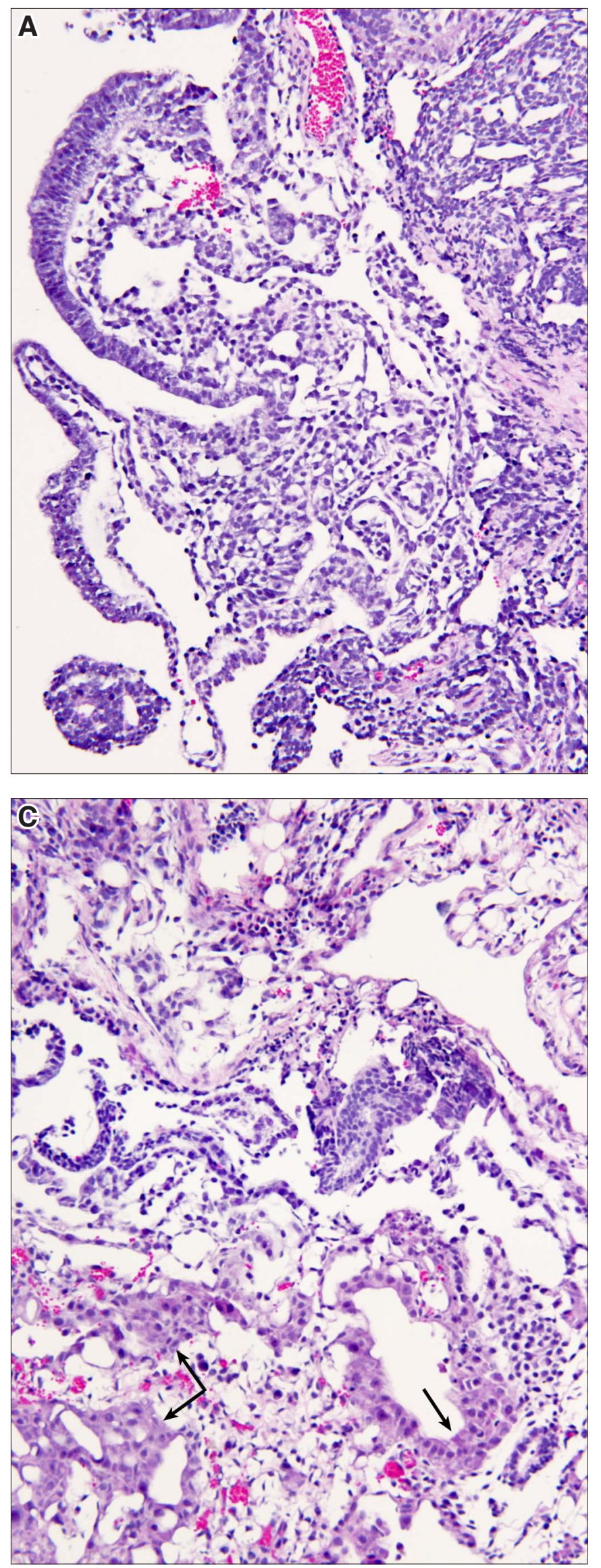
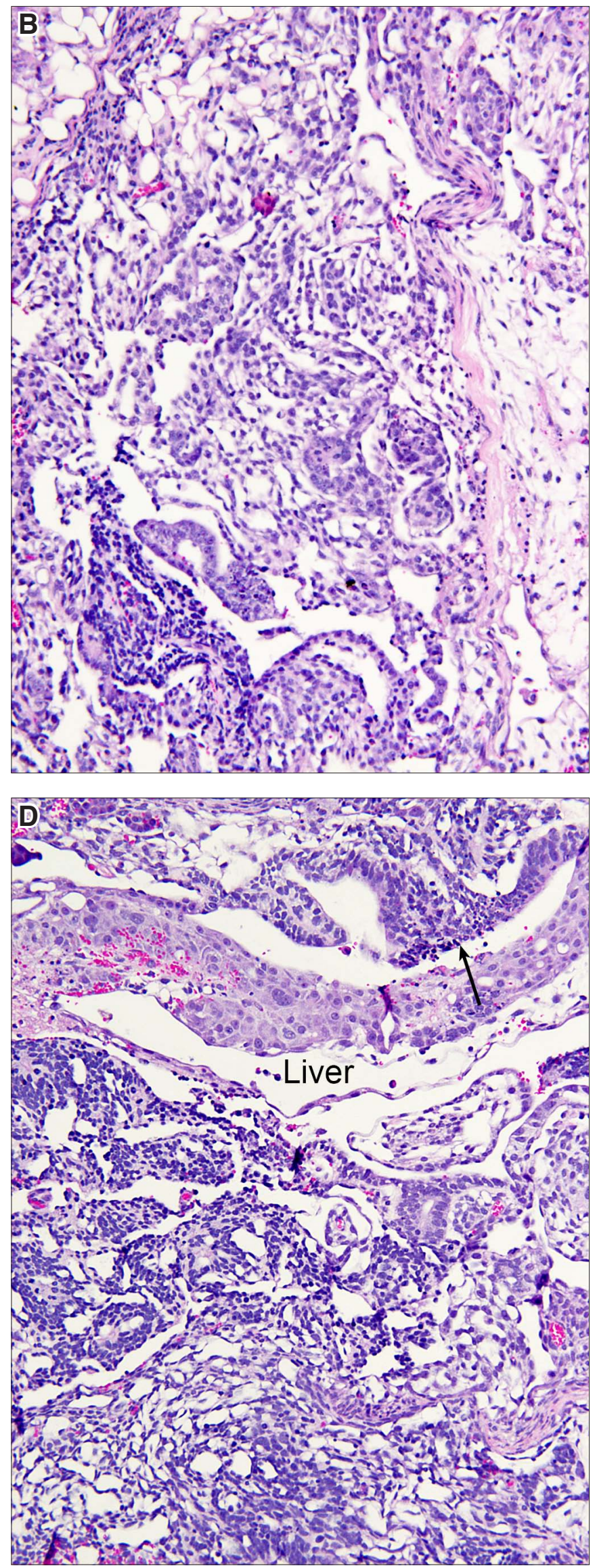
414 I. Damjanov and P. W. Andrews

Fig. 31. Yolk sac with putative hPSCs. (A) Loosely structured yolk sac with cords of unidentified cells which may be hPSCs. (B) Another view of a yolk sac with possible hPSCs. The small cells with round nuclei most likely correspond to hematopoiesis. (C) Another area of yolk sac with a compact embryoid body in the upper midfield and a loosely structured one towards the lower edge of the figure. (D) $A$ loosely structured yolk sac with a branching tubule, possibly lined by hPSCs. A nidus of liver cells is seen in the lower midfield. Magnification: (A, B,C) 280x; (D) 160x. 

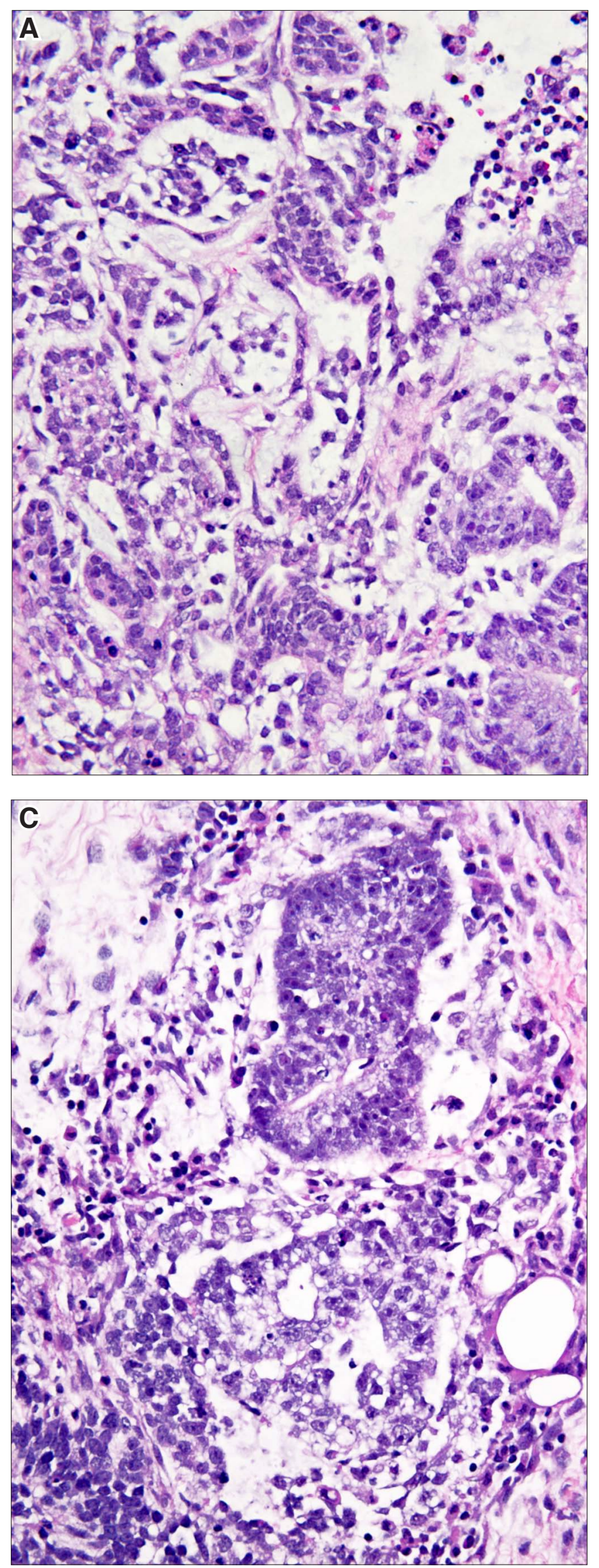
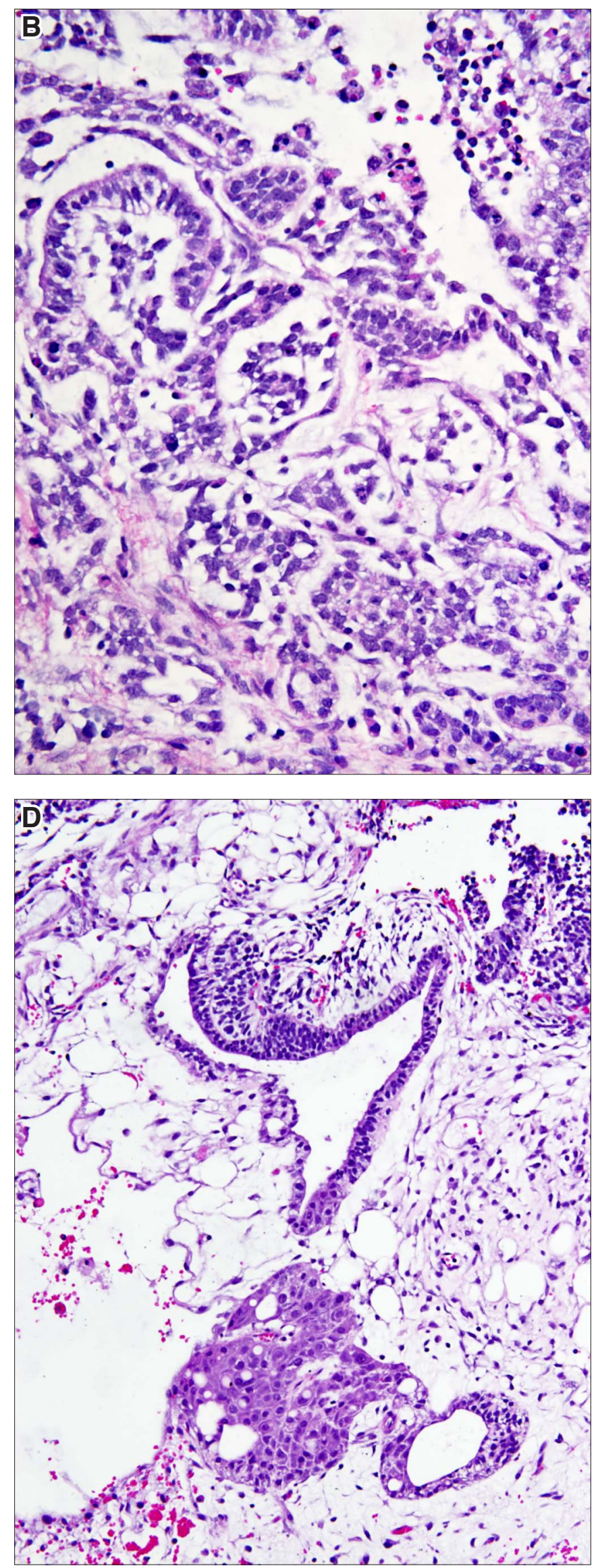
416 I. Damjanov and P. W. Andrews

Fig. 32. Hematopoiesis in the yolk sac. (A) Nucleated red blood cell and white blood cell precursors forming a nest of hematopoiesis in the loose stroma. (B) Hematopoietic precursor cells are seen in a vascular space (arrow). (C) Hematopoietic cells lined in a row are seen in a dilated vascular space (arrow). (D) Small groups of cells with dark round nuclei corresponding to hematopoietic islands in a loosely textured yolk sac area (arrow). Magnification: $(A, B, C, D) 280 x$. 

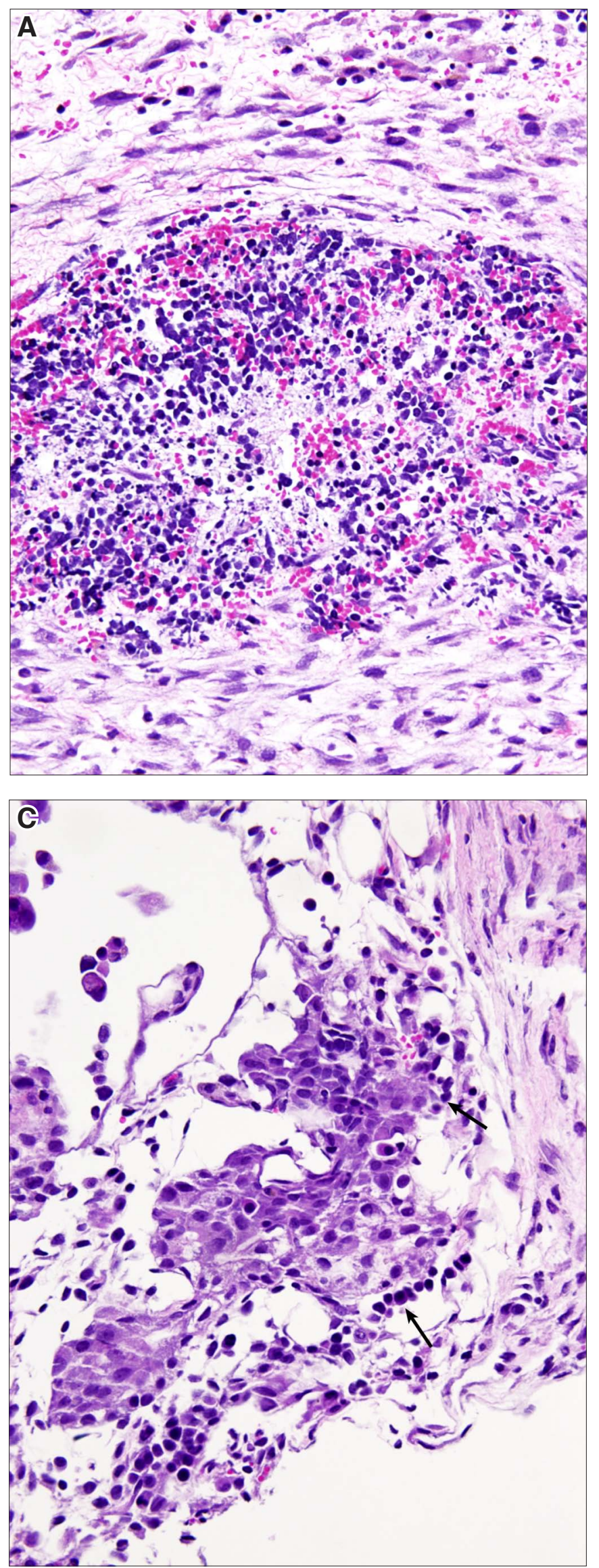

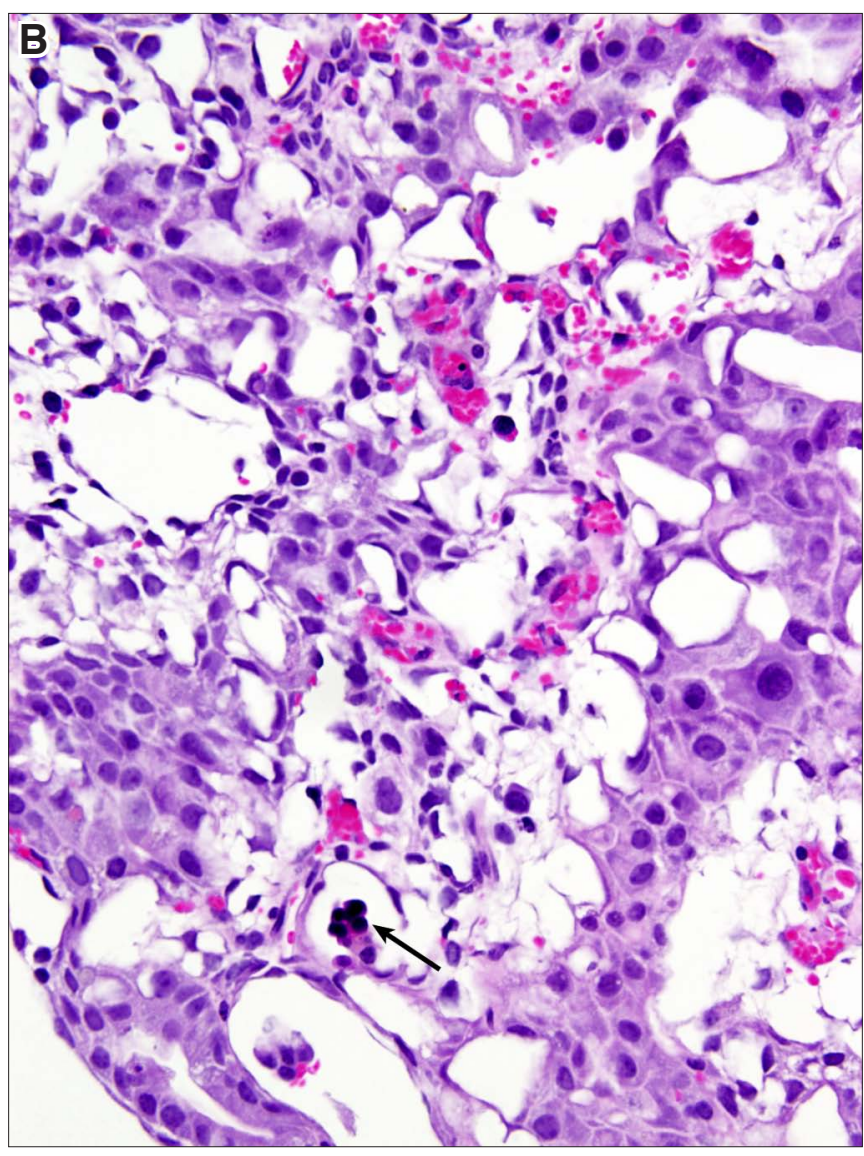

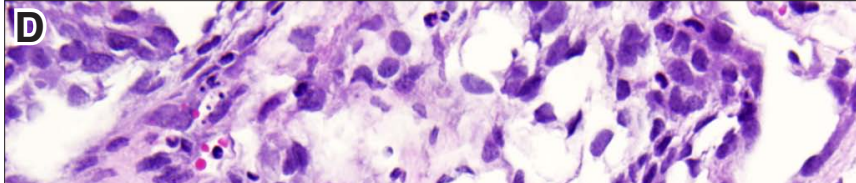

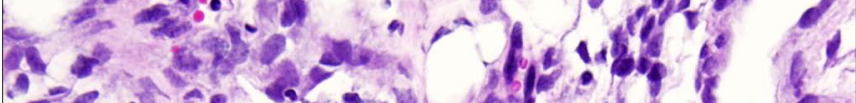

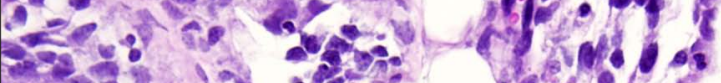

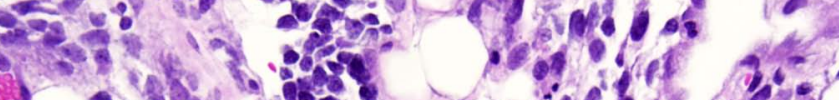

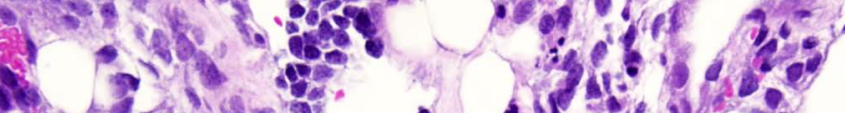

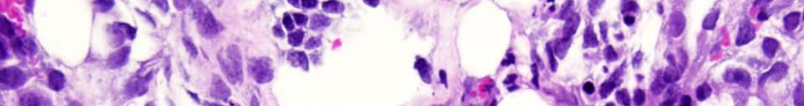

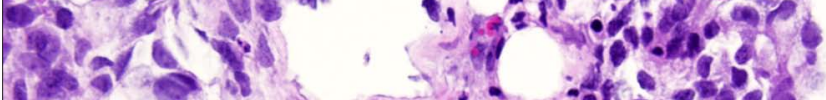

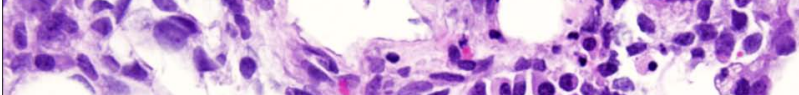

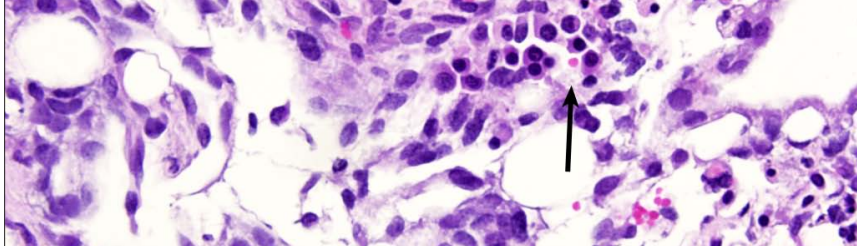

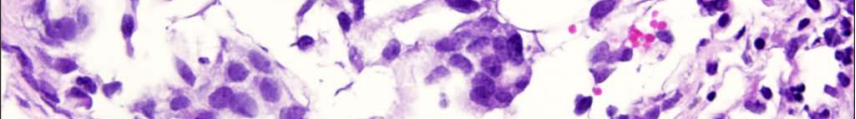
M.

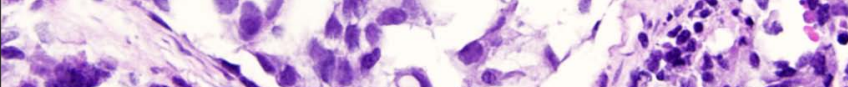

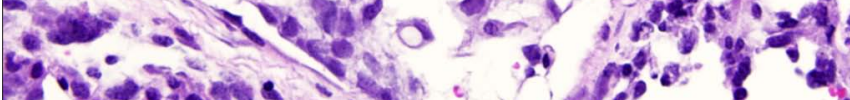

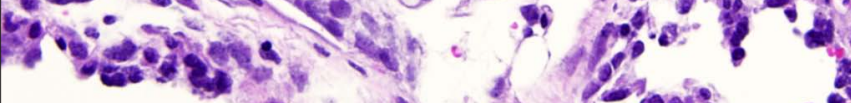

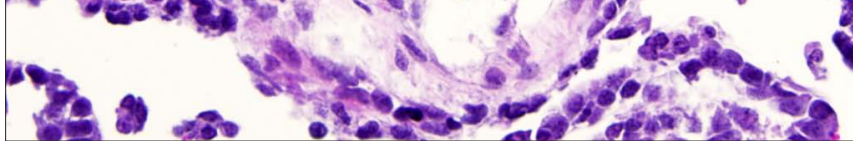


418 I. Damjanov and P. W. Andrews

Fig. 33. Immunohistochemistry. (A) Human pluripotent stem cells (hPSCs) show nuclear staining with the antibody to OCT4. (B) hPSCs react with the antibody TRA-1-60. (C) Yolk sac reacts with antibodies to alpha-fetoprotein. (D) Yolk sac cells react with the antibody to glypican-3. Magnification: $(A, B, C, D) 160 x$. 

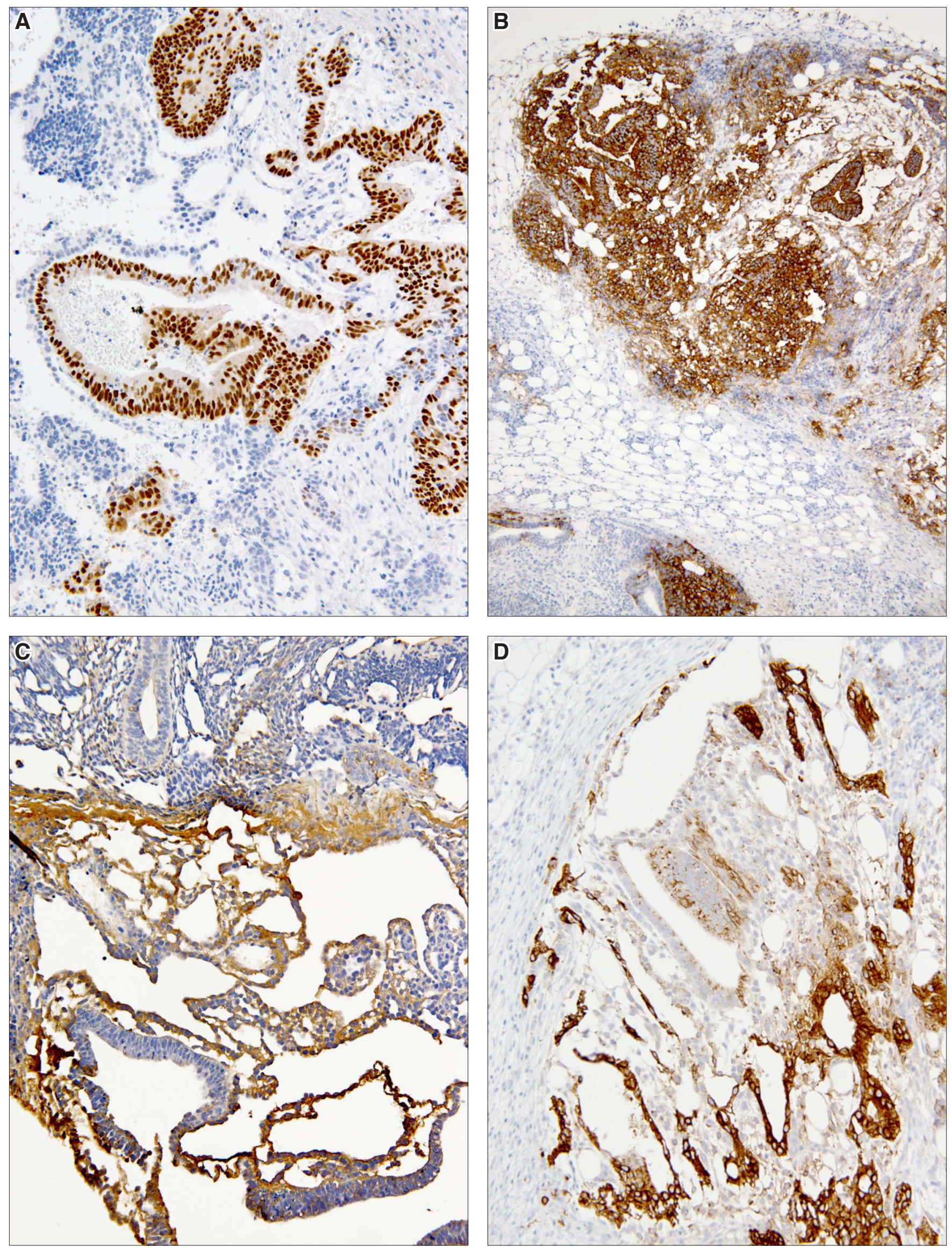
Further Related Reading, published previously in the Int. J. Dev. Biol.

Pathobiology of germ cell tumors - applying the gossip test!

Leendert H. J. Looijenga and J. Wolter Oosterhuis

Int. J. Dev. Biol. (2013) 57: 289-298

Development of malignant germ cells - the genvironmental hypothesis

Leendert H.J. Looijenga, Ton Van Agthoven and Katharina Biermann

Int. J. Dev. Biol. (2013) 57: 241-253

Testicular teratomas: an intersection of pluripotency, differentiation and cancer biology Ximena Bustamante-Marín, Jason A. Garness and Blanche Capel

Int. J. Dev. Biol. (2013) 57: 201-210

From testis to teratomas: a brief history of male germ cells in mammals Massimo De Felici and Susanna Dolci

Int. J. Dev. Biol. (2013) 57: 115-121

Testicular germ cell tumors and related research from a historical point of view Ivan Damjanov and Nicolai Wewer-Albrechtsen Int. J. Dev. Biol. (2013) 57: 197-200

Above the borderland between normal and neoplastic development Juan Aréchaga and Ivan Damjanov Int. J. Dev. Biol. (2012) 56: 939-948

Highly efficient cryopreservation of human induced pluripotent stem cells using a dimethyl sulfoxide-free solution

Tatsuya Nishigaki, Yuji Teramura, Akira Nasu, Kei Takada, Junya Toguchida and Hiroo Iwata Int. J. Dev. Biol. (2011) 55: 305-311

Foetal germ cells: striking the balance between pluripotency and differentiation Patrick Western

Int. J. Dev. Biol. (2009) 53: 393-409

Teratocarcinoma stem cells as a model for differentiation in the mouse embryo. E Lehtonen, A Laasonen and J Tienari

Int. J. Dev. Biol. (1989) 33: 105-115

The germ cell--the mother of all stem cells.

P J Donovan

Int. J. Dev. Biol. (1998) 42: 1043-1050

5 yr ISI Impact Factor $(2013)=2.879$
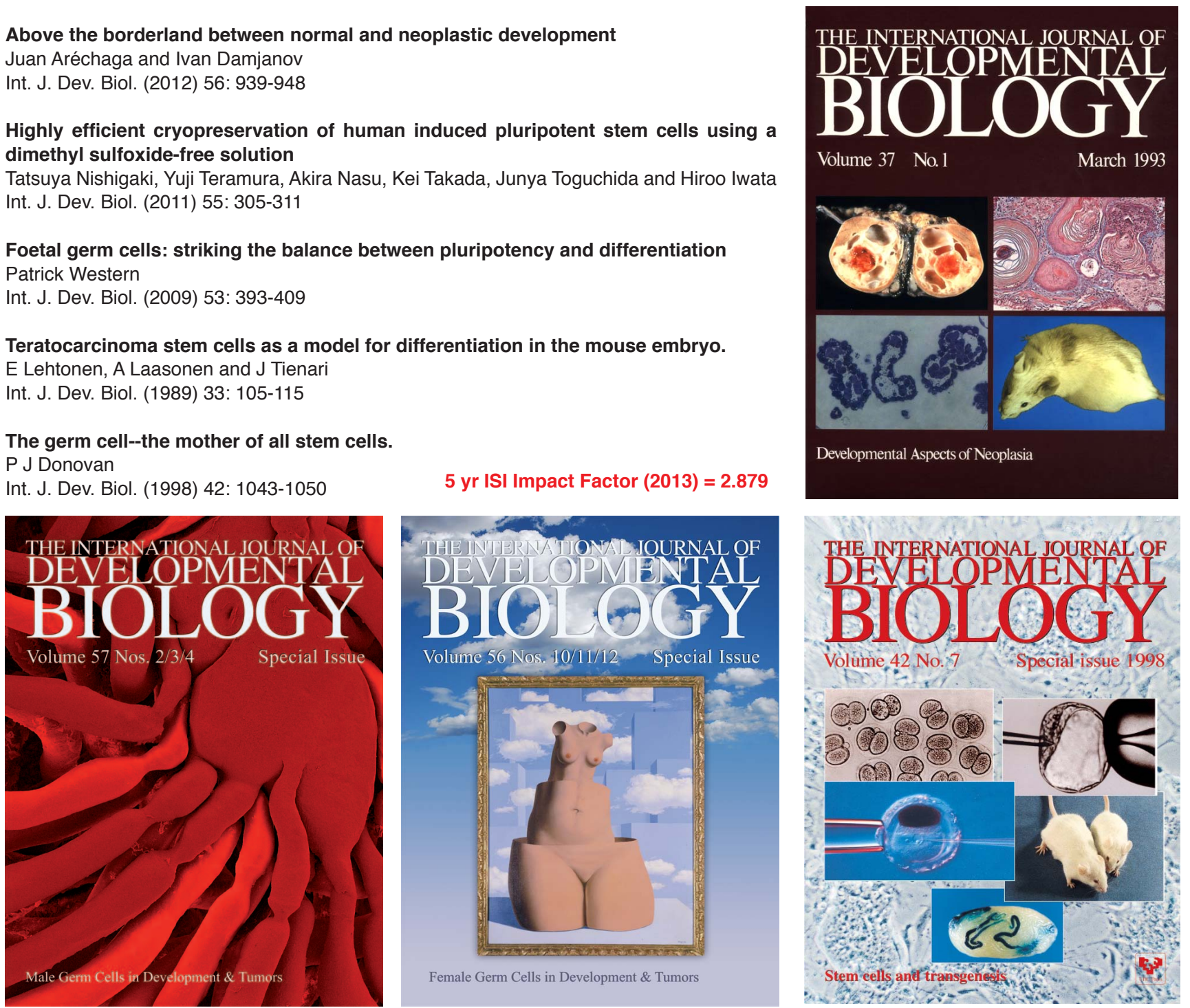